\title{
ALIMENTAÇÃO NO PRIMEIRO ANO DE VIDA: \\ Prevalência de Consumo de Alimentos em dois Centros de Saúde do Município de São Paulo
}

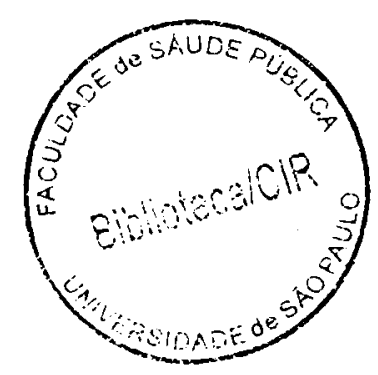

Dissertação apresentada ao Departamento de Nutrição da Faculdade de Saúde Pública da Universidade de São Paulo, para obtenção do grau de Mestre.

Área de concentração: Nutrição

Orientadora: Prof. Dra. Sônia Buongermino de Souza

São Paulo

1999 
Há que se cuidar do broto para que árvore nos dé flor e fruto.

Milton Nascimento. 
Dedico este trabalho

Ao meu marido:

Osmar

Ao meus filhos:

Mariana e Guilherme.

...Quando não estou com vocês sinto falta de mim mesmo... 


\section{AGRADECIMENTOS}

À Prof.. Dra. SÔNIA BUONGERMINO DE SOUZA, pela orientação, gentileza, paciência e disponibilidade em todas as horas.

À Dra. MARIA DO ROSÁRIO DIAS DE OLIVEIRA LATORRE, pelo auxilio precioso em todas as etapas.

À Prof. Dra. REGINA MARA FISBERG, pelos conselhos valiosos e pela amizade.

Ao Prof. Dr. JOSÉ MARIA PACHECO DE SOUZA, pelo auxílio estatistico.

À amiga BETZABETH pela paciência e atenção.

À CLAUDIA e ADÁLIO pela amizade e estímulo.

À ANA MARIA CERVATO, pelo papel fundamental no início desta empreitada.

À minha familia: pais, marido e filhos pelo seu amor e apoio constantes.

À FAPESP - Fundação de Amparo à Pesquisa do Estado de São Paulo, pelo financiamento da pesquisa que gerou os dados aqui utilizados.

À CAPES - Coordenação de Aperfeiçoamento de Pessoal de Nível Superior, pela bolsa de estudos concedida.

À todos que participaram, direta ou indiretamente, deste trecho do meu caminho.

OBRIGADA !!! 


\section{RESUMO}

Marchioni DML. Alimentação no primeiro ano de vida: prevalência de consumo de alimentos em dois Centros de Saúde do municipio de São Paulo. São Paulo, 1999. [Tese de Mestrado - Faculdade de Saúde Pública da USP].

Objetivos. A alimentação da criança no primeiro ano de vida é fundamental para o seu crescimento e desenvolvimento. Este estudo foi delineado com o objetivo de verificar a prevalência de consumo de alimentos no primeiro ano de vida. Metodologia. Participaram do estudo 175 crianças com até um ano de idade, atendidas em dois Centros de Saúde do município de São Paulo. A prática alimentar, obtida pelo método status quo, foi analisada por regressão logística por meio da elaboração de curvas de prevalência para as práticas de aleitamento e para o consumo de alimentos complementares. Resultados. A estimativa da prevalência de aleitamento materno exclusivo aos 120 dias foi baixa: $16 \%$ em mães com baixa escolaridade e $27 \%$ em mães com maior escolaridade. No entanto, para o aleitamento materno estimou-se a prevalência de $51 \%$ ao final do primeiro ano, para crianças com mães de escolaridade não baixa. Verificou-se associação positiva somente entre prática de aleitamento materno e escolaridade materna As frutas foram o primeiro alimento complementar sólido na dieta, seguindo-se as hortaliças e cereais. As carnes e feijão foram consumidos por $100 \%$ das crianças somente ao final do primeiro ano de vida. Conclusões. $O$ aleitamento materno exclusivo é pouco praticado. A introdução dos alimentos complementares é precoce e feita com alimentos de baixa densidade 
calórica. A escolaridade materna é importante fator no tipo de aleitamento, mas pouco influenciou o consumo de alimentos complementares.

Descritores: Alimentação do lactente. Aleitamento Materno. Desmame. Suplementação alimentar. Leite. 


\section{SUMMARY}

Marchioni DMt. Alimentação no primeiro ano de vida: prevalência de consumo de alimentos em dois Centros de Saúde do município de São Pauto. [Feeding in the first year of life: food consumption prevalence in two health centers in the Municipality of São Paulo]. São Paulo (BR), 1999. [Tese de Mestrado - Faculdade de Saúde Pública da Universidade de São Paulo].

Objectives. The child's feeding in its first year of life is fundamental for its growth and development. This study was designed to examine food consumption prevalence in the first year of life. Methodology. One hundred and seventy-five (175) children up to one year old, attending two health centers in the municipality of São Paulo, took part in the study. Feeding practices, obtained by the status quo method, were analyzed by logistical regression through prevalence curves for breastfeeding and the consumption of supplementary foods. Results. Estimated prevalence of exclusive maternal breastfeeding up to 120 days was low. $16 \%$ in mothers with low levets of education, and $27 \%$ in better-educated mothers. However, for maternal breastfeeding a prevalence of $51 \%$ for children of mothers with nonlow education was estimated. There was a positive association between the practice of breastfeeding and the mothers' education levels. Fruit was the first solid supplementary food in the diet, followed by vegetables and cereals. Meat and beans were consumed by all children only at the end of the first year of life. Conclusions. Exclusive maternal breastfeeding is rarely practiced. Introduction of supplementary foods is early, and uses products of low catoric density. The maternal education level is an important factor in the type of breastfeeding, but had little influence on the supplementary foods.

Descriptors. Infant nutrition. Breastfeeding. Weaning. Supplementary feeding. Milk. 


\section{ÍNDICE}

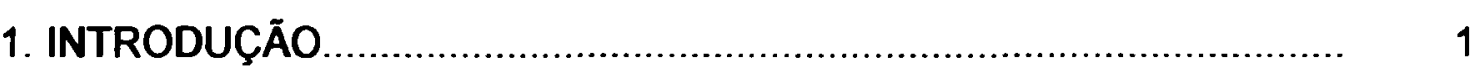

1.1. Alimentação no primeiro ano de vida.................................................

1.2. Alimentação de transição................................................................ 6

1.3. Bases para alimentação no primeiro ano de vida........................... 12

1.3.1. Necessidades e recomendações nutricionais........................ 13

1.3.2. Guias alimentares.......................................................... 16

1.4. Alimentação e características sócio-econômicas............................. 20

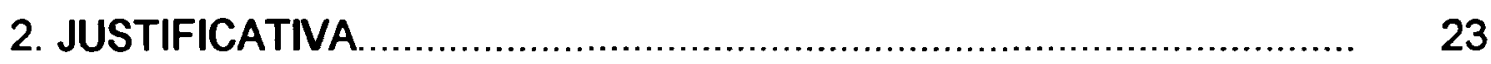

3. OBJETIVOS

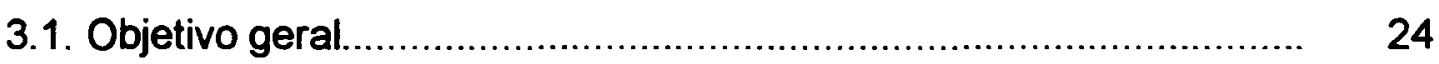

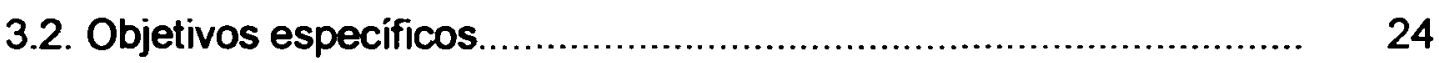

4. MATERIAL E MÉTODOS................................................................ 25

4.1. Delineamento

4.2. Populaçăo e local de estudo.......................................................... 25

4.3. Coleta e registro de dados......................................................... 26

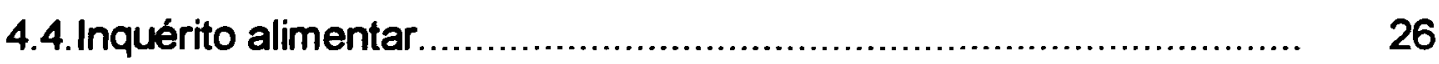

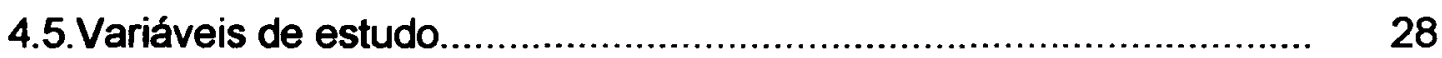

4.5.1. Variáveis independentes.................................................. 28

4.5.2. Variáveis dependentes..................................................... 29

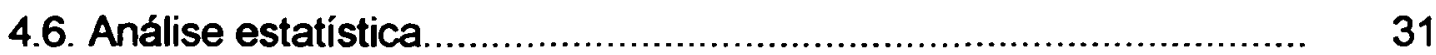

4.7. Índice de descontinuidade........................................................... 32

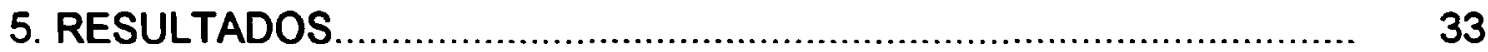

5.1. Características da populaçăo de estudo.......................................... 33

5.2. Fatores associados à prática alimentar.......................................... 38

5.3. Aleitamento materno............................................................... 39

5.4. Aleitamento materno exclusivo...................................................... 43

5.4.1. Índice de descontinuidade................................................ 47

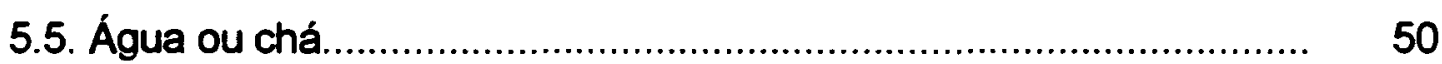

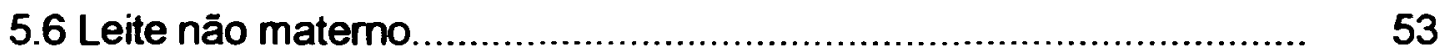

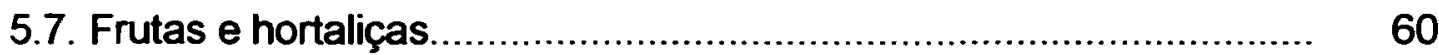




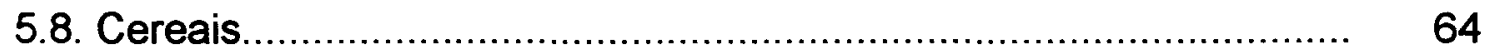

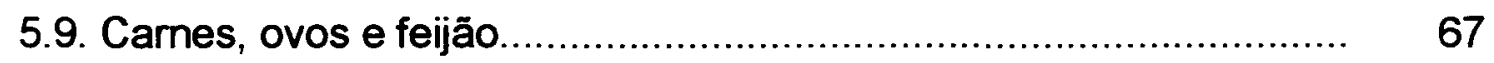

5.10. Peixes e ovos .................................................................. 72

6. DISCUSSÃO

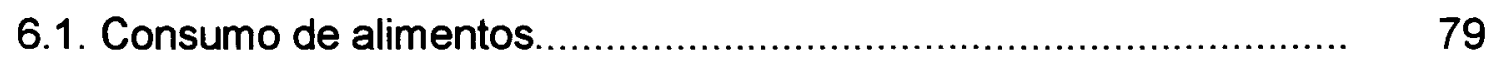

6.2. Aleitamento materno exclusivo.................................................... $\quad 80$

6.3. Aleitamento materno ................................................................. 84

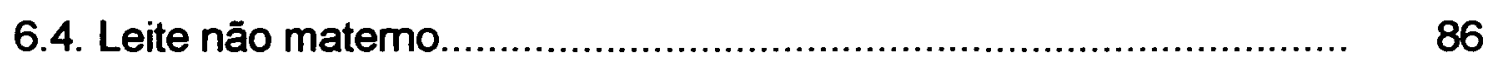

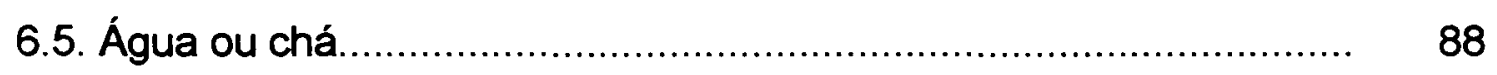

6.6. Alimentos complementares....................................................... 90

7. CONCLUSÓES

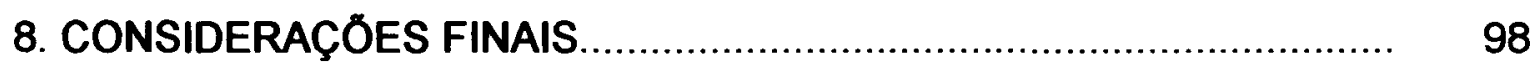

9. REFERÉNCIAS.

ANEXOS

Anexo 1 - Termo de consentimento para participação na pesquisa "Dieta de desmame e anemia no primeiro ano de vida, em crianças atendidas na rede pública de saúde".

Anexo 2 - Modelo do formulário - "Alimentação no primeiro ano de A2 vida". 


\section{Lista de tabelas}

página

Tabela 1 - Distribuição do número e porcentagem das crianças segundo sexo e localidade. São Paulo, 1998.

Tabela 2 - Distribuição do número e porcentagem das crianças segundo idade e localidade. São Paulo, 1998.

Tabela 3 - Distribuição do número e porcentagem das crianças segundo peso ao nascer e localidade. São Paulo, 1998.

Tabela 4 - Distribuição do número e porcentagem das crianças segundo peso para idade e localidade. São Paulo, 1998.

Tabela 5 - Distribuição do número e porcentagem das crianças segundo idade materna e localidade. São Paulo, 1998.

Tabela 6 - Distribuição do número e porcentagem das crianças segundo escolaridade materna e localidade. São Paulo, 1998.

Tabela 7 - Distribuição do número e porcentagem das crianças segundo escolaridade paterna e localidade. São Paulo, 1998.

Tabela 8 - Distribuição do número e porcentagem das crianças segundo aleitamento materno e as variáveis de análise, valores da Odds Ratio (OR) e intervalo de confiança 95\%. São Paulo, 1998

Tabela 9 - Valores da Odds Ratio (OR), intervalo de confiança (IC) no modelo de regressão logística multivariada.

Tabela 10 - Resultados da regressão logística multivariada para aleitamento materno.

Tabela 11 - Prevalência de aleitamento materno segundo escolaridade materna. São Paulo, 1998. 
Tabela 12 - Distribuição do número e porcentagem das crianças segundo aleitamento materno exclusivo e as variáveis de análise, valores da Odds ratio (OR), intervalo de confiança de $95 \%$. São Paulo, 1998.

Tabela 13 - Resultados da regressão logística multivariada para aleitamento materno exclusivo

Tabela 14 - Índices de Descontinuidade cumulativos para aleitamento materno exclusivo de 0 a 30,60, 120 e 180 dias de idade nos Centros de Saúde. São Paulo, 1998.

Tabela 15 - Resultados da regressão logística multivariada para aleitamento materno exclusivo.

Tabela 16 - Prevalência de aleitamento materno exclusivo segundo escolaridade materna. São Paulo, 1998.

Tabela 17 - Distribuiçăo do número e porcentagem das crianças segundo consumo de água ou chá e demais variáveis de estudo. São Paulo, 1998

Tabela 18 - Resultados da regressão logística multivariada para consumo de água ou chá.

Tabela 19 - Distribuição do número e porcentagem das crianças segundo consumo de leite não materno e demais variáveis de estudo. São Paulo, 1998

Tabela 20 - Resultados da regressão logística multivariada para consumo de leite não materno

Tabela 21 - Prevalência de consumo de leite não materno em diferentes idades, segundo localidade. São Paulo, 1998.

Tabela 22 - Resultados da regressão logística multivariada para consumo de leite não materno. 
Tabela 23- Distribuição do número e porcentagem das crianças segundo o consumo de frutas e demais variáveis de estudo. São Paulo, 1998.

Tabela 24- Distribuição do número e porcentagem das crianças segundo o consumo de hortaliças e demais variáveis de estudo. São Paulo, 1998

Tabela 25 - Resultados da regressão logística para consumo de frutas e hortaliças. São Paulo, 1998.

Tabela 26 - Distribuição do número e porcentagem das crianças segundo o consumo de cereais e as demais variáveis de estudo. São Paulo, 1998.

Tabela 27 - Resultados da regressão logística para consumo de cereais. São Paulo, 1998

Tabela 28 - Distribuição do número e porcentagem das crianças segundo consumo de carnes e ovos e demais variáveis de estudo. São Paulo, 1998.

Tabela 29 - Distribuição do número e porcentagem das crianças segundo consumo de feijão e demais variáveis de estudo. São Paulo, 1998

Tabela 30 - Resultados da regressão logística para consumo de carnes e feijão. São Paulo, 1998.

Tabela 31 - Prevalência de consumo de carnes e/ou ovos e feijão. São Paulo, 1998.

Tabela 32 - Distribuição do número e porcentagem das crianças segundo consumo de peixes e demais variáveis de estudo. São Paulo, 1998 
Tabela 33 - Distribuição do número e porcentagem das crianças segundo consumo de ovos e demais variáveis de estudo. São Paulo, 1998

Tabela 34 - Resultados da regressão logística para consumo de peixe e ovos. São Paulo, 1998.

Tabela 35 - Comparação entre os Índices de Descontinuidade cumulativos para aleitamento materno exclusivo de 0 a 30, 60, 120 e 180 dias de idade nos Centros de Saúde. São Paulo, Santo André e Cuba, 1989. 


\section{Lista de figuras}

página

Figura 1 - Porcentagem das crianças segundo escolaridade dos pais 38

Figura 2 - Curvas de prevalência de aleitamento materno segundo escolaridade materna. São Paulo, 1998.

Figura 3 - Curvas de prevalência de aleitamento materno exclusivo segundo localidade de estudo. São Paulo, 1998.

Figura 4 - Curvas de prevalência de aleitamento materno exclusivo segundo escolaridade da mãe. São Paulo, 1998

Figura 5, - Curvas de prevalência de consumo de água ou chá segundo escolaridade materna nos Centros de saúde. São Paulo, 1998.

Figura 6 - Curvas de prevalência de consumo de leite não materno segundo localidade. São Paulo, 1998

Figura 7 - Curvas de prevalência de consumo de leite não materno segundo escolaridade materna. São Paulo, 1998.

Figura 8 - Curvas de prevalência de consumo de leite materno, leite não materno e água ou chá nos Centros de Saúde, segundo escolaridade materna. São Paulo, 1998.

Figura 9 - Curvas de prevalência de consumo de frutas e hortaliças nos Centros de Saúde. São Paulo, 1998.

Figura 10 - Curva de prevalência de consumo de cereais nos Centros de Saúde. São Paulo, 1998

Figura 11 - Curvas de prevalência de consumo de carnes elou ovos e feijão nos Centros de Saúde São Paulo 1998

Figura 12 - Curvas de prevalência de consumo de peixes e ovos nos Centros de Saúde. São Paulo.

Figura 13 - Curvas de prevalência de consumo de frutas, hortaliças, cereais, carnes elou ovos, feijão, peixe e ovos nos Centros de Saúde. São Paulo, 1998. 


\section{INTRODUÇÃO}

\subsection{ALIMENTAÇÃO NO PRIMEIRO ANO DE VIDA}

O aleitamento materno era a prática mais comum de alimentação do lactente até o início deste século. No entanto, já na Antigüidade buscavamse métodos alternativos de alimentação para quando a amamentação não era possivel ou desejada pela mãe. Nestes casos, a opção mais comum era a utilização das amas de leite, muito populares na Grécia, Roma Antiga e na Europa do século XVII e XVIII (BARNESS 1987, WEINBERG 1993; PALMER 1993).

Quando não era possível arcar com os custos de uma ama, eram ministrados para a criança um tipo de cerveja com baixo teor alcóolico, papas feitas com cereal ou pão e água ou leite. Algumas vezes, as crianças eram colocadas diretamente nas tetas de animais, especialmente cabras ou mulas. (RADBIL 1981, BARNESS 1987, HERVADA e NEWMAN 1992, WEINBERG 1993)

As conseqüências destas práticas se revelaram através de altíssimos indices de mortalidade infantil. As tentativas de alimentação artificial nas primeiras semanas de vida resultavam em óbito de $100 \%$ das crianças. (RADBILL 1981, HEFTI 1993, WEINBERG, 1993)

No final do século $X I X$ e início do século $X X$, o desenvolvimento das técnicas de produção e conservação de alimentos, a expansão na comercialização de leites formulados para lactentes e o desenvolvimento 
dos bicos de borracha facilitaram o aleitamento artificial (BULLOUGH 1987, BARNESS 1987, HERVADA e NEWMAN 1992, WEINBERG 1993).

Tais fatores atuando num cenário sócio-cultural complexo, onde se destacam a intensa medicalização da sociedade, mudanças na estrutura familiar e crescente urbanização, colaboraram com o declínio da amamentação natural. (REA 1990, RODRíGUEZ 1993, FISBERG e BRAGA 1996, VENÂNCIO 1996)

O desmame precoce e o aleitamento artificial levaram a elevação da prevalência de doenças diarréicas e de desnutrição, em especial nos países em desenvolvimento (JELLIFFE e JELLIFE 1971). Inicia-se então, a partir da década de 70, um movimento de revalorização da amamentação, com o apoio e mobilização de várias instituições, destacando-se a Organização Mundial da Saúde e o Fundo das Naçōes Unidas para a Infância (VENÂNCIO 1996).

MARTINEZ e DODD, 1983, analisando dados de inquérito nacional nos Estados Unidos, constataram aumento da amamentação nos anos 80 comparado com a década anterior, tanto em incidência quanto em duração, em todos os níveis de renda e educaçăo.

AMADOR e colaboradores, 1994, averiguando as tendências de aleitamento materno na América Central e na América Latina, utilizando dados de inquéritos nacionais da década de 70 e do Censo Demográfico e de Saúde, conduzido entre 1986 e 1991 pela PAHO - Pan American Health Organization, referem um aumento da prevalência e duração do aleitamento 
materno nos paises estudados: Costa Rica, Argentina, Cuba, México, Equador, Colômbia e República Dominicana, no período de 1986 a 1991.

No Brasil, VENÂNCIO, 1996, analisando dados de duas pesquisas nacionais realizadas em 1975 e 1989, verificou uma considerável expansão na prática da amamentação, passando o tempo mediano de sua duração de 2,5 meses para 5,5 meses.

Universalmente, reconhece-se que o leite materno é o alimento perfeito para o bebê nos primeiros seis meses de vida. É mais que um leite, é um fluido corporal biológico, que contém a mistura equilibrada dos nutrientes necessários para o lactente, com exceção de vitamina $D$ e flúor. (RADRIGAN e col. 1989, HERVADA e NEWMAN 1992, AKRÉ 1994, WHITEHEAD 1995). É o alimento ideal para o crescimento e desenvolvimento dos lactentes, devido às suas propriedades físico-químicas e imunológicas, e por sua especificidade em relação às necessidades nutricionais e fisiológicas da criança. (AKRÉ 1989).

Além do mais, proporciona o contato, a atenção e o carinho que são críticos para o desenvolvimento da criança (BARNESS 1987). Estudos recentes demonstraram a importância do fortalecimento do vínculo afetivo entre mãe e filho na gênese de distúrbios nutricionais. (RAMAKRISHNAN 1995, NÓBREGA e CAMPOS 1996)

A OMS, na "Declaração dos Inocentes", afirma que o aleitamento materno: 
- Oferece nutrição ideal ao lactente e contribui para seu crescimento e desenvolvimento saudável;

- Reduz a incidência e severidade de doenças infecciosas, diminuindo a mortalidade e morbidade infantil;

- Contribui para a saúde da mulher através da redução do risco de câncer no seio e ovários e pelo espaçamento entre as gestações;

- Fornece benefícios sociais para a família e a nação (WHO 1990).

A idade adequada para o início da introdução da alimentação complementar é um tópico controverso. Por muitas décadas, a OMS recomendou o início da complementação do leite materno entre os 4 e 6 meses de idade (WHO 1995a). Atualmente, recomenda oferecer os alimentos complementares por volta dos seis meses de idade (DEWEY e col. 1998).

Estudos recentes sugerem que a criança amamentada ao peito tende a manter sua ingestão habitual de energia (COHEN e col.1994, BROWN e col. 1995a). Dessa forma, a alimentação complementar não adiciona conteúdo energético à dieta, pois em resposta à introdução de alimentos, o lactente reduz o consumo de leite materno. 
BORRENSEN, 1995, em revisão crítica da literatura, afirma que a alegada inadequação no volume de leite depois dos 4 a 6 meses, é causada artificialmente devido à queda na produção induzida pela complementação. O autor conclui que alimentos sólidos não deveriam ser recomendados até os 8 ou 9 meses de idade.

Estudo conduzido por BROWN e colaboradores (1995a) em Honduras, mostrou que crianças que recebiam alimentos complementares consumiam significativamente menos leite materno. Além disso, os autores ponderam que é difícil estimular uma criança saciada por outras fontes a consumir o leite materno.

O COMA - Comittee on Medical Aspects of Food Policy, em documento sobre alimentação complementar publicado pelo Departamento de Saúde Britânico em 1994, recomenda que uma dieta variada seja oferecida à criança por volta dos seis meses, permitindo o contato com novas texturas e sabores, enfatizando que os alimentos sejam oferecidos através de uma colher e não misturados com líquidos em mamadeiras, de forma a desenvolver na crianças a capacidade de mastigar e engolir (JAMES e UNDERWOOD 1997).

A Sociedade de Pediatria de São Paulo recomenda o aleitamento materno exclusivo até o sexto mês para as crianças com crescimento e desenvolvimento normais. Se houver desaceleração do ganho de peso após o quarto mês, inicia-se com alimentos não lácteos, complementares ao leite materno (PALMA e col 1998). 


\subsection{ALIMENTAÇÃO DE TRANSIÇÃO}

As primeiras descrições de alimentos de transição apareceram entre 1500 e 1800. Recomendava-se que as crianças recebessem unicamente leite e mucilagens até romper o primeiro dente, quando então poderiam receber pão amolecido e caldo de carne (HERVADA e NEWMAN, 1992).

$\mathrm{Na}$ primeira informação impressa sobre desmame encontrada na América, em 1708, recomendava-se desmamar o bebê mais forte primeiro e - mais fraco depois, num reconhecimento empírico do valor da amamentação. Recomendava-se a introdução precoce de frutas e vegetais, além de leite fervido com pão e gema de ovo por volta de três meses de idade. A introdução de alimentos sólidos deveria se dar após um ano. Esta prática consolidou-se e persistiu até o início do século XX (HERVADA e NEWMAN 1992).

Entre 1920 e 1970 ocorreram as mais expressivas mudanças nas práticas de alimentação infantil: cereais e alimentos preparados, além de frutas e vegetais, eram adicionados na dieta infantil para suprir energia, ferro e vitaminas. A tendência de introduzir alimentos sólidos precocemente teve seu período mais extremado entre 1950 e 1960, com pediatras sugerindo sua introdução já no segundo dia de vida (HERVADA e NEWMAN 1992).

Em 1954, foi criado nos Estados Unidos o Comitê em Nutrição, da Academia Americana de Pediatria, com o intuito de estabelecer guias e orientações para as práticas alimentares infantis (HERVADA e NEWMAN 1992). 
A prática alimentar adotada, a duração do aleitamento materno, e os alimentos de transição, constituem elementos fundamentais na mortalidade, morbidade, crescimento e desenvolvimento da criança, com reflexos na vida adulta (PLANK e MILANESE 1973, MARTELL e col. 1981, KOVAR e col. 1984, VICTORA e col. 1987, MONTEIRO 1988, BECKER e col. 1991, SILVA e col. 1993, CABALLERO e col. 1994, CHAVES e col. 1995, LANTING e BOERSMA 1996).

A transição para a alimentação da familia é um processo que envolve complexos fatores nutricionais, sociais, econômicos e culturais. As medidas do sucesso deste processo são incertas e os resultados visíveis ocorrem em um futuro distante (KRETCHMER 1985, BALLABRIGA e REY 1987, BARNESS 1990).

Segundo HERVADA e NEWMAN, 1992, as necessidades nutricionais para os primeiros seis meses de vida foram "resolvidas" no presente pela amamentação ou pelo uso das modernas fórmulas fortificadas com ferro. Resta o desafio de como deve ser a alimentação da criança dos seis aos dezoito meses de vida.

O período de desmame, definido como o período que a dieta muda do aleitamento materno exclusivo para a alimentação da família, é uma etapa crítica que, com freqüência, conduz à má-nutrição e à enfermidade quando a criança não recebe uma dieta adequada, tanto em qualidade quanto em quantidade, preparada higienicamente e aceitável do ponto de vista social, cultural e econômico (WHO 1979, 1988). 
A OMS recomenda que a amamentação se estenda até os dois anos de idade ou mais (WHO 1995a). É consensual a recomendação para que o aleitamento materno se estenda pelo menos até o final do primeiro ano de vida (GIUGLIANI E VICTORA 1997, REA, 1998).

Assim, para enfatizar que a introdução de alimentos para a criança não objetiva o término do aleitamento materno, mas, sim, sua complementação, o termo "alimentos de desmame" tem sido substituido por "alimentos de transição", entendendo-se por alimentos complementares quaisquer alimentos oferecidos à criança que não o leite materno (GIUGLIANI e VICTORA 1997).

A complementação do leite materno por volta dos seis meses de idade é necessária porque o leite materno sozinho já não atende as necessidades nutricionais da criança (WHITEHEAD 1985, KRETCHEMER 1985). O objetivo primeiro na alimentação infantil é proporcionar calorias e nutrientes para sustentar o ótimo crescimento e desenvolvimento da criança (ARRÉGUIN 1994)

A introdução precoce de alimentos sólidos, antes do $4^{\circ}$ mês, está associada à maior prevalência de infecções gastro-intestinais, doença diarréica, alergias alimentares e pior estado nutricional (JASON e MARKS 1984, VICTORA e col. 1987, HENDRICKS e BADRUDDIN 1992, HAIDER e col. 1996, RÉA 1998).

A introdução de alimentos tardiamente, após o sexto mês, também pode trazer conseqüências indesejadas tais como deficiência no 
crescimento, diminuição da proteção imunológica e levar ao desenvolvimento de problemas nutricionais (HENDRICKS e BADRUDDIN 1992, CAUFIELD e col. 1996).

Em países em desenvolvimento, a idade em que as crianças recebem alimentos complementares pela primeira vez, é relevante para a Saúde Pública, devido ao risco de doença diarréica em decorrência da contaminação dos alimentos de desmame, e ao risco potencial para o adequado crescimento infantil, se os alimentos não forem apropriados (AKRÉ 1994; COHEN e col. 1994).

UNDERWOOD, 1984, destaca que as dietas monótonas em sabor e textura, comuns em ambientes de baixo nivel sócio-econômico, podem atuar sinergicamente com os repetidos episódios de doenças infecciosas, resultando em falta de apetite crônica e baixa aceitação de alimentos na época crítica para o desenvolvimento e crescimento.

AKRÉ, 1994, também destaca os riscos futuros do desmame precoce, sugerindo dois mecanismos: através da criação de hábitos alimentares que condicionem práticas dietéticas inadequadas e pelo efeito acumulativo de alterações que embora se iniciem precocemente, só resultem em morbidade anos mais tarde.

A alimentação na infância e seus efeitos imediatos e a longo prazo estão em evidência. Explora-se a hipótese de que os alimentos consumidos durante as primeiras semanas ou meses de vida tenham efeitos 
permanentes no metabolismo. (LUCAS 1998, ROBERTS e McDONALD 1998).

Estudos epidemiológicos sugerem que a duração do aleitamento ao seio afeta a concentração de lipoproteínas e relaciona-se com o desenvolvimento de cardiopatias isquêmicas em idosos (FALL e col. 1992 MOTT 1994, MCGILL 1997). Como o leite materno contém significativamente mais colesterol que as fórmulas lácteas comerciais, os lactentes amamentados têm níveis séricos de colesterol total e de colesterol de lipoproteínas de baixa densidade (LDL-C) mais altos que os alimentados com fórmulas. O colesterol total e o LDL-C do soro são aterogênicos e correlacionam-se positivamente com a intensidade de lesões ateroscleróticas da aorta e das artérias coronárias em crianças e adultos jovens (MOTT 1994, WONG 1994). No entanto os resultados dos estudos são conflitantes e não permitem mudanças nas atuais recomendações para alimentação infantil. (MCGILL 1997).

O Comitê de Nutrição da Academia Americana de Pediatria sugere que os filhos de familias com histórias de acidentes vasculares cerebrais ou de hipertensão recebam dietas com baixo conteúdo de sal e alto conteúdo de potássio. O leite materno contém pouco sódio, mas a ingestão de sódio pode aumentar drasticamente quando inicia-se o desmame com alimentos da família (HOLLIDAY 1994, AKRÉ 1994).

POSKITT, 1994, afirma que vários estudos com crianças obesas sugerem a existência de correlação entre a obesidade ou excesso de peso 
durante a infância e o aparecimento da obesidade em fases posteriores. No entanto, avaliações adicionais também sugerem que a maior parte dos lactentes obesos tornam-se magros nos primeiros anos do período préescolar. Parece que a obesidade está mais associada com práticas permissivas e hábitos errôneos adquiridos na infância que com o estado nutricional pregresso.

Estudos recentes sugerem associação entre a duração do aleitamento materno e o diabetes mellitus do tipo I - IDDM (BORCH-JOHNSEN e col. 1984, SCOTT 1990, DRASH e col. 1994). Existem evidências que as proteínas do leite de vaca são um importante fator ambiental para desencadear um processo autoimune que afeta as células $\beta$ do pâncreas em individuos geneticamente suscetíveis (AKERBLOM e col. 1994).

GIMENO e SOUZA, 1997, em estudo de caso controle conduzido em São Paulo, verificaram que as crianças não-doentes (controle) tinham significativamente maior tempo de aleitamento materno exclusivo e haviam recebido leite de vaca mais tarde que as crianças com IDDM (caso).

WILSON e colaboradores, 1998, em estudo de coorte, verificaram que a probabilidade de ocorrência de doença respiratória em qualquer período da infância é significativamente reduzida se a criança tiver sido amamentada exclusivamente por quinze semanas. Parece haver um efeito protetor na amamentação e na introdução tardia de alimentos sólidos.

A saúde dos dentes também é afetada pelos alimentos selecionados para complementação, em especial preparações e bebidas contendo 
dextrose, glicose, lactose, maltose, amido hidrolisado, frutose e sacarose. 0 Departamento de Saúde Britânico recomenda que os açúcares provenientes de outras fontes que não o leite não excedam $10-11 \%$ da energia total da dieta. (HOLT 1997)

\subsection{BASES PARA A ALIMENTAÇÃO NO PRIMEIRO ANO DE VIDA}

A alimentação da criança no primeiro ano de vida deve atender às necessidades nutricionais, que variam de acordo com a idade, sexo, ritmo de crescimento, atividade física, fatores genéticos, condições ambientais, além da necessidade de multiplicação e diferenciação celular, fenômenos que caracterizam o crescimento e o desenvolvimento (WOISKI 1988, AKRÉ1994)

Ao nascer, o bebê passa a se alimentar, porém, os sistemas digestivo e excretor não estão completamente maduros. Os reflexos de sucção e extrusão, presentes nos primeiros meses de vida, condicionam o bebê à alimentação líquida. Somente entre 4 a 6 meses 0 reflexo de extrusão desaparece, permitindo à criança engulir alimentos semi sólidos. $O$ desenvolvimento de habilidades para se alimentar e auto-regular a ingestão são passos fundamentais no processo de introdução de alimentos. Dessa forma, as práticas alimentares devem ser condicionadas tanto pelas necessidades nutricionais quanto pelo grau de maturidade funcional do 
lactente (PRIDHAM 1990, HENDRICKS e BADRUDDIN 1992, HERVADA e NEWMAN 1992, GOMEZ 1993, AKRÉ 1994).

\subsubsection{Necessidades e Recomendações Nutricionais}

O crescimento no início da vida é rápido. O peso do bebê normal dobra aos 4 meses e triplica ao final do primeiro ano. $O$ crescimento no primeiro trimestre representa 30 a $34 \%$ do consumo energético da criança. As necessidades de energia e nutrientes no primeiro mês de vida são o triplo das dos adultos, por quilo de peso. As necessidades minerais são consideráveis, principalmente em relação ao ferro para a formação de hemoglobina e ao cálcio para formação dos ossos (RADRIGAN e col.1989, MILNER 1990, AKRÉ, 1994, RYAN e SCHAFER 1995).

WATERLOW e THOMSON, 1979, estimaram a necessidade infantil de proteina e energia, e compararam com a quantidade de energia e proteína contidas no leite humano. Concluíram que a energia é inadequada a partir do $4^{\circ}$ mês, enquanto que a proteína permanece adequada até o $6^{\circ}$ mês, conclusão compartilhada por outros pesquisadores. (JASON e MARKS1984, WHITEHEAD 1985)

BERGMAN e BERGMAN, 1979, verificaram que, em crianças alimentadas ad libitum, as necessidades energéticas para manutenção 
determinam a ingestão. Quando a energia é deficiente, crescimento e manutenção competem, podendo surgir desordens no crescimento.

As proteinas fornecem os aminoácidos para a síntese de novas células do organismo. No neonato, as necessidades de aminoácidos essenciais são proporcionalmente muito maiores que nas crianças mais velhas ou adultos. Dessa forma, dificilmente as necessidades serão satisfeitas com o aporte na dieta de proteínas de baixo valor biológico. A proteína pode ser o nutriente limitante da dieta da criança, principalmente quando o desmame é iniciado com misturas compostas unicamente por vegetais e cereais. (HERVADA e NEWMAN 1992, AKRÉ 1994)

Os lipídios são importantes como fontes de energia. São também essenciais para o desenvolvimento do cérebro, além de fornecerem as vitaminas lipossolúveis. As crianças em aleitamento materno recebem, aproximadamente, $50 \%$ da energia da dieta em forma de lipídios. Há ainda dois ácidos graxos essenciais: o linoleico e o alfa-linoleico. A dieta de desmame deve fornecer pelo menos $30 \%$ ou $40 \%$ das calorias em forma de lipídios. (HERVADA e NEWMAN 1992, AKRÉ, 1994)

AGOSTINI e colaboradores, 1995, em revisão da literatura, sugerem que sejam ministrados à criança alimentos ricos em fibras solúveis e insolúveis, provenientes de cereais integrais, vegetais verdes e legumes, introduzidos a partir do $6^{\circ}$ mês, de acordo com o seu potencial alergênico. A contribuição destes alimentos na dieta refere-se, principalmente, ao seu conteúdo nutricional (vitamina $\mathrm{C}$, selênio, carotenóides), além do seu papel 
na colonização intestinal pela flora fermentativa e na formação do bolo fecal. Cuidados devem ser tomados devido à presença de fatores antinutricionais (fitatos, fitohemaglutininas) e pela interferência na absorção de minerais e elementos traços.

O problema de saúde mais comum no desmame é a deficiência de ferro (LöNNERDAL 1989, HOKAMA e YAMAMOTO 1996). Nos primeiros meses de vida há uma marcada redução fisiológica na concentração da hemoglobina sangüínea e um aumento proporcional das reservas corporais de ferro, as quais se mobilizam posteriormente. Entre os 4 a 6 meses de idade, as reservas corporais se encontram reduzidas e a absorção de ferro aumenta. O atendimento das necessidades de ferro é afetado pela biodisponiblidade da dieta, ou seja, em função da presença de ferro hemínico ou não hemínico, e pela presença de fatores que favorecem (carnes e ácido ascórbico) ou inibem a absorção (ácido fítico, compostos fenólicos, cálcio) (TORÚN e col. 1996, HURRELL, 1997). As recomendaçōes de ferro são $25 \%$ maiores que as necessidades. O INCAP, Instituto de Nutrición de Centro América e Panamá, nas recomendações dietéticas diárias (RDD), levando em conta as características sanitárias da maior parte da América Latina e as altas taxas de mortalidade infantil, recomenda $10 \mathrm{mg}$ de ferro/dia para crianças entre 6 a 12 meses de idade (TORÚN e col. 1996)

A deficiência crônica de vitamina $A$ tem sido associada a uma maior taxa de mortalidade infantil. As estimativas das necessidades basais de vitamina A se basearam em observaçōes em crianças em aleitamento 
materno de populações pobres da Índia que cresceram bem e não apresentaram sinais de deficiência. À esta cifra se agregou arbitrariamente $50 \%$ para permitir o estabelecimento de reservas hepáticas adequadas. Dessa forma, o INCAP recomenda $350 \mathrm{mcg}$ de vitamina Addia, para crianças de 0 a 12 meses de idade.(TORÚN e col. 1996)

Ainda que se reconheça que o ácido pantotênico, a biotina e a vitamina $\mathrm{K}$ sejam nutrientes essenciais, a deficiência dietética para estes compostos é praticamente inexistente, manifestando-se apenas em condições experimentais ou iatrogênicas. Também a deficiência de vitamina D é praticamente inexistente nas regiões tropicais da América Latina (CABALLERO e col. 1994)

Os elementos-traço, apesar de relativamente escassos nos tecidos, têm importante função na saúde e na resistência à enfermidades. São reconhecidos 15 elementos (arsênio, crômio, cobalto, cobre, flúor, ferro, iodo, manganês, molibdênio, níquel, selênio, aluminio, sílica, vanádio, zinco). As necessidades fisiológicas de elementos traço para adultos são conhecidas com variados graus de certeza, porém os conhecimentos das necessidades nutricionais para a criança no período de desmame são praticamente inexistentes, bem como a biodisponibilidade destes elementos na dieta de desmame. (MILNER, 1990)

\subsubsection{Guias alimentares}

A necessidade de elaboração de guias de alimentação para esta fase da vida é reconhecida pela OMS que incentiva pesquisas sobre os efeitos 
dos diferentes alimentos complementares no crescimento dos lactentes, principalmente dentro da ótica das recomendações atuais (WHO, 1995b).

Em trabalho proposto para servir de base para o desenvolvimento de guias alimentares para a América Latina, especialistas sugerem que entre 4 a 6 meses seja complementado o leite materno, introduzindo-se na dieta infantil cereais sem glúten, tubérculos, vegetais e frutas, com exceção das cítricas; entre 6 e 12 meses a carne bovina, frango, peixe e ovos, todos os cereais e leguminosas. Entre 12 e 24 meses progressivamente se passe à alimentação do adulto. A introdução de alimentos potencialmente alergênicos como clara de ovo e peixe deve ser postergada até o $8^{\circ}$ mês. $\mathrm{A}$ administração de espinafre e folhas de beterraba deve ser evitada no primeiro ano de vida para reduzir o risco de metahemoglobinemia, como conseqüência da produção de nitritos a partir dos nitratos contidos nestes alimentos. (CABALLERO e col. 1994).

A OMS, em guia dirigido à agentes de saúde, sugere o início do desmame entre os 4 e 6 meses, de acordo com o desenvolvimento do lactente, complementando-se o leite materno com alimentos acessíveis à família e que não sejam dispendiosos. Sugere introduzir primeiro papas de cereais, tubérculos ou raizes como arroz, milho, trigo, batata e mandioca, em seguida, produtos de origem animal, vegetais verde escuros e laranjas, óleos e gorduras e frutas. Não são mencionados os períodos de introdução. (WHO 1988). 
SILVA e colaboradores, 1993, baseado nas recomendações do Instituto de Nutrición e Higiene de los Alimentos de Cuba sugerem a introdução de sucos entre 120 a 150 dias de idade, verduras de 150 a 180 dias, carne de 180 a 210 dias e peixe de 300 a 360 dias.

O Departamento de Saúde britânico recomenda a introdução de alimentos sólidos entre 4 a 6 meses de idade, iniciando-se com uma papa de cereais, prosseguindo com a alimentação da família, tomando-se cuidado com dietas de desmame que contenham somente frutas e vegetais. (WHARTON, 1997)

A BROADWAY PEDIATRIC ASSOCIATES (1997), em artigo veiculado na Internet, recomenda a introdução dos alimentos sólidos a partir do $4^{\circ}$ mês de idade, iniciando-se com cereal em grão (arroz, farinha de aveia ou cevada), em seguida vegetais amarelos, e frutas. Um número maior de alimentos pode ser introduzido por volta dos 7 ou 8 meses, como vegetais verdes, carnes, iogurte e queijo cottage. Sugere cautela na introdução de leite de vaca, farinha de trigo e ovos, pois são potencialmente alergênicos.

A Sociedade de Pediatria de São Paulo recomenda que por volta dos seis meses sejam introduzidas a papa de frutas e uma refeição de sal. Sugere compor a papa de sal com cereais e tubérculos, leguminosas, carne (bovina, frango ou peixe), hortaliças, óleo, sal e cebola. Introduz-se também os ovos, levando-se em conta a história familiar de atopia para o início do consumo da clara do ovo e de outras proteínas potencialmente alergênicas. Entre 7 e 8 meses inicia-se a segunda refeição de sal (PALMA e col. 1998). 
HENDRICKS e BADRUDDIN, 1992, em revisão da literatura, concluem que a ordem e os períodos de introdução dos alimentos não são rigorosos, sendo que o essencial para atingir as necessidades nutricionais do lactente é a densidade calórica, a adequação protéica e a variedade dos alimentos ou suas misturas.

BROWN e colaboradores, 1995b, estimaram a quantidade de energia proveniente da alimentação complementar necessária nas crianças dos grupos etários de 6-8, 9-11 e 12-23 meses, bem como a densidade energética em função do número de refeições, chegando a conclusão que para atingir $135 \mathrm{Kcal} / \mathrm{kg} /$ dia em três refeições, a densidade energética deve ser de $121 \mathrm{kcal} / 100 \mathrm{~g}$

EGASHIRA, 1998, em estudo realizado no município de São Paulo, verificou que a densidade energética média da alimentação das crianças menores de 24 meses foi de $0,98 \mathrm{kcal} / \mathrm{g}$ e a freqüência média foi de 7,8 refeições.

Um estudo epidemiológico retrospectivo sobre o desmame conduzido por FERRANTE e colaboradores 1994, em Roma, encontrou alguns hábitos incorretos: início precoce ou tardio do desmame e uso do leite de vaca no $2^{\circ}$ semestre de vida.

POTUR e KALMAZ, 1993, observaram os principais erros de alimentação em crianças de 0 a 4 meses, em clínica pediátrica na Turquia: pequena proporção de crianças em aleitamento materno exclusivo, diluição 
incorreta da fórmula láctea, mingau de arroz preparado com água e uso da água de arroz como alimento.

Em estudo epidemiológico no município de São Paulo, MONTEIRO e SZARFARC, 1988, verificaram que o leite materno era oferecido até o terceiro ou quarto mês de vida, sendo em seguida substituído por leite de vaca fluido. A carne e o feijāo eram oferecidos apenas após o primeiro ano de vida.

TUDISCO e colaboradores, 1988, analisando as dietas de 466 crianças menores de dois anos em áreas periurbanas de quatro capitais brasileiras, verificaram que a principal mistura de alimentos fornecida às crianças foi o leite artificial, acrescido de amido e açúcar. O consumo de feculentos foi prática comuns nas regiões analisadas. Verificou-se ainda baixo consumo de carnes e hortaliças.

SOUZA, 1994, em estudo realizado em quatro Centros de Saúde Escola do municipio de São Paulo averiguou como idades médias para introdução de frutas, 3,4 meses; carnes, 4,6 meses; feijão, 5,8 meses; gema, 5,2 meses; hortaliças de folha, 4,7 meses.

\subsection{ALIMENTAÇÃO E CARACTERÍSTICAS SÓCIO-ECONÓMICAS}

Grande parcela da população das nações em desenvolvimento vivem em estado de grande pobreza, resultando em baixas ingestöes dietéticas e grande incidência de doenças infecciosas. Os mecanismos de produção da 
pobreza são vários, e envolvem má distribuição de renda, falta de oportunidades educacionais e ausência de serviços públicos (MARTELL e col. 1981).

As investigações epidemiológicas em nutrição têm incorporado a análise da categoria social, procurando inserir o processo nutricional dentro de uma abordagem histórico-social. A operacionalização do conceito de classe social tem sido proposta em alguns trabalhos. (BARROS 1986, LOMBARDI e col. 1988, VICTORA e col. 1990)

Em estudos urbanos de saúde infantil, as variáveis empregadas com mais freqüência para caracterizar o nível sócio-econômico das famílias têm sido a renda familiar, a escolaridade materna e, em menor escala, a escolaridade paterna. (MONTEIRO 1988, VICTORA e col. 1990).

A escolaridade da mãe e a escolaridade do pai têm sido amplamente utilizadas por estarem imediatamente relacionadas ao processo saúdedoença, além de serem de fácil obtenção e operacionalização. Existem evidências consistentes de associação negativa entre escolaridade dos pais e morbidade. O progresso nos níveis educativos da população, em especial da mulher, cria condições favoráveis para a atenção e cuidado integral com a criança, mesmo favorecendo o ingresso das mães no mercado de trabalho. A desvantagem no uso deste índice, é que a escolaridade é determinada pela classe social, atuando, portanto, mais como um marcador de risco do que como determinante (VICTORA e col. 1990, VASCONCELOS 1993, CABALLERO e col. 1994.) 
SIGULEM e TUDISCO, 1980, em estudo sobre aleitamento natural no município de São Paulo, observaram uma tendência de maior tempo de aleitamento entre as mães de baixa renda, apesar da mediana de tempo de aleitamento para o total da amostra ter sido inferior a um mês.

PÉREZ ESCAMILLA, 1993, comparando os padrões de aleitamento materno em 9 países da América Latina e Caribe, e sua relação com indicadores sócio econômicos, verificou que dentro de cada país, o aleitamento materno foi mais prolongado em zonas urbanas que em rurais, e as mães com níveis mais baixos de escolaridade amamentaram mais tempo que as mães com maior nível educativo.

VENÂNCIO,1996, verificou aumento da prática de amamentação mais acentuado no área urbana da região Centro-Sul do país, entre mulheres de maior poder aquisitivo e escolaridade.

Outros estudos mostram maior freqüência de amamentação entre mulheres com maior escolaridade pertencentes à classes sócio-econômicas mais elevadas que entre mulheres de classes sócio-econômicas mais baixas (HELSING 1981; LAWRENCE 1994)

BROWN e colaboradores, 1989, em estudo longitudinal realizado no Peru sobre as práticas alimentares e morbidade por doenças infecciosas, relata que mães e pais de crianças que eram amamentadas exclusivamente tendiam a ter menos anos de educação formal, apesar das diferenças observadas não apresentarem diferenças estatisticamente significativas. 


\section{JUSTIFICATIVA}

A prática alimentar no primeiro ano de vida tem papel relevante na saúde e crescimento infantil, sendo que há cada vez mais evidências do papel da alimentação nas primeiras fases da vida e seus reflexos na vida adulta.

O conhecimento dos padrōes de consumo dos diferentes alimentos da dieta no primeiro ano e como são estes padrões em diferentes situações de escolaridade dos pais, pode fornecer subsídios para açōes que implementem a adoção de práticas que conduzam à melhoria alimentar neste grupo da população, que é especialmente vulnerável.

Dessa forma, este trabalho foi delineado utilizando dados relativos à alimentação infantil de pesquisa do Departamento de Nutrição da Faculdade de Saúde Pública da USP, sobre aleitamento materno, dieta de transiçăo e anemia no primeiro ano de vida. 


\section{OBJETIVOS}

\subsection{OBJETIVO GERAL}

Estudar os alimentos utilizados na dieta do primeiro ano de vida, em crianças que freqüentam dois Centros de Saüde estaduais no Municipio de São Paulo.

\subsection{OBJETIVOS ESPECÍFICOS}

- Descrever a prevalência do aleitamento materno e aleitamento exclusivo;

- Descrever a prevalência de consumo de leite não materno;

- Descrever a prevalência de consumo de frutas, hortaliças, carnes e feijão;

- Descrever a prevalência de consumo de alimentos potencialmente alergênicos;

- Verificar a relação entre a prática de aleitamento e consumo de alimentos e idade da mãe, escolaridade da mãe e do pai, peso ao nascer; tipo de parto, duração da gestação e estado nutricional da criança. 


\section{MATERIAL E MÉTODOS}

Este estudo tem como fonte de dados pesquisa desenvolvida pelo Departamento de Nutrição da Faculdade de Saúde Pública da USP, financiada pela FAPESP ${ }^{1}$ objetivando verificar a prevalência da anemia no primeiro ano de vida e sua relação com a prática alimentar, em especial com o aleitamento materno e com o crescimento e desenvolvimento infantil.

Os dados foram levantados em serviços públicos de saúde de 10 cidades de diferentes regiões do Brasil, entre 1997 e 1999, constituindo a população de estudo crianças menores de um ano atendidas nos serviços de saúde.

O presente estudo utiliza os dados referentes à alimentação infantil e características sócio-econômicas coletados em dois Centros de Saúde do Municipio de São Paulo.

\subsection{Delineamento}

Foi conduzido um estudo descritivo, transversal.

\subsection{População e Local de Estudo}

\footnotetext{
${ }^{1}$ Processo FAPESP n ${ }^{\circ} 1996 / 6886-30$
} 
A população de estudo foi constituida por 175 crianças menores de um ano, atendidas em dois Centros de Saúde da rede pública estadual do Município de São Paulo: Centro de Saúde do Bom Retiro e Centro de Saúde da Vila Granada.

Os serviços de saúde foram indicados pela Secretaria de Estado da Saúde, selecionando-se um serviço na região central (Bom Retiro) e outro de localização periurbana (Vila Granada), ambos oferecendo atendimento pediátrico.

Fizeram parte do estudo as crianças com até 12 meses, que compareceram nos Centros de Saúde entre novembro de 1997 e agosto de 1998 para atendimento médico e/ou vacinação.

\subsection{Coleta e Registro de dados}

Após o consentimento esclarecido das mães ou responsáveis, atendentes de enfermagem dos Centros de Saúde, previamente treinados, procediam ao levantamento dos dados.(Anexo 1).

A seguir, a mãe ou responsável respondia a um formulário estruturado, com questões fechadas sobre a criança, dados sobre os pais e sobre a alimentação praticada pela criança (Anexo 2).

\subsection{Inquérito alimentar}


A prática alimentar foi levantada por meio do processo conhecido como status-quo: um estudo transversal em que se investiga a idade de cada criança e sua relação com o fenômeno de interesse no momento da pesquisa. Consta do formulário uma lista de alimentos utilizados habitualmente no primeiro ano de vida. Para cada alimento, a resposta quanto ao consumo poderá ser "sim" ou "não" (Anexo 2).

O estado da criança em relação ao consumo de determinado alimento se denota por $Y$, uma variável que pode tomar dois valores: $Y=1$ ou $Y=0$, dependendo se a criança consome ou não o alimento, respectivamente. A condição dicotômica desta variável permite utilizar-se um modelo de regressão logística, neste caso, para obter a estimativa da prevalência segundo idade (SILVA e col. 1993).

A utilização do modelo de regressāo logística permite utilizar um delineamento transversal para estimar a prevalência de consumo de alimentos no primeiro ano de vida, ao invés de realizar um estudo tipo coorte, de maior complexidade e custo (SILVA e col. 1993).

A utilização do status quo é uma alternativa para evitar o viés de memória, tanto o viés de memória (quando ocorrem diferenças na recordação de determinado fato, dependendo da exposição ao fator de interesse do estudo), quanto falhas na memória ou ainda a diferença entre o comportamento percebido e relatado e o comportamento verdadeiro do respondente. (RAPHAEL 1987; RIOS e col. 1992; SILVA e col., 1993; SILVA e col. 1995; FERREIRA e CARDOSO 1996a). 


\subsection{Variáveis de Estudo}

\subsubsection{Variáveis independentes}

Selecionaram-se para o estudo as variáveis que poderiam ter influenciado o padrão alimentar (quadro 1).

As variáveis independentes foram categorizadas, com exceção da idade, que foi mantida contínua, em dias, para os propósitos da análise.

Consideraram-se duas categorias para peso ao nascer: baixo peso, menor $2500 \mathrm{~g}$, e adequado, acima ou igual este peso (WHO 1995).

Para avaliar o estado nutricional das crianças nos dois centros de saúde, utilizou-se 0 indice de peso para idade em unidades de desviopadrão (escore Z) Considerou-se baixo peso para idade as crianças com escore $\mathrm{Z}$ igual a -2 , normal entre $-2 \mathrm{e}+2$ e alto peso para idade maior que +2 (WHO 1995) 
Quadro 1 - Categorias das variáveis independentes analisadas

\begin{tabular}{|c|c|}
\hline Variavel & Categorlas \\
\hline \multirow[t]{2}{*}{ Peso ao nascer } & Baixo peso $<2500 \mathrm{~g}$ \\
\hline & Peso adequado $\geq 2500 \mathrm{~g}$ \\
\hline \multirow[t]{2}{*}{ Idade mãe } & Mãe jovem $\leq 19 a n o s$ \\
\hline & Mãe adulta > 19 anos \\
\hline \multirow[t]{4}{*}{ Escolaridade mãe } & Escolaridade baixa - até 4 série do ensino \\
\hline & fundamental \\
\hline & Escolaridade não baixa -ensino fundamental \\
\hline & completo ou acima \\
\hline \multirow[t]{4}{*}{ Escolaridade pai } & Escolaridade baixa - até 4 série do ensino \\
\hline & fundamental \\
\hline & Escolaridade não baixa -ensino fundamental \\
\hline & completo ou acima \\
\hline \multirow[t]{2}{*}{ Tipo parto } & Normal \\
\hline & Outro (cesáreo ou fórceps) \\
\hline \multirow[t]{2}{*}{ Duração gestação } & Prematuro (< 9 meses) \\
\hline & A termo ( 9 meses) \\
\hline \multirow[t]{3}{*}{ Estado nutricional } & Baixo peso para idade $(\leq-2 \mathrm{z})$ \\
\hline & Normal $(-2<z<+2)$ \\
\hline & Peso alto para idade $(\geq+2 z)$ \\
\hline
\end{tabular}

\subsubsection{Variáveis dependentes:}

A prática alimentar foi tratada como variável categórica dicotômica (sim ou não).

Em relação ao consumo de leite materno, foram consideradas as categorias propostas pela OMS (SECRETARIA DA SAÚDE DO ESTADO DA BAHIA 1995): 
Aleitamento materno exclusivo, quando a criança recebe leite materno, diretamente da mama ou extraido, e nenhum outro sólido ou líquido, com exceção de gotas ou xaropes de vitaminas, minerais e/ou medicamentos.

Aleitamento materno, quando a criança recebe leite materno, diretamente do seio ou extraído, independente de estar recebendo qualquer alimento ou líquido;

Em relação ao consumo de alimentos, foram consideradas as seguintes categorias:

\section{água ou chá;}

leite não materno: de vaca, modificado ou outro;

frutas: em forma de sucos ou papas;

hortaliças: batata, legumes elou verduras;

cereais e derivados: arroz, macarrão, pão e/ou bolacha;

carnes: bovina, de frango ou outras aves, figado e/ou peixe.

feijão: feijão ou caldo de feijão;

ovos: gema ou ovo inteiro;

peixe. 


\subsection{Análise estatística}

A análise descritiva foi feita por medidas de tendência central e dispersão. As associações de interesse foram examinadas pelo teste Quiquadrado $\left(\chi^{2}\right)$ com correção de Yates.

A relação entre os alimentos ou grupos de alimentos que formam as variáveis independentes e as variáveis dependentes foi analisada utilizandose regressão logística univariada e multivariada não condicional, por meio da técnica stepwise forward.

O padrão de introdução dos alimentos da dieta foi verificado pela construção de uma curva de prevalência do consumo em função da idade, pelo uso da técnica de regressão logística, expresso pela função:

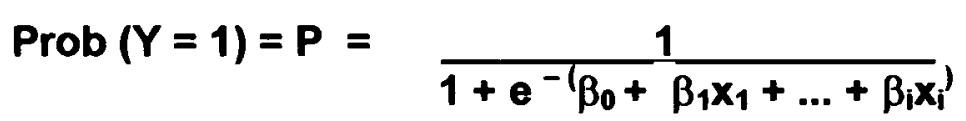

onde $\beta_{0}, \beta_{1}$ e $\beta_{i}$ são os parâmetros estimados da regressão logística, a partir dos dados levantados na amostra da população de estudo e os $x_{i}$ são as variáveis independentes já citadas.

Esta função permite a estimativa da probabilidade de que uma dada criança da amostra já tenha iniciado o consumo de determinado alimento em 
função da idade, medida em dias, controlando-se as outras variáveis de interesse.

A verificação do ajuste dos modelos de regressão foi feita por meio do teste de residuo de HOSMER e LEMESHOW, 1989.

Este procedimento foi utilizado por Silva e colaboradores, 1993, para avaliar o padrão prevalente de introdução de alimentos em Cuba.

As análises estatísticas foram feitas com o auxílio dos programas EPI INFO versão 6.040 (DEAN e col. 1994) e MULTLR (CAMPOS e FRANCO 1989). Os gráficos foram elaborados na planilha eletrônica EXCEL 7.0 para Windows 95.

\subsection{Indice de Descontinuidade}

Calculou-se o Índice de Descontinuidade - ID, (SILVA e col. 1995, FERREIRA e CARDOSO 1996b). O ID representa a porcentagem de crianças que eram amamentadas no início de um determinado intervalo de idade e tinham abandonado este modo de alimentação ao final do período.

$$
I D=\left[\left(P_{0}-P_{x}\right) / P_{0}\right] * 100
$$

onde $P_{0}$ é a prevalência da amamentação exclusiva no início do intervalo e $P_{x}$ é a prevalência ao final dele.

O ID foi calculado para os seguintes intervalos: $0-30$ dias; $0-60$ dias; 0 - 120 dias e 0 - 180 dias, que correspondem aos ID cumulativos. 


\section{RESULTADOS}

\subsection{Características da População de Estudo}

As tabelas 1 e 2 mostram a distribuição das crianças segundo sexo e idade nas localidades estudadas.

Tabela 1 - Distribuição do número e porcentagem das crianças segundo sexo e localidade. São Paulo, 1998.

\begin{tabular}{|c|c|c|c|c|c|c|}
\hline \multirow[t]{3}{*}{ SEXO } & \multicolumn{4}{|c|}{ LOCALIDADE } & & \\
\hline & \multicolumn{2}{|c|}{ CS Central } & \multicolumn{2}{|c|}{ CS Periferia } & \multicolumn{2}{|c|}{ TOTAL } \\
\hline & $\mathrm{N}^{0}$ & $\%$ & $N^{0}$ & $\%$ & $N^{\circ}$ & $\%$ \\
\hline masculino & 46 & 60,5 & 51 & 51,5 & 97 & 55,4 \\
\hline feminino & 30 & 39,5 & 48 & 48,5 & 78 & 44,6 \\
\hline TOTAL & 76 & 100,0 & 99 & 100,0 & 175 & 100,0 \\
\hline
\end{tabular}

Parece haver maior proporção de crianças do sexo masculino no CS Central $(60,5 \%)$. No entanto, não houve associação estatisticamente significativa $(p=0,300)$ entre sexo e localidade de estudo. 
Tabela 2 - Distribuição do número e porcentagem das crianças segundo idade e localidade. São Paulo, 1998.

\begin{tabular}{|c|c|c|c|c|c|c|}
\hline \multirow{3}{*}{$\begin{array}{r}\text { IDADE } \\
\text { (dias) }\end{array}$} & \multicolumn{4}{|c|}{ LOCALIDADE } & & \\
\hline & \multicolumn{2}{|c|}{ CS Central } & \multicolumn{2}{|c|}{ CS Periferia } & \multicolumn{2}{|c|}{ TOTAL } \\
\hline & $N^{0}$ & $\%$ & $N^{0}$ & $\%$ & $N^{0}$ & $\%$ \\
\hline $0 \longmapsto 90$ & 21 & 27,6 & 35 & 35,4 & 56 & 32,0 \\
\hline $90 \dashv 180$ & 23 & 30,3 & 33 & 33,3 & 56 & 32,0 \\
\hline $180-270$ & 26 & 34,2 & 17 & 17,2 & 43 & 24,6 \\
\hline $270-365$ & 6 & 7,9 & 14 & 14,1 & 20 & 11,4 \\
\hline TOTAL & 76 & 100,0 & 99 & 100,0 & 175 & 100,0 \\
\hline
\end{tabular}

Não houve associação estatisticamente significativa entre idade e localidade $(p=0,058)$. Observa-se que a maioria das crianças tem até dois trimestres de idade $(64 \%)$. A presença da criança no serviço de saúde é mais freqüente nesta faixa etária em decorrência do calendário de vacinação, fato que provavelmente influiu na distribuição etária da amostra.

A idade mínima foi de 4 dias no CS periferia e a máxima de 356 dias no CS central. A média de idade foi de 149 dias ( $d p=88,7$ dias) e a mediana de idade 138 dias.

As tabelas 3 e 4 mostram a distribuição das crianças segundo os indicadores de saúde peso ao nascer e estado nutricional 
Tabela 3 - Distribuição do número e porcentagem das crianças segundo peso ao nascer e localidade. São Paulo, 1998.

\begin{tabular}{|c|c|c|c|c|c|c|}
\hline \multirow{3}{*}{$\begin{array}{l}\text { PESO AO } \\
\text { NASCER }\end{array}$} & \multicolumn{4}{|c|}{ LOCALIDADE } & & \\
\hline & \multicolumn{2}{|c|}{ Cs Central } & \multicolumn{2}{|c|}{ CS Periferia } & \multicolumn{2}{|c|}{ TOTAL } \\
\hline & $\mathbf{N}^{0}$ & $\%$ & $\mathrm{~N}^{0}$ & $\%$ & $\mathbf{N}^{0}$ & $\%$ \\
\hline $\begin{array}{l}\text { Baixo Peso } \\
(<2500 \mathrm{~g})\end{array}$ & 7 & 9,2 & 12 & 12,1 & 19 & 10,9 \\
\hline $\begin{array}{l}\text { Peso adequado } \\
(\geq 2500 \mathrm{~g})\end{array}$ & 69 & 90,8 & 87 & 87,9 & 156 & 89,1 \\
\hline$\overline{\text { TOTAL }}$ & 76 & 100,00 & 99 & 100,0 & 175 & 100,0 \\
\hline
\end{tabular}

No CS periferia parece haver uma maior proporção de crianças com baixo peso ao nascer. No entanto, não houve associação entre peso ao nascer e localidade $(p=0,712)$.

A média de peso ao nascer observada foi de $3237 \mathrm{~g}(\mathrm{dp}=584 \mathrm{~g})$, sendo que o peso de nascimento das crianças do estudo variou de $1800 \mathrm{~g}$ a $5020 \mathrm{~g}$.

Tabela 4 - Distribuição do número e porcentagem das crianças segundo peso para idade e localidade. São Paulo, 1998.

\begin{tabular}{lcccccc}
\hline Peso para Idade & \multicolumn{3}{c}{ LOCALIDADE } & \multicolumn{2}{c}{ TOTAL } \\
& \multicolumn{2}{c}{ CS Central } & \multicolumn{2}{c}{ CS Periferia } & \multicolumn{2}{c}{ TOTA } \\
& $N^{0}$ & $\%$ & $N^{0}$ & $\%$ & $N^{\circ}$ & $\%$ \\
\hline Baixo & 4 & 5,3 & 2 & 2,0 & 6 & 3,4 \\
Normal & 72 & 94,7 & 88 & 88,9 & 160 & 91,4 \\
Alto & 0 & 0,0 & 9 & 9,1 & 9 & 5,1 \\
\hline TOTAL & 76 & 100,0 & 99 & 100,0 & 175 & 100,0 \\
\hline$p=0,015$ & & & & & &
\end{tabular}


A prevalência de baixo peso para idade foi de 5,3\% no CS Central e de $2,0 \%$ no CS Periferia. Houve associação estatisticamente significativa entre a distribuição das crianças segundo o escore $Z$ de peso para idade nos serviços de saúde estudados ( $p=0,015)$. A situação é pior no CS do bairro Central. A comunidade atendida por este centro é composta por um número considerável de migrantes.

As tabelas 5 e 6 apresentam dados relativos às mães das crianças: distribuição etária e escolaridade.

Tabela 5 - Distribuição do número e porcentagem das crianças segundo idade materna e localidade. São Paulo, 1998.

\begin{tabular}{|c|c|c|c|c|c|c|}
\hline \multirow[t]{3}{*}{ Idade mãe } & \multicolumn{4}{|c|}{ LOCALIDADE } & & \\
\hline & \multicolumn{2}{|c|}{ CS Central } & \multicolumn{2}{|c|}{ CS Periferia } & \multicolumn{2}{|c|}{ TOTAL } \\
\hline & $N^{0}$ & $\%$ & $N^{0}$ & $\%$ & $N^{0}$ & $\%$ \\
\hline $\begin{array}{l}\text { Jovem } \\
\text { ( } \leq 19 \text { anos) }\end{array}$ & 16 & 21,0 & 20 & 20,0 & 36 & 21,0 \\
\hline $\begin{array}{l}\text { Adulta } \\
\text { (>19 anos) }\end{array}$ & 60 & 79,0 & 79 & 80,0 & 139 & 79,0 \\
\hline Total & 76 & 100,0 & 99 & 100,0 & 175 & 100,0 \\
\hline
\end{tabular}

A distribuição de idade materna não diferiu nos dois centros de saúde. A proporção total de mães jovens foi de aproximadamente 1/5 da população (21\%). A idade materna média foi de 25,7 anos ( $d p=6.2$ anos). 
Tabela 6 - Distribuição do número e porcentagem das crianças segundo escolaridade materna e localidade. São Paulo, 1998.

\begin{tabular}{|c|c|c|c|c|c|c|}
\hline \multirow{3}{*}{$\begin{array}{c}\text { Escolaridade da } \\
\text { máe }\end{array}$} & \multicolumn{4}{|c|}{ LOCALIDADE } & \multicolumn{2}{|c|}{ TOTAL } \\
\hline & \multicolumn{2}{|c|}{ CS Central } & \multicolumn{2}{|c|}{ CS Periferia } & \multirow[b]{2}{*}{$N^{\circ}$} & \multirow[b]{2}{*}{$\%$} \\
\hline & $N^{0}$ & $\%$ & $\mathrm{~N}^{0}$ & $\%$ & & \\
\hline Até $4^{a}$ série & 38 & 50,7 & 45 & 46,4 & 83 & 48,3 \\
\hline $5^{a}$ a $8^{a}$ série & 15 & 20,0 & 33 & 34,0 & 48 & 27,9 \\
\hline $1^{\circ}$ a $3^{\circ}$ colegial & 19 & 25,3 & 13 & 13,4 & 32 & 18,6 \\
\hline Universitário & 3 & 4,0 & 6 & 6,2 & 9 & 5,2 \\
\hline Total & 75 & 100,0 & 97 & 100,00 & $172^{*}$ & 100,0 \\
\hline
\end{tabular}

Aproximadamente $50 \%$ das mães têm escolaridade baixa, até a $4^{\text {a }}$ série do ensino fundamental. Apenas $5 \%$ detêm grau universitário. Não houve associação estatisticamente significativa entre escolaridade materna e localidade $(p=0,216)$

Na tabela 7 encontra-se a distribuição da escolaridade paterna.

Tabela 7 - Distribuição do número e porcentagem das crianças segundo escolaridade paterna e localidade. São Paulo, 1998.

\begin{tabular}{|c|c|c|c|c|c|c|}
\hline \multirow{3}{*}{$\begin{array}{c}\text { Escolaridade do } \\
\text { pai }\end{array}$} & \multicolumn{4}{|c|}{ LOCALIDADE } & & \\
\hline & \multicolumn{2}{|c|}{ CS Central } & \multicolumn{2}{|c|}{ CS Periferia } & \multicolumn{2}{|c|}{ TOTAL } \\
\hline & $N^{0}$ & $\%$ & $N^{0}$ & $\%$ & $N^{\circ}$ & $\%$ \\
\hline Até $4^{\text {a }}$ série & 29 & 42,6 & 45 & 48,4 & 74 & 46,0 \\
\hline $5^{a}$ a $8^{a}$ série & 19 & 27,9 & 19 & 20,4 & 38 & 23,6 \\
\hline $1^{\circ}$ à $3^{\circ}$ colegial & 21 & 29,4 & 25 & 26,9 & 46 & 28,0 \\
\hline Universitário & 0 & 0,0 & 4 & 4,3 & 4 & 2,5 \\
\hline Total & 68 & 100,0 & 93 & 100,00 & $162^{*}$ & 100,0 \\
\hline
\end{tabular}

Foram excluídos 13 indivíduos sem informação $p=0.237$ 
Em 13 casos, a escolaridade do pai era desconhecida (7\%). Não houve associação estatisticamente significativa entre escolaridade paterna e localidade $(p=0,237)$.

À semelhança das mães, quase $50 \%$ dos pais têm baixa escolaridade. Observa-se pela figura 1, que a distribuição da escolaridade da mãe é semelhante à escolaridade dos pais.

Figura 1 - Porcentagem de crianças segundo escolaridade dos pais. São Paulo, 1998.

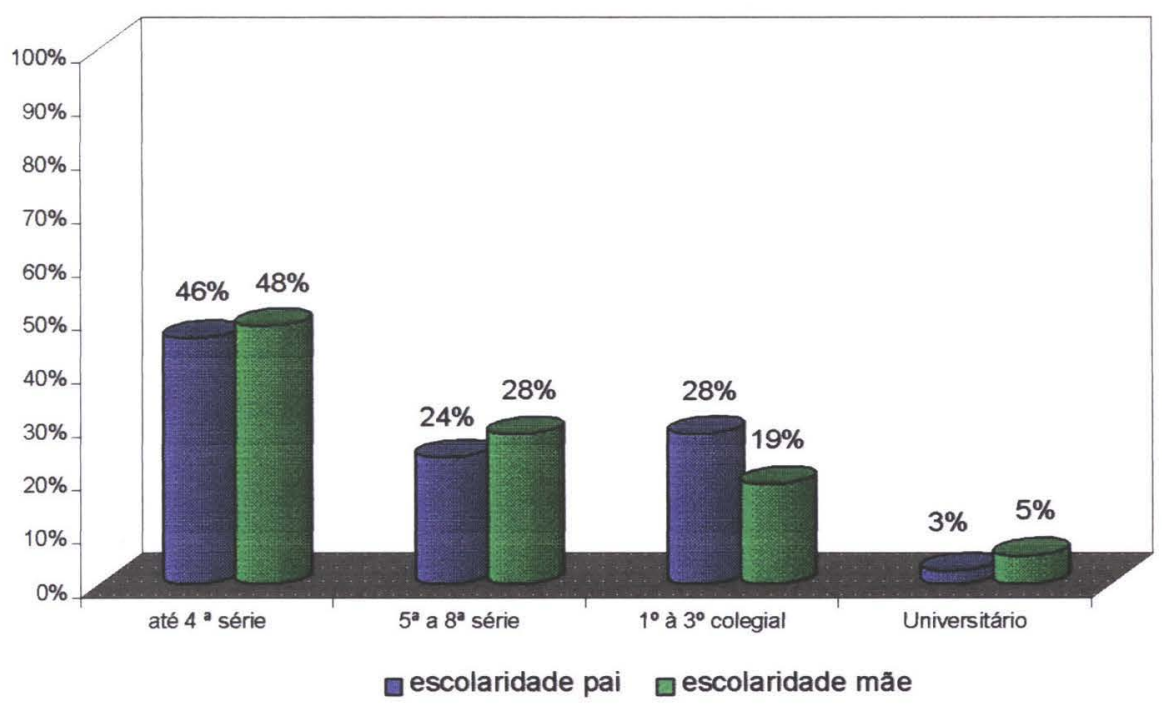

\subsection{Fatores associados à prática alimentar}

Considerando-se que as populações nos dois serviços não diferiram quanto às características apresentadas, com exceção do estado nutricional das crianças, elas foram reunidas para verificação da prática alimentar no primeiro ano de idade. 


\subsection{Aleitamento Materno}

$\mathrm{Na}$ tabela 8 encontra-se a distribuição das crianças do estudo segundo a presença de aleitamento materno e demais variáveis de estudo no momento da pesquisa.

Tabela 8 - Distribuição do número e porcentagem das crianças segundo aleitamento materno e as variáveis de análise, valores da Odds Ratio (OR) e intervalo de confiança 95\%. São Paulo, 1998.

\begin{tabular}{|c|c|c|c|c|c|c|c|c|c|}
\hline \multirow[b]{3}{*}{ Variável } & \multirow[b]{3}{*}{ Categoria } & \multicolumn{6}{|c|}{ Aleitamento materno } & \multirow{3}{*}{$\begin{array}{c}\text { OR } \\
\left(\text { IC }_{95 \%}{ }^{(\mathrm{OR})}\right)\end{array}$} & \\
\hline & & \multicolumn{2}{|c|}{ Sim } & \multicolumn{2}{|c|}{ Não } & \multicolumn{2}{|c|}{ Total } & & \multirow[b]{2}{*}{ p } \\
\hline & & $\mathbf{N}$ & $\%$ & $\mathbf{N}$ & $\%$ & N & $\%$ & & \\
\hline \multirow{3}{*}{$\begin{array}{l}\text { Peso ao } \\
\text { nascer }\end{array}$} & Baixo peso & $\overline{14}$ & 66,7 & 7 & 33,3 & 21 & 100,0 & 1,0 & \multirow[t]{3}{*}{0,943} \\
\hline & \multirow[t]{2}{*}{ Adequado } & \multirow[t]{2}{*}{108} & \multirow[t]{2}{*}{70,1} & \multirow[t]{2}{*}{46} & \multirow[t]{2}{*}{29,9} & \multirow[t]{2}{*}{154} & \multirow[t]{2}{*}{100,0} & 1,174 & \\
\hline & & & & & & & & $(0,473-6,116)$ & \\
\hline \multirow{3}{*}{$\begin{array}{l}\text { Tipo de } \\
\text { parto* }\end{array}$} & Normal & 66 & 74,2 & 23 & 25,8 & 89 & 100,0 & 1,0 & \multirow[t]{3}{*}{0,234} \\
\hline & \multirow[t]{2}{*}{ Outro } & \multirow[t]{2}{*}{55} & \multirow[t]{2}{*}{64,7} & \multirow[t]{2}{*}{30} & \multirow[t]{2}{*}{35,3} & \multirow[t]{2}{*}{85} & \multirow[t]{2}{*}{100,0} & 0,639 & \\
\hline & & & & & & & & $(0,333-1,224)$ & \\
\hline Duração & Prematuro & 11 & 78,6 & 3 & 21,4 & 14 & 100,0 & 1,0 & 0,771 \\
\hline \multirow[t]{2}{*}{ gestação } & \multirow[t]{2}{*}{ A Termo } & \multirow[t]{2}{*}{111} & \multirow[t]{2}{*}{68,9} & \multirow[t]{2}{*}{50} & 31,1 & 161 & 100,0 & 0,605 & \\
\hline & & & & & & & & $(0,162-2,265)$ & \\
\hline Idade da & Jovem & 22 & 61,1 & 14 & 38,9 & 36 & 100,0 & 1,0 & 0,290 \\
\hline mãe & Adulta & 100 & 71,9 & 39 & 28,1 & 139 & 100,0 & 1,632 & \\
\hline & & & & & & & & $(0,759-3,508)$ & \\
\hline Escolaridade & Baixa & 50 & 60,2 & 33 & 39,8 & 83 & 100,0 & 1,0 & 0,013 \\
\hline da mãe ${ }^{\star \star}$ & Não baixa & 70 & 78,7 & 19 & 21,3 & 89 & 100,0 & 2,432 & \\
\hline & & & & & & & & $(1,243-4,757)$ & \\
\hline Escolaridade & Baixa & 53 & 71,6 & 21 & 28,4 & 74 & 100,0 & 1,0 & 0,991 \\
\hline do pai* ${ }^{i \star \star}$ & Não baixa & 62 & 70,5 & 26 & 29,5 & 88 & 100,0 & 0,945 & \\
\hline & & & & & & & & $(0,478-1,869)$ & \\
\hline Estado & Baixo peso & 1 & 16,7 & 5 & 88,3 & 6 & 100,0 & 1,0 & 0,014 \\
\hline nutricional & Normal & 114 & 71,3 & 46 & 28,8 & 160 & 100,0 & 12,390 & \\
\hline & & & & & & & & $(1,409-108,908)$ & \\
\hline & Peso alto & 7 & 77,8 & 2 & 22,2 & 9 & 100,0 & 17,503 & \\
\hline & & & & & & & & $(1,223-250,364)$ & \\
\hline
\end{tabular}

* excluído um indivíduo sem informação

** excluídos três indivíduos sem informação

*** excluídos treze indivíduos sem informação 
De todas as variáveis independentes analisadas, as únicas que mostraram associação com a criança estar em aleitamento materno foi a escolaridade materna e o estado nutricional da criança (Tabela 8).

Iniciou-se a modelagem multivariada com a adição da variável escolaridade da mãe e em seguida estado nutricional ao modelo com idade (Tabela 9).

Tabela 9 - Valores da Odds Ratio (OR), intervalo de confiança (IC) no modelo de regressão logistica multivariada.

\begin{tabular}{llccc}
\hline \multicolumn{1}{c}{ Variável } & \multicolumn{1}{c}{ Categoria } & OR & IC $_{95 \%}{ }^{(\text {OR) }}$ & PWald \\
\hline Idade & Contínua & 0,994 & $0,990-0,998$ & 0,003 \\
Escolaridade & Baixa & 1,00 & & \\
materna & Não baixa & 2,313 & $1,147-4,663$ & 0,019 \\
Estado & Baixo peso & 1,00 & & \\
nutricional & Normal & 8,209 & $0,902-74,708$ & 0,062 \\
& Peso alto & 17,500 & $0,921-212,735$ & 0,057 \\
\hline
\end{tabular}

$p\left(\chi_{491}^{2}\right)<0,001$

A variável estado nutricional neste modelo perdeu a significância estatística, optando-se então pelo modelo com idade e escolaridade materna. As estimativas dos parâmetros da regressão logistica multivariada $(\beta)$, considerando-se a variável dependente aleitamento materno estão na tabela 10. 
Tabela 10 - Resultados da regressão logística multivariada para aleitamento materno.

\begin{tabular}{|c|c|c|c|c|c|}
\hline Variável & categoria & $\overline{O R}$ & IC $_{95 \%}{ }^{\text {(ORT) }}$ & $\bar{\beta}$ & $\frac{P}{\text { Wald }}$ \\
\hline Constante & & & & 1,3707 & \\
\hline Idade & Contínua & 0,994 & 0,$990 ; 0,998$ & $-0,0062$ & 0,002 \\
\hline Escolaridade & Baixa & 1,0 & & & \\
\hline materna & Não-baixa & 2,472 & $1,246-4,905$ & 0,9369 & 0,010 \\
\hline
\end{tabular}

Verificou-se que, ajustando-se pela idade da criança, a mãe com escolaridade não-baixa tem 2,47 vezes a chance de estar amamentando.

Assim, pode-se estimar a prevalência do aleitamento materno por meio dos coeficientes de regressão:

$$
\operatorname{Prob}(Y=1)=P=\frac{1}{1+e^{-(1,3707-0,00621 d a d e+0,9369 \text { escolaridade materna })}}
$$
teremos:

Se escolaridade materna for baixa (escolaridade materna $=0$ ), então

$$
\operatorname{Prob}(Y=1)=P=\frac{1}{1+e^{-(1,3707-0,0062 \text { idade })}}
$$

Se a escolaridade materna for não-baixa (escolaridade = 1), correspondente à outra categoria, teremos:

$$
\operatorname{Prob}(Y=1)=P=\frac{1}{1+e^{-(2,31-0,0062 \text { idade })}}
$$


Obtém-se, então, duas curvas (figura 2):

Figura 2 - Curvas de prevalência de aleitamento materno segundo escolaridade materna. São Paulo, 1998.

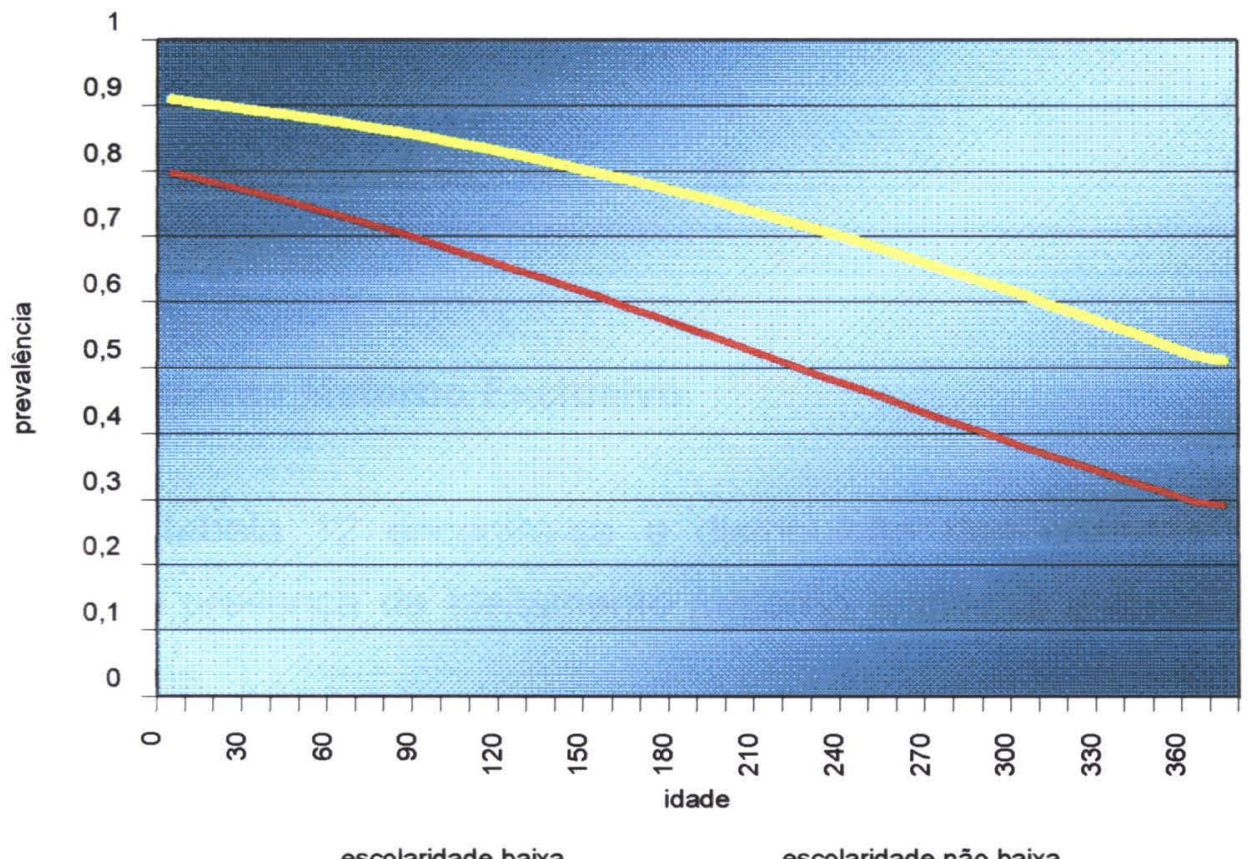

Fazendo-se a análise do resíduo, verificou-se que o modelo estava ajustado $(p=0,533)$.

Tomando-se como pontos de corte, para a análise, o aleitamento materno aos 4, 6, 9 e 12 meses de idade, podemos observar que aos 4 meses de idade a prevalência de consumo é de $65 \%$ nas crianças com mães com baixa escolaridade e de $83 \%$ nas crianças cujas mães possuem escolaridade não baixa (tabela 11). Ressaltamos que aproximadamente $50 \%$ das mães nesta população têm escolaridade baixa. 
Tabela 11 - Prevalência de aleitamento materno segundo escolaridade materna. São Paulo, 1998.

\begin{tabular}{|c|c|c|}
\hline \multirow[t]{2}{*}{ Idade (dias) } & \multicolumn{2}{|c|}{ Prevalência de aleitamento materno (\%) } \\
\hline & Escolaridade Baixa & Escolaridade não baixa \\
\hline 120 & 65 & 83 \\
\hline 180 & 56 & 77 \\
\hline 270 & 42 & 65 \\
\hline 360 & 29 & 51 \\
\hline
\end{tabular}

\subsection{Aleitamento Materno Exclusivo}

Na tabela 12 encontra-se a distribuição das crianças do estudo segundo a presença de aleitamento materno exclusivo e demais variáveis pesquisadas. 
Tabela 12 - Distribuição do número e porcentagem das crianças segundo aleitamento materno exclusivo e as variáveis de análise, valores da Odds ratio (OR), intervalo de confiança de 95\%. São Paulo, 1998.

\begin{tabular}{|c|c|c|c|c|c|c|c|c|c|}
\hline \multirow[b]{3}{*}{ Variável } & \multirow[b]{3}{*}{ Categoria } & \multicolumn{7}{|c|}{ Aleitamento materno exclusivo } & \multirow[b]{3}{*}{ p } \\
\hline & & \multicolumn{2}{|c|}{ Sim } & \multicolumn{2}{|c|}{ Não } & \multicolumn{2}{|c|}{ Total } & \multirow{2}{*}{$\begin{array}{c}\text { OR } \\
\left(\mathrm{IC}_{95 \%}{ }^{(\mathrm{OR})}\right)\end{array}$} & \\
\hline & & $\mathbf{N}$ & $\%$ & $\mathbf{N}$ & $\%$ & $\mathbf{N}$ & $\%$ & & \\
\hline Peso ao & Baixo peso & 3 & 14,3 & 18 & 85,7 & 21 & 100,0 & 1,0 & 0,592 \\
\hline \multirow[t]{2}{*}{ nascer } & Adequado & 34 & 22,1 & 120 & 77,9 & 154 & 100,0 & 1,700 & \\
\hline & & & & & & & & $(0,473-6,116)$ & \\
\hline \multirow[t]{3}{*}{ Tipo de parto } & Normal & 17 & 19,1 & 72 & 80,9 & 89 & 100,0 & 1,0 & 0,732 \\
\hline & Outro & 19 & 22,4 & 66 & 77,6 & 85 & 100,0 & 1,219 & \\
\hline & & & & & & & & $(0,585-2,542)$ & \\
\hline Duração & Prematuro & 3 & 21,4 & 11 & 78,6 & 14 & 100,0 & 1,0 & 0,756 \\
\hline \multirow[t]{2}{*}{ gestação } & A Termo & 34 & 21,1 & 127 & 78,9 & 161 & 100,0 & 0,982 & \\
\hline & & & & & & & & $(0,259-3,717)$ & \\
\hline Idade da & Jovem & 4 & 11,1 & 32 & 88,9 & 36 & 100,0 & 1,0 & 0,154 \\
\hline \multirow[t]{2}{*}{ mãe } & Adulta & 33 & 23,7 & 106 & 76,3 & 139 & 100,0 & 2,491 & \\
\hline & & & & & & & & $(0,820-7,561)$ & \\
\hline Escolaridade & Baixa & 13 & 15,7 & 70 & 84,3 & 83 & 100,0 & 1,0 & 0,146 \\
\hline \multirow[t]{2}{*}{ da mãe } & Não baixa & 23 & 25,8 & 66 & 74,2 & 89 & 100,0 & 1,876 & \\
\hline & & & & & & & & $(0,879-4,007)$ & \\
\hline Escolaridade & Baixa & 14 & 18,9 & 60 & 81,1 & 74 & 100,0 & 1,0 & 0,461 \\
\hline \multirow[t]{2}{*}{ do pai } & Não baixa & 22 & 25,0 & 66 & 75,0 & 88 & 100,0 & 1,429 & \\
\hline & & & & & & & & $(0,671-3,042)$ & \\
\hline Estado & Baixo peso & 0 & 0 & 6 & 100 & 6 & 100,0 & & 0,312 \\
\hline \multirow[t]{2}{*}{ nutricional } & Normal & 36 & 22,5 & 124 & 77,5 & 160 & 100,0 & nd & \\
\hline & Peso alto & 1 & 11,1 & 8 & 88,9 & 9 & 100,0 & & \\
\hline \multirow[t]{3}{*}{ Localidade } & Central & 9 & 11,8 & 67 & 88,2 & 76 & 100,0 & 1,0 & 0,014 \\
\hline & Periferia & 28 & 28,3 & 71 & 71,7 & 99 & 100,0 & 2,936 & \\
\hline & & & & & & & & $(1,291-6,678)$ & \\
\hline
\end{tabular}

\footnotetext{
* excluído um indivíduo sem informação

** excluídos três indivíduos sem informação

** excluídos treze indivíduos sem informação nd não definido
} 
Não houve associação estatisticamente significativa entre as variáveis independentes e aleitamento materno exclusivo, com exceção da localidade de estudo. Como observou-se associação positiva $(p=0.014)$ entre $o$ aleitamento exclusivo e o Centro de Saúde da periferia, elaborou-se um modelo de regressão multivariado com a variável idade (contínua), adicionando-se localidade. A tabela 13 mostra os parâmetros da regressão logística multivariada considerando-se a variável dependente aleitamento materno exclusivo.

Tabela 13 - Resultados da regressão logística multivariada para aleitamento materno exclusivo

\begin{tabular}{|c|c|c|c|c|c|}
\hline Variável & categoria & OR & $\begin{array}{c}\text { IC } \\
95 \%\end{array}$ & $\beta$ & $\begin{array}{c}\mathrm{P} \\
\text { Wald }\end{array}$ \\
\hline Constante & & & & $-0,4158$ & 0,3930 \\
\hline Idade & Contínua & 0,987 & $0,981-0,993$ & $-0,0126$ & $<0,001$ \\
\hline \multirow[t]{2}{*}{ Localidade } & Central & 1,0 & & & \\
\hline & Periferia & 2,851 & $1,195-6,802$ & 1,0478 & 0,0182 \\
\hline
\end{tabular}

$\mathrm{p} \chi^{2}<0,001$

Estimou-se a prevalência do aleitamento materno exclusivo segundo a idade da criança, ajustando-se pela localidade:

$\operatorname{Prob}(Y=1)=P=\frac{1}{1+e^{-(-0,4168-0,0126 \text { didade }+1,047 \text { 8localidade })}}$

Se a localidade for CS central (localidade=0), então teremos:

$$
\operatorname{Prob}(Y=1)=P=\frac{1}{1+e^{-(-0,4168-0,0126 \text { idade })}}
$$


Se a localidade for CS Periferia (localidade = 1), correspondente à outra categoria, teremos:

$$
\operatorname{Prob}(Y=1)=P=\frac{1}{1+e^{-(0,632-0,01261 \mathrm{dade})}}
$$

As curvas que representam a prevalência do aleitamento materno exclusivo de acordo com idade e localidade podem ser observados na figura 3.

Figura 3 - Curvas de prevalência de aleitamento materno exclusivo segundo localidade de estudo. Săo Paulo, 1998.

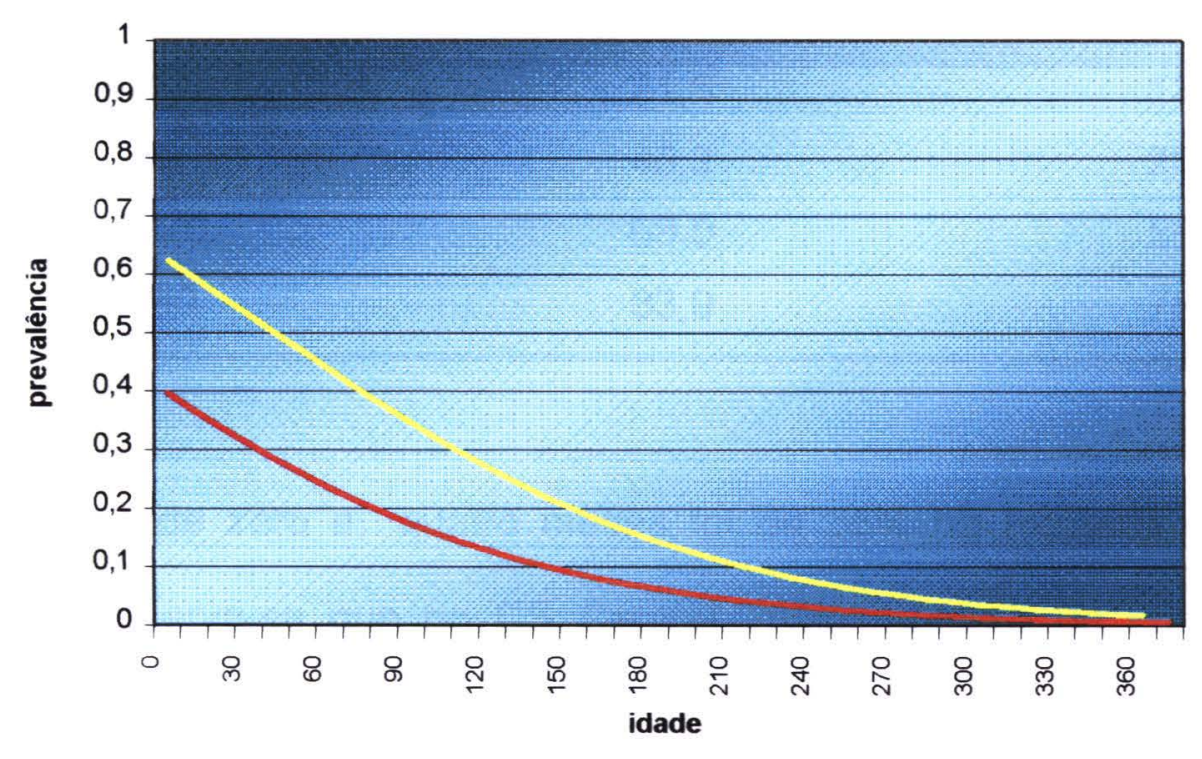

Pode-se observar que a prevalência do aleitamento materno exclusivo é baixa em ambos os Centros de Saúde, desde o início. Através da equação da regressão, estimou-se para um dia de idade a prevaléncia de $65 \%$ no CS Periferia e apenas $40 \%$ no CS Central. Aos 4 meses, a prevalência no CS Periferia é de $29 \%$ e no CS Central 13\%. Aos seis meses, época 
recomendada para a complementação do leite materno, é $16,3 \%$ no CS Periferia e $6,3 \%$ no CS Central.

\section{Índice de Descontinuidade}

Os valores do Índice de Descontinuidade - ID - cumulativos para aleitamento materno exclusivo nos intervalos de 0 a 30 dias, 60, 120 e 180 dias de idade encontram-se na tabela 14.

Tabela 14 - Índices de Descontinuidade cumulativos para aleitamento materno exclusivo de 0 a 30, 60, 120 e 180 dias de idade nos Centros de Saúde. São Paulo, 1998.

\begin{tabular}{ccc}
\hline $\begin{array}{c}\text { Periodo } \\
\text { (dias) }\end{array}$ & \multicolumn{2}{c}{$\begin{array}{c}\text { Indice de Descontinuidade } \\
\text { (\%) }\end{array}$} \\
& Central & Periferia \\
\hline $0-30$ & 21,6 & 13,7 \\
$0-60$ & 40,3 & 28,1 \\
$0-120$ & 68,0 & 55,1 \\
$0-180$ & 83,9 & 75,0 \\
\hline
\end{tabular}

O ID de zero a quatro meses foi de $55 \%$ na Periferia e $68 \%$ no Central. Observa-se que no CS Central, maior número de crianças que iniciaram o aleitamento materno exclusivo não estão mais nesta forma de alimentação, considerando-se todos os intervalos estudados, comparandose com o CS Periferia.

Apesar de não ter sido observada associação entre escolaridade e aleitamento materno exclusivo, verificou-se sua prevalência nas duas categorias de escolaridade. Os resultados da regressão logística 
multivariada para a variável dependente aleitamento materno exclusivo, segundo idade da criança ajustando-se por escolaridade materna estão na tabela 15.

Tabela 15 - Resultados da regressão logística multivariada para aleitamento materno exclusivo

\begin{tabular}{|c|c|c|c|c|c|}
\hline Variável & categoria & OR & $\mathrm{IC}_{95 \%}{ }^{(\mathrm{OR})}$ & $\bar{\beta}$ & $\begin{array}{c}P \\
\text { Wald }\end{array}$ \\
\hline Constante & & & & $-0,1345$ & 0,7625 \\
\hline Idade & Contínua & 0,988 & $0,982-0,994$ & $-0,0125$ & $<0,001$ \\
\hline Escolaridade & Baixa & 1,0 & & & \\
\hline matema & Não-baixa & 1,925 & $0,857-4,323$ & 0,6549 & 0,1126 \\
\hline
\end{tabular}

Estimou-se então a prevalência do aleitamento materno exclusivo segundo a idade da criança, ajustado por escolaridade por meio da equação:

$\operatorname{Prob}(Y=1)=P=\frac{1}{1+e^{-(-0.1346+0,6540 \text { escolaridade materna }-0,01251 d a d e)}}$ 
Figura 4 - Curvas de prevalência de aleitamento materno exclusivo segundo escolaridade da mãe. São Paulo, 1998.

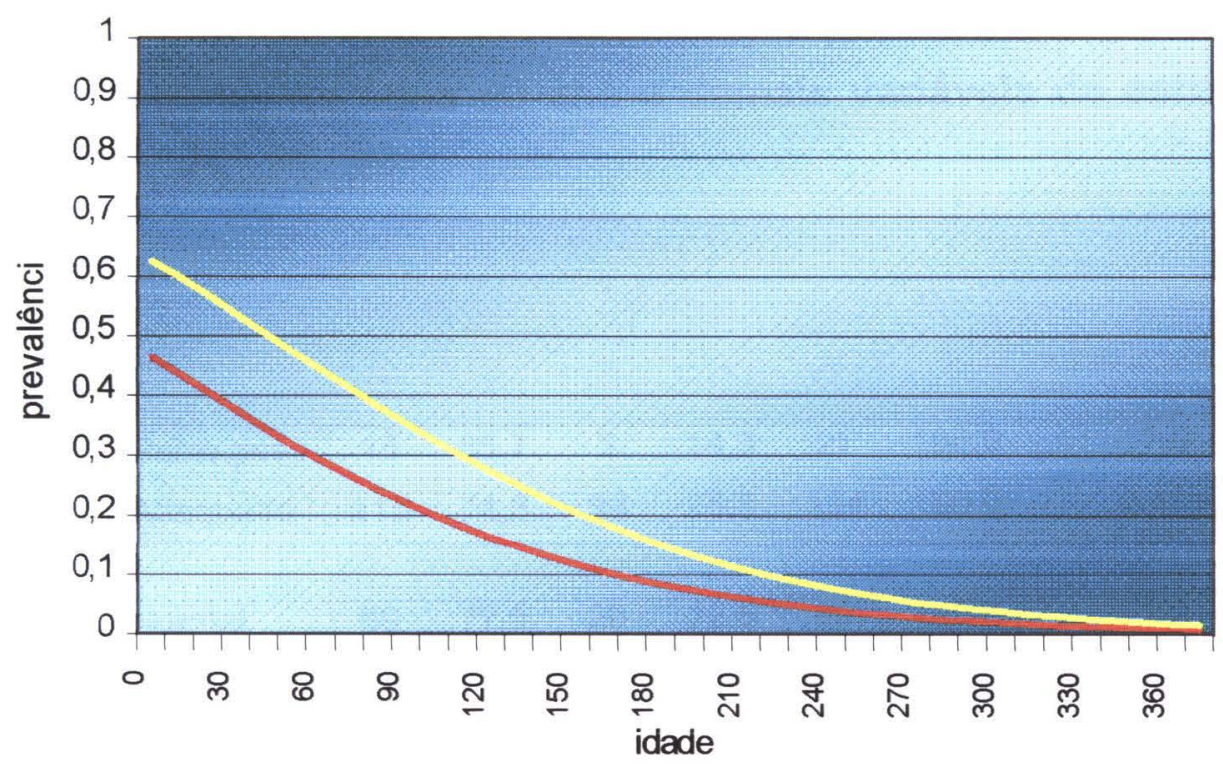

escolaridade baixa

escolaridade não baixa

Pode-se observar que a prevalência desta forma de alimentação, juntando-se as populações das duas localidades, é mais elevada nas crianças cujas mães têm maior escolaridade (figura 4, Tabela 16).

Tabela 16 - Prevalência de aleitamento materno exclusivo segundo escolaridade materna. São Paulo, 1998.

Idade (dias)

Prevalência de aleitamento materno exclusivo

(\%)

Escolaridade baixa Escolaridade não baixa

\begin{tabular}{ccc}
30 & 38 & 54 \\
60 & 29 & 44 \\
90 & 22 & 35 \\
120 & 16 & 27 \\
180 & 8 & 15 \\
\hline
\end{tabular}




\section{5. Água ou chá}

A tabela 17 mostra a distribuição das crianças segundo o consumo de água ou chá e as demais variáveis de estudo.

Tabela 17 - Distribuição do número e porcentagem das crianças segundo consumo de água ou chá e demais variáveis de estudo. São Paulo, 1998.

\begin{tabular}{|c|c|c|c|c|c|c|c|c|c|}
\hline \multirow[b]{3}{*}{ Variável } & \multirow[b]{3}{*}{ Categoria } & \multicolumn{6}{|c|}{ Consumo de água ou chá } & \multirow{3}{*}{$\begin{array}{c}\text { OR } \\
\left(\text { IC }_{95 \%}{ }^{(\mathrm{OR})}\right)\end{array}$} & \multirow[b]{3}{*}{ p } \\
\hline & & \multicolumn{2}{|c|}{ Sim } & \multicolumn{2}{|c|}{ Não } & \multicolumn{2}{|c|}{ Total } & & \\
\hline & & $\mathbf{N}$ & $\%$ & $\mathbf{N}$ & $\%$ & N & $\%$ & & \\
\hline Peso ao & Baixo peso & 18 & 85,7 & 3 & 14,3 & 21 & 100.0 & 1,0 & 0,402 \\
\hline nascer & Adequado & 115 & 74,3 & 39 & 25,3 & 154 & 100.0 & $\begin{array}{c}0,491 \\
(0,137-1,759)\end{array}$ & \\
\hline $\begin{array}{l}\text { Tipo de } \\
\text { parto* }\end{array}$ & $\begin{array}{l}\text { Normal } \\
\text { Outro }\end{array}$ & $\begin{array}{l}69 \\
64\end{array}$ & $\begin{array}{l}77,5 \\
75,3\end{array}$ & $\begin{array}{l}20 \\
21\end{array}$ & $\begin{array}{l}22,5 \\
24,7\end{array}$ & $\begin{array}{l}89 \\
35\end{array}$ & $\begin{array}{l}100.0 \\
100.0\end{array}$ & $\begin{array}{c}1,0 \\
0,883 \\
(0,438-1,780)\end{array}$ & 0,866 \\
\hline $\begin{array}{l}\text { Duração } \\
\text { gestação }\end{array}$ & $\begin{array}{l}\text { Prematuro } \\
\text { A Termo }\end{array}$ & $\begin{array}{c}11 \\
122\end{array}$ & $\begin{array}{l}78,6 \\
75,8\end{array}$ & $\begin{array}{c}3 \\
39\end{array}$ & $\begin{array}{l}21,4 \\
24,2\end{array}$ & $\begin{array}{c}14 \\
161\end{array}$ & $\begin{array}{l}100.0 \\
100.0\end{array}$ & $\begin{array}{c}1,0 \\
0,853 \\
(0,226-3,215)\end{array}$ & 0,927 \\
\hline $\begin{array}{l}\text { Idade da } \\
\text { mãe }\end{array}$ & $\begin{array}{l}\text { Jovem } \\
\text { Adulta }\end{array}$ & $\begin{array}{c}30 \\
103\end{array}$ & $\begin{array}{l}83,3 \\
74,1\end{array}$ & $\begin{array}{c}6 \\
36\end{array}$ & $\begin{array}{l}16,7 \\
25,9\end{array}$ & $\begin{array}{c}36 \\
139\end{array}$ & $\begin{array}{l}100.0 \\
100.0\end{array}$ & $\begin{array}{c}1,0 \\
0,572 \\
(0,220-1,487)\end{array}$ & 0,349 \\
\hline $\begin{array}{l}\text { Escolaridade } \\
\text { da mãe }\end{array}$ & $\begin{array}{l}\text { Baixa } \\
\text { Năo baixa }\end{array}$ & $\begin{array}{l}66 \\
65\end{array}$ & $\begin{array}{l}79,5 \\
73,0\end{array}$ & $\begin{array}{l}17 \\
24\end{array}$ & $\begin{array}{l}20,5 \\
58,5\end{array}$ & $\begin{array}{l}83 \\
89\end{array}$ & $\begin{array}{l}100.0 \\
100.0\end{array}$ & $\begin{array}{c}1,0 \\
0,698 \\
(0,343-1,418)\end{array}$ & 0,413 \\
\hline $\begin{array}{l}\text { Escolaridade } \\
\text { do pai»"* }\end{array}$ & $\begin{array}{l}\text { Baixa } \\
\text { Não baixa }\end{array}$ & $\begin{array}{l}57 \\
64\end{array}$ & $\begin{array}{l}77,0 \\
72,7\end{array}$ & $\begin{array}{l}17 \\
24\end{array}$ & $\begin{array}{c}23 \\
27,3\end{array}$ & $\begin{array}{l}74 \\
88\end{array}$ & $\begin{array}{l}100.0 \\
100.0\end{array}$ & $\begin{array}{c}1,0 \\
0,795 \\
(0,388-1,628)\end{array}$ & 0,656 \\
\hline Estado & Baixo peso & 6 & 100 & 0 & 0,0 & 6 & 100.0 & & 0,229 \\
\hline nutricional & Normal & 119 & 74,4 & 41 & 25,6 & 160 & 100.0 & nd & \\
\hline & Peso alto & 8 & 88,9 & 1 & 11,1 & 9 & 100.0 & & \\
\hline
\end{tabular}

Não houve associação entre situação da crianças quanto ao consumo de água ou chá e as variáveis de estudo (tabela 17). Optou-se por manter no 
modelo a escolaridade materna, apesar da associação não ter sido estatisticamente significativa, para posterior comparação com aleitamento materno, aleitamento materno exclusivo e consumo de leite não materno. Os parâmetros da regressão logística estão no tabela18.

Tabela 18 - Resultados da regressão logística multivariada para consumo de água ou chá.

\begin{tabular}{|c|c|c|c|c|c|}
\hline Variável & categoria & OR & IC $_{95 \%}$ & $\beta$ & $\frac{P}{\text { Wald }}$ \\
\hline Constante & & & & $-0,4735$ & 0,2794 \\
\hline Idade & Contínua & 1,015 & $1,009-1,021$ & 0,0148 & $<0,001$ \\
\hline Escolaridade & Baixa & 1,0 & & & \\
\hline materna & Năo-baixa & 0,699 & $0,320-1,525$ & $-0,3581$ & 0,3683 \\
\hline
\end{tabular}

Estimou-se então a prevalência do aleitamento materno segundo a idade da criança, ajustado por escolaridade por meio da equação:

$$
\operatorname{Prob}(Y=1)=P=\frac{1}{1+e^{-(-0.4736-0,3681 \text { escolaridade materna +0.01481dade })}}
$$

As curvas de prevalência de consumo de água ou chá estão representadas na figura 5 . 
Figura 5 - Curvas de prevalência de consumo de água ou chá segundo escolaridade materna nos Centros de saúde. São Paulo, 1998.

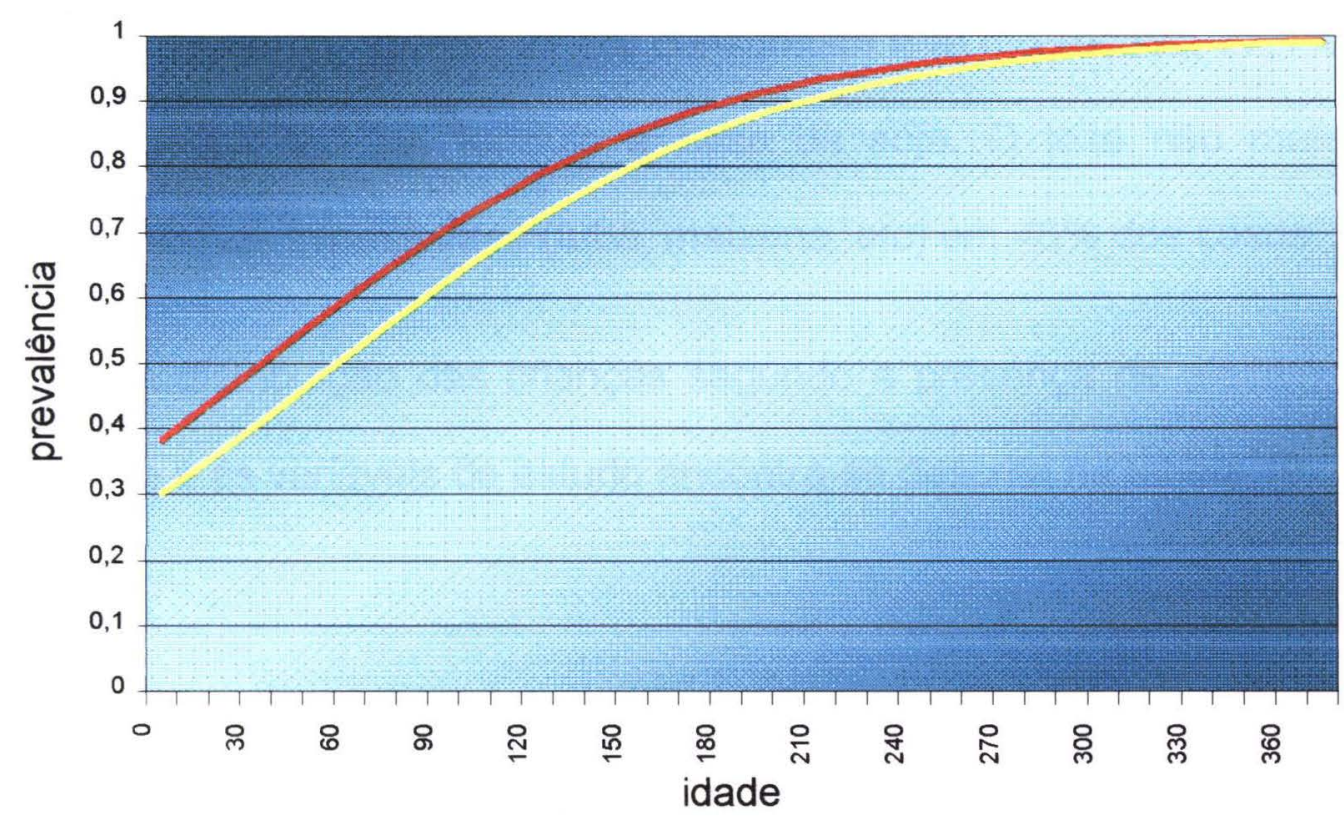

—escolaridade baixa escolaridade não baixa

O modelo está bem ajustado $(p=0,638)$.

Apesar de não haver associação estatisticamente significativa entre escolaridade e consumo de água ou chá, nas crianças cujas mães têm escolaridade mais baixa, as taxas de prevalência de consumo de água ou chá são mais elevadas. No início da vida ( 0 dias) estima-se que $38 \%$ das mães com escolaridade baixa e $30 \%$ das mães com escolaridade não baixa ministrem água ou chá para seus filhos. Aos 120 dias de idade, $78 \%$ das crianças com mães com baixa escolaridade e $72 \%$ nas crianças com mães com escolaridade não baixa recebem água ou chá. 


\subsection{Leite Não Materno}

No momento da pesquisa, das 83 crianças que estavam recebendo leite não materno, apenas $21,7 \%$ consumiam leite modificado, $77,1 \%$ leite de vaca integral e 1,2\% fórmula a base de soja. $O$ leite não materno era adicionado de espessantes (fubá, maizena, etc) em $46 \%$ dos casos.

A distribuição das crianças segundo a presença de aleitamento não materno e as variáveis de estudo encontra-se descrita na tabela 19. 
Tabela 19 - Distribuição do número e porcentagem das crianças segundo consumo de leite não materno e demais variáveis de estudo. São Paulo, 1998.

\begin{tabular}{|c|c|c|c|c|c|c|c|c|c|}
\hline \multirow[b]{3}{*}{ Variável } & \multirow[b]{3}{*}{ Categoria } & \multicolumn{6}{|c|}{ Consumo de leite não materno } & \multirow{3}{*}{$\begin{array}{c}\text { OR } \\
\text { IC }_{95 \%}{ }^{(0 R)}\end{array}$} & \multirow[b]{3}{*}{ p } \\
\hline & & \multicolumn{2}{|c|}{ Sim } & \multicolumn{2}{|c|}{ Não } & \multicolumn{2}{|c|}{ Total } & & \\
\hline & & N & $\%$ & $\mathbf{N}$ & $\%$ & $\mathbf{N}$ & $\%$ & & \\
\hline Peso ao & Baixo peso & 8 & 38,1 & 13 & 61,9 & 21 & 100,0 & 1,0 & \\
\hline \multirow[t]{2}{*}{ nascer } & Adequado & 84 & 45,5 & 70 & 54,5 & 154 & 100,0 & 0,513 & 0,237 \\
\hline & & & & & & & & $(0,201-1,308)$ & \\
\hline \multirow[t]{3}{*}{ Tipo de parto } & Normal & 37 & 41,6 & 52 & 58,4 & 89 & 100,0 & 1,0 & \\
\hline & Outro & 46 & 54,1 & 39 & 45,9 & & 100,0 & 1,658 & 0,133 \\
\hline & & & & & & & & $(0,910-3,020)$ & \\
\hline Duração & Prematuro & 9 & 64,3 & 5 & 35,7 & 14 & 100,0 & 1,0 & \\
\hline \multirow[t]{2}{*}{ gestação } & A Termo & 74 & 46,0 & 87 & 54,0 & 161 & 100,0 & 0,473 & 0,299 \\
\hline & & & & & & & & $(0,152-1,472)$ & \\
\hline Idade da & Jovem & 18 & 50 & 18 & 50 & 36 & 100,0 & 1,0 & \\
\hline \multirow[t]{2}{*}{ mãe } & Adulta & 74 & 53,2 & 65 & 46,8 & 139 & 100,0 & 0,878 & 0,872 \\
\hline & & & & & & & & $(0,422-1,829)$ & \\
\hline Escolaridade & Baixa & 46 & 55,4 & 37 & 44,6 & 83 & 100,0 & 1,0 & \\
\hline \multirow[t]{2}{*}{ da mãe } & Não baixa & 36 & 40,4 & 53 & 59,6 & 89 & 100,0 & 0,546 & 0,070 \\
\hline & & & & & & & & $(0,298-1,001)$ & \\
\hline Escolaridade & Baixa & 31 & 41,9 & 43 & 58,1 & 74 & 100,0 & 1,0 & \\
\hline \multirow[t]{2}{*}{ do pai } & Não baixa & 45 & 51,1 & 43 & 48,9 & 88 & 100,0 & 1,452 & 0,309 \\
\hline & & & & & & & & $(0,779-2,706)$ & \\
\hline Estado & Baixo peso & 6 & 0 & 0 & 100 & 6 & 100,0 & Nd & 0,026 \\
\hline \multirow[t]{2}{*}{ nutricional } & Normal & 72 & 55 & 88 & 45 & 160 & 100,0 & & \\
\hline & Peso alto & 5 & 44,4 & 4 & 55,6 & 9 & 100,0 & & \\
\hline \multirow[t]{3}{*}{ Localidade } & Central & 50 & 65,8 & 26 & 34,2 & 76 & 100,0 & 1,0 & $<$ \\
\hline & Periferia & 33 & 33,3 & 66 & 66,7 & 99 & 100,0 & 0,260 & 0,001 \\
\hline & & & & & & & & $(0,138-0,480)$ & \\
\hline
\end{tabular}

\footnotetext{
* excluído um indivíduo sem informação

** excluídos três indivíduos sem informação

*** excluídos treze indivíduos sem informaçăo nd não definido
} 
Observou-se associação estatisticamente significativa entre consumo de leite não materno e estado nutricional. e localidade. No entanto, o pequeno número de individuos na categoria baixo peso, bem como a presença de caselas vazias impossibilita a confecção do modelo de regressão logística.

Os parâmetros da regressão logística para a variável dependente leite não materno segundo idade da criança, ajustado por localidade encontram-se na tabela 20.

Tabela 20 - Resultados da regressão logística multivariada para consumo de leite não materno.

\begin{tabular}{|c|c|c|c|c|c|}
\hline Variavel & categoria & OR & IC $_{95 \%}(\mathrm{BR})$ & $\beta$ & $\begin{array}{c}\mathbf{P} \\
\text { Wald }\end{array}$ \\
\hline Constante & & & & $-0,1025$ & 0,7791 \\
\hline Idade & Contínua & 1,005 & $1,001-1,009$ & 0,0051 & 0,007 \\
\hline \multirow[t]{2}{*}{ Localidade } & Central & 1,0 & & & \\
\hline & Periferia & 0,256 & $0,134-0,490$ & -1.3618 & $<0,001$ \\
\hline
\end{tabular}

Estimou-se a prevalência do consumo de leite não materno segundo a idade da criança, ajustando-se pela localidade:

$\operatorname{Prob}(Y=1)=P=\frac{1}{1+e^{-(1.2593-1.361810 \mathrm{calidade}+0.005 \text { 1तdade })}}$

O CS central corresponde à localidade $=0$, e o CS da periferia corresponde à localidade $=1$. As curvas que representam a prevalência de 
consumo de leite não materno segundo idade e localidade podem ser observados na figura 6.

Figura 6 - Curvas de prevalência de consumo de leite não materno segundo localidade. São Paulo, 1998.

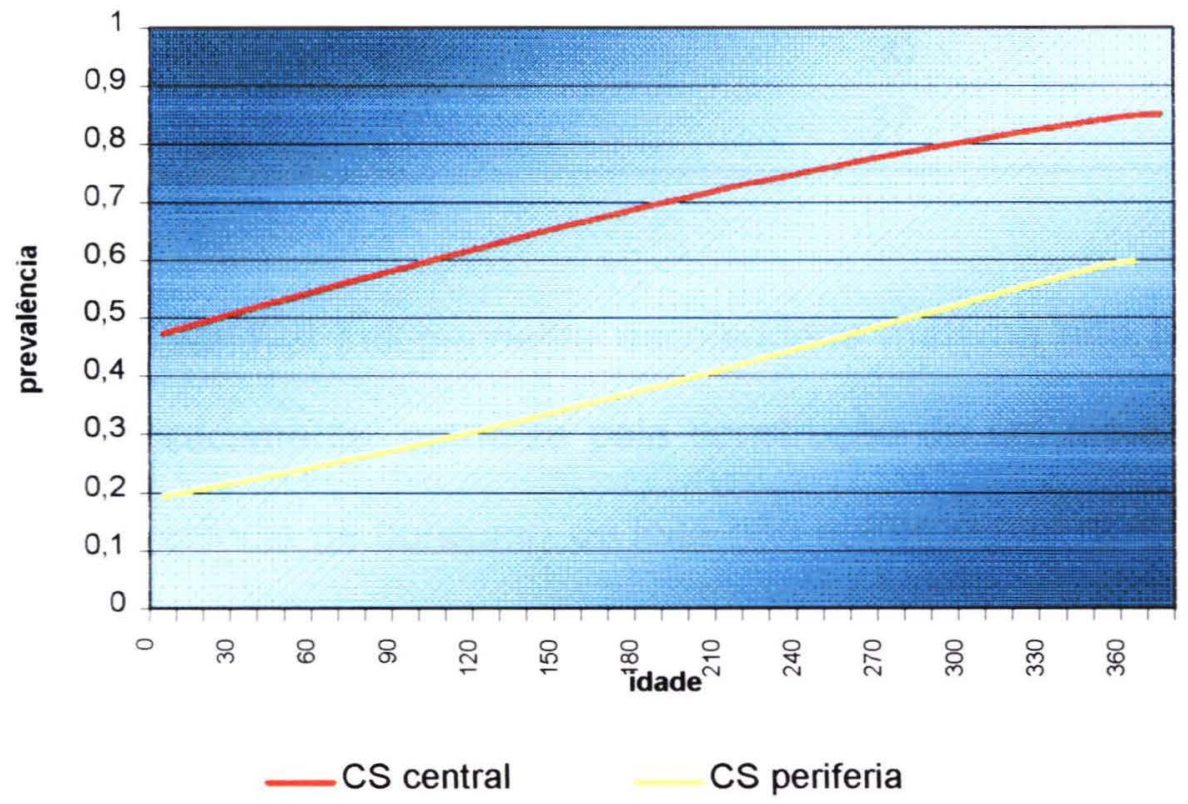

Chama a atenção a diferença entre a prevalência de consumo de leite não materno entre os dois Centros de Saúde, em especial nos quatro primeiros meses de vida da criança (tabela 21). 
Tabela 21 - Prevalência de consumo de leite não materno em diferentes idades, segundo localidade. Săo Paulo, 1998.

\begin{tabular}{|c|c|c|}
\hline \multirow{2}{*}{$\begin{array}{l}\text { Idade } \\
\text { (dias) }\end{array}$} & \multicolumn{2}{|c|}{ Prevalência (\%) } \\
\hline & CS central & CS periferia \\
\hline$\overline{0}$ & $\overline{47}$ & $\overline{19}$ \\
\hline 30 & 51 & 21 \\
\hline 60 & 55 & 24 \\
\hline 90 & 59 & 27 \\
\hline 120 & 62 & 30 \\
\hline 180 & 70 & 37 \\
\hline
\end{tabular}

Apesar da variável independente escolaridade materna não ter sido significativa estatisticamente, optou-se pela construção de um modelo que mostrasse a prevalência de consumo de leite não materno nas duas faixas de escolaridade para posterior comparação dos resultados (tabela 22)

Tabela 22 - Resultados da regressão logística multivariada para consumo de leite não materno.

\begin{tabular}{llcccc}
\hline \multicolumn{1}{c}{ Variável } & Categoria & OR & IC $_{96 \%}{ }^{(\text {OR) }}$ & $\beta$ & $\begin{array}{c}\text { P } \\
\text { Wald }\end{array}$ \\
\hline Constante & & & & $-0,5294$ & 0,1300 \\
Idade & Contínua & 1,005 & $1,001-1,009$ & 0,0050 & $<0,001$ \\
$\begin{array}{l}\text { Escolaridade } \\
\text { materna }\end{array}$ & Baixa & 1,0 & & & \\
& Não-baixa & 0,537 & $0,289-0,999$ & $-0,6217$ & 0,0495 \\
\hline \multicolumn{1}{c}{$\mathbf{p} \chi^{2}<0,001$} & & & & &
\end{tabular}

Estimou-se então a prevalência do aleitamento materno segundo a idade da criança, ajustado por escolaridade, por meio da equação: 


$$
\operatorname{Prob}(Y=1)=P=\frac{1}{1+e^{-(-0.5294-0.6217 \text { escolaridade materna + 0.0050idade }}}
$$

As curvas que estimam a prevalência de consumo de leite não materno se encontram na figura 7

Figura 7 - Curvas de prevalência de consumo de leite não materno segundo escolaridade materna. São Paulo, 1998.

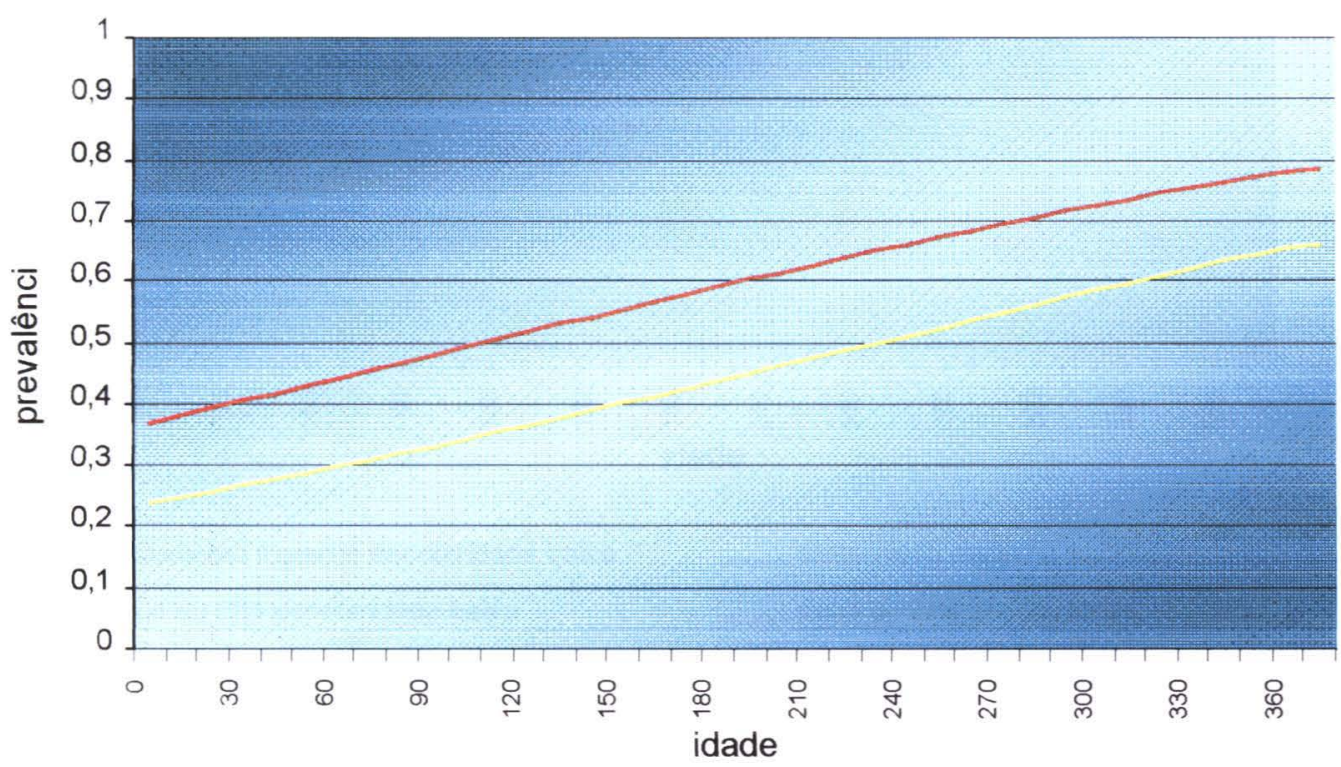

O modelo está bem ajustado $(p=0,661)$. 
As mulheres com escolaridade baixa ministram leite não materno mais precocemente do que mulheres com escolaridade não baixa, como ocorreu quanto ao consumo de água e chá.

Para comparar o consumo, podemos observar a figura 8 , com as curvas já mencionadas dispostas em conjunto.

Figura 8 - Curvas de prevalência de consumo de leite materno, leite não materno e água ou chá nos Centros de Saúde, segundo escolaridade materna. São Paulo, 1998.

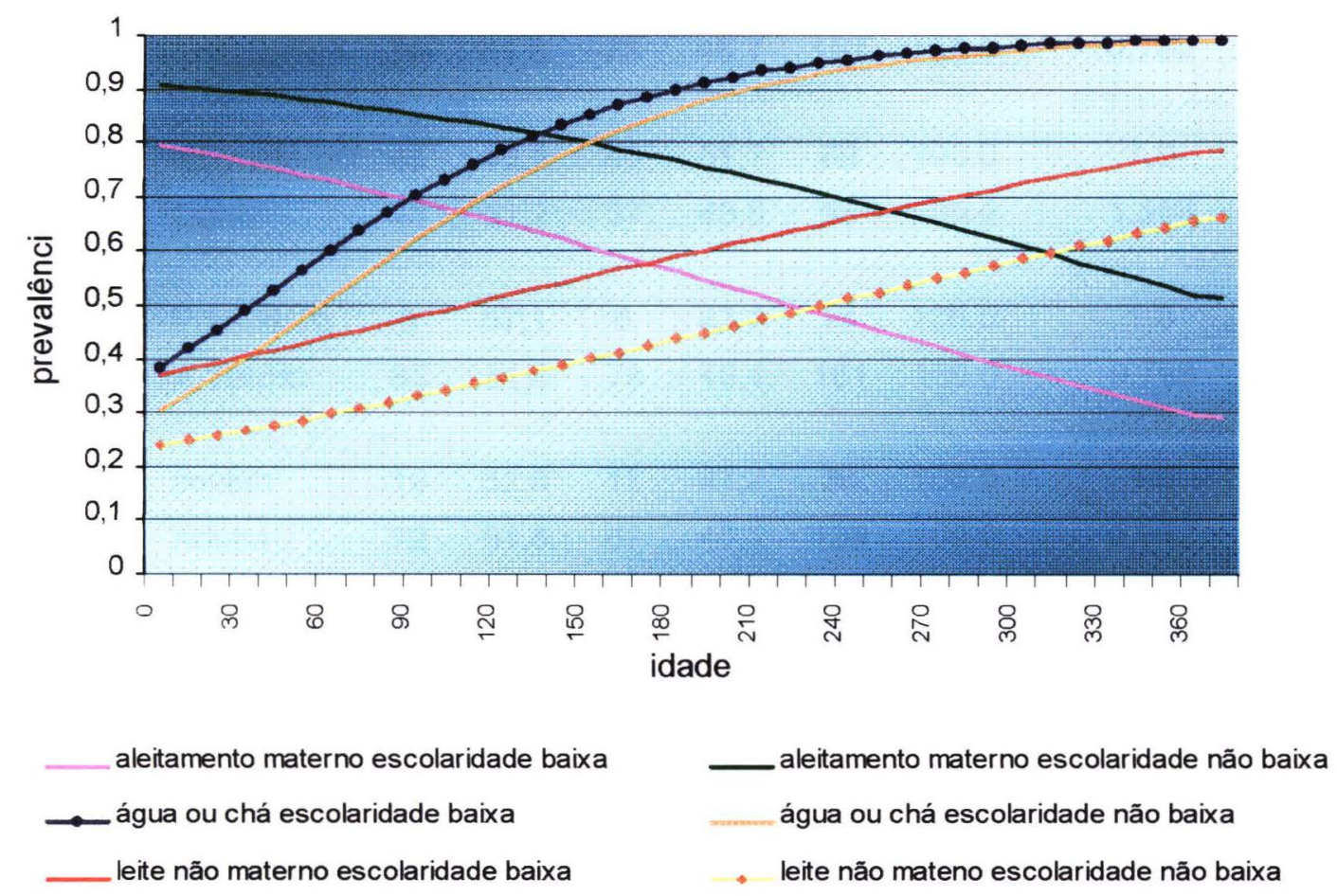




\subsection{Frutas e Hortaliças}

A distribuição das crianças em relação ao consumo de frutas e hortaliças segundo as variáveis encontram-se nas tabelas 23 e 24 .

Tabela 23- Distribuição do número e porcentagem das crianças segundo o consumo de frutas e demais variáveis de estudo. São Paulo, 1998.

\begin{tabular}{|c|c|c|c|c|c|c|c|c|c|}
\hline & & & & sum & de Fr & tas & & & \\
\hline & & & & & & & tal & OR & \\
\hline Variável & Categoria & $\mathbf{N}$ & $\%$ & $\mathbf{N}$ & $\%$ & N & $\%$ & $\left(I C_{95 \%}^{(O R)}\right)$ & p \\
\hline Peso ao & Baixo peso & 12 & 57,1 & 9 & 42,9 & 21 & 100.0 & 1,0 & \\
\hline nascer & Adequado & 79 & 51,3 & 75 & 48,7 & 154 & 100.0 & 0,790 & 0,787 \\
\hline & & & & & & & & $(0,224-2,440$ & \\
\hline Tipo de & Normal & 43 & 48,3 & 46 & 51,7 & 89 & 100.0 & 1,0 & \\
\hline parto* & Outro & 48 & 51,7 & 37 & 43,5 & 85 & 100.0 & 1,388 & 0,355 \\
\hline & & & & & & & & $(0,764-2,522)$ & \\
\hline Duração & Prematuro & 8 & 57,1 & 6 & 42,9 & 14 & 100.0 & 1,0 & \\
\hline gestação & A Termo & 83 & 51,6 & 78 & 48,4 & 161 & 100.0 & 0,798 & 0,902 \\
\hline & & & & & & & & $(0,265-2,404)$ & \\
\hline Idade da & Jovem & 19 & 52,8 & 17 & 47,2 & 36 & 100.0 & 1,0 & \\
\hline mãe & Adulta & 72 & 51,8 & 67 & 48,2 & 139 & 100.0 & 0,962 & 0,934 \\
\hline & & & & & & & & $(0,461-2,003)$ & \\
\hline Escolaridade & Baixa & 39 & 53,0 & 44 & 47,0 & 83 & 100.0 & 1,0 & \\
\hline da mãe $e^{\star \star}$ & Não baixa & 43 & 51,7 & 46 & 48,3 & 89 & 100.0 & 0,948 & 0,983 \\
\hline & & & & & & & & $(0,521-1,726)$ & \\
\hline Escolaridade & Baixa & 37 & 50,0 & 37 & 50,0 & 74 & 100.0 & 1,0 & \\
\hline do pai $i^{\star \star \star \star}$ & Não baixa & 46 & 52,3 & 42 & 47,7 & 88 & 100.0 & 1,095 & 0,896 \\
\hline & & & & & & & & $(0,590-2,033)$ & \\
\hline Estado & Baixo peso & 5 & 83,3 & 1 & 16,7 & 6 & 100.0 & 1,0 & \\
\hline nutricional & Normal & 80 & 50,0 & 80 & 50,0 & 160 & 100.0 & 0,200 & 0,183 \\
\hline & & & & & & & & $(0,023-1,750)$ & \\
\hline & Peso alto & 6 & 66,7 & 3 & 33,3 & 9 & 100.0 & 0,400 & \\
\hline & & & & & & & & $(0,031-8,151)$ & \\
\hline
\end{tabular}

\footnotetext{
* excluído um indivíduo sem informação

* excluídos três indivíduos sem informação

*** excluidos treze indivíduos sem informaçăo
} 
Tabela 24- Distribuição do número e porcentagem das crianças segundo o consumo de hortaliças e demais variáveis de estudo. São Paulo, 1998.

\begin{tabular}{|c|c|c|c|c|c|c|c|c|c|}
\hline \multirow[b]{3}{*}{ Variável } & \multirow[b]{3}{*}{ Categoria } & \multicolumn{6}{|c|}{ Consumo de Hortaliças } & \multirow[b]{2}{*}{ OR } & \multirow[b]{3}{*}{ p } \\
\hline & & \multicolumn{2}{|c|}{ Sim } & \multicolumn{2}{|c|}{ Não } & \multicolumn{2}{|c|}{ Total } & & \\
\hline & & $\mathbf{N}$ & $\%$ & $\mathbf{N}$ & $\%$ & $\mathbf{N}$ & $\%$ & $\left(I_{95 \%}{ }^{(O R)}\right)$ & \\
\hline Peso ao & Baixo peso & 13 & 38,1 & 8 & 38,1 & 6 & 100.0 & 1,0 & \\
\hline \multirow[t]{2}{*}{ nascer } & Adequado & 66 & 42,9 & 88 & 57,1 & 154 & 100.0 & 0,462 & 0,158 \\
\hline & & & & & & & & $(0,181-1,178)$ & \\
\hline Tipo de & Normal & 34 & 38,2 & 55 & 61,8 & 89 & 100.0 & 1,0 & \\
\hline \multirow[t]{2}{*}{ parto* } & Outro & 45 & 52,9 & 40 & 47,1 & 85 & 100.0 & 1,820 & 0,072 \\
\hline & & & & & & & & $(0,955-3,328)$ & \\
\hline Duração & Prematuro & 9 & 64,3 & 5 & 35,7 & 14 & 100.0 & 1,0 & \\
\hline \multirow[t]{2}{*}{ gestação } & A Termo & 70 & 43,8 & 91 & 56,3 & 161 & 100.0 & 0,427 & 0,222 \\
\hline & & & & & & & & $(0,137-1,332)$ & \\
\hline Idade da & Jovem & 17 & 47,2 & 19 & 52,8 & 36 & 100.0 & 1,0 & \\
\hline \multirow[t]{2}{*}{ mãe } & Adulta & 62 & 44,6 & 77 & 55,4 & 139 & 100.0 & 0,900 & 0,926 \\
\hline & & & & & & & & $(0,432-1,877)$ & \\
\hline Escolaridade & Baixa & 36 & 43,4 & 47 & 56,6 & 83 & 100.0 & 1,0 & \\
\hline \multirow[t]{2}{*}{ da mãe** } & Não baixa & 42 & 47,2 & 47 & 52,8 & 89 & 100.0 & 1,167 & 0,727 \\
\hline & & & & & & & & $(0,639-2,129)$ & \\
\hline Escolaridade & Baixa & 29 & 39,2 & 45 & 60,8 & 74 & 100.0 & 1,0 & \\
\hline \multirow[t]{2}{*}{ 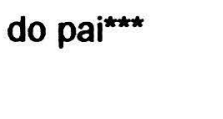 } & Não baixa & 42 & 47,7 & 46 & 52,3 & 88 & 100.0 & 1,417 & 0,351 \\
\hline & & & & & & & & $(0,757-2,652)$ & \\
\hline Estado & Baixo peso & 3 & 50 & 3 & 50 & 6 & 100.0 & 1,0 & \\
\hline \multirow[t]{4}{*}{ nutricional } & Normal & 70 & 43,8 & 90 & 56,3 & 160 & 100.0 & 0,778 & 0,393 \\
\hline & & & & & & & & $(0,152-3,972)$ & \\
\hline & Peso alto & 6 & 66,7 & 3 & 33,3 & 9 & 100.0 & 2,0 & \\
\hline & & & & & & & & $(0,241-16,613)$ & \\
\hline
\end{tabular}


Não houve associação entre nenhuma das variáveis independentes e o consumo de frutas ou hortaliças.

Optou-se por manter no modelo apenas a variável independente idade. Os parâmetros da regressão logística para as variáveis dependentes "consumo de frutas" e "consumo de hortaliças" estão na tabela 25.

Tabela 25 - Resultados da regressão logística para consumo de frutas e hortaliças. São Paulo, 1998.

\begin{tabular}{lcccc}
\hline Variável dependente & $\beta$ constante & $\beta$ idade & $p$ \\
& (EP) & (EP) & \\
\hline Frutas & -4.1773 & 0,0306 & $<0,001$ \\
& $(0.6334)$ & $(0,0045)$ & \\
Hortaliças & $-4,9683$ & 0,0320 & $<0,001$ \\
& $(0,7334)$ & $(0,0047)$ & \\
\hline
\end{tabular}

A prevalência de consumo de frutas foi estimadas a partir da equação:

$$
\operatorname{Prob}(Y=1)=P=\frac{1}{1+e^{-(-4,1773+0,03061 d a d e)}}
$$

A prevalência de consumo de hortaliças foi estimadas a partir da equação:

$$
\operatorname{Prob}(\mathrm{Y}=1)=\mathrm{P}=\frac{1}{1+\mathrm{e}^{-(-4,9683+0,03201 \mathrm{dad})}}
$$


As curvas de prevalência de consumo de frutas e hortaliças estão descritas na figura 9.

Figura 9 - Curvas de prevalência de consumo de frutas e hortaliças nos Centros de Saúde. São Paulo, 1998.

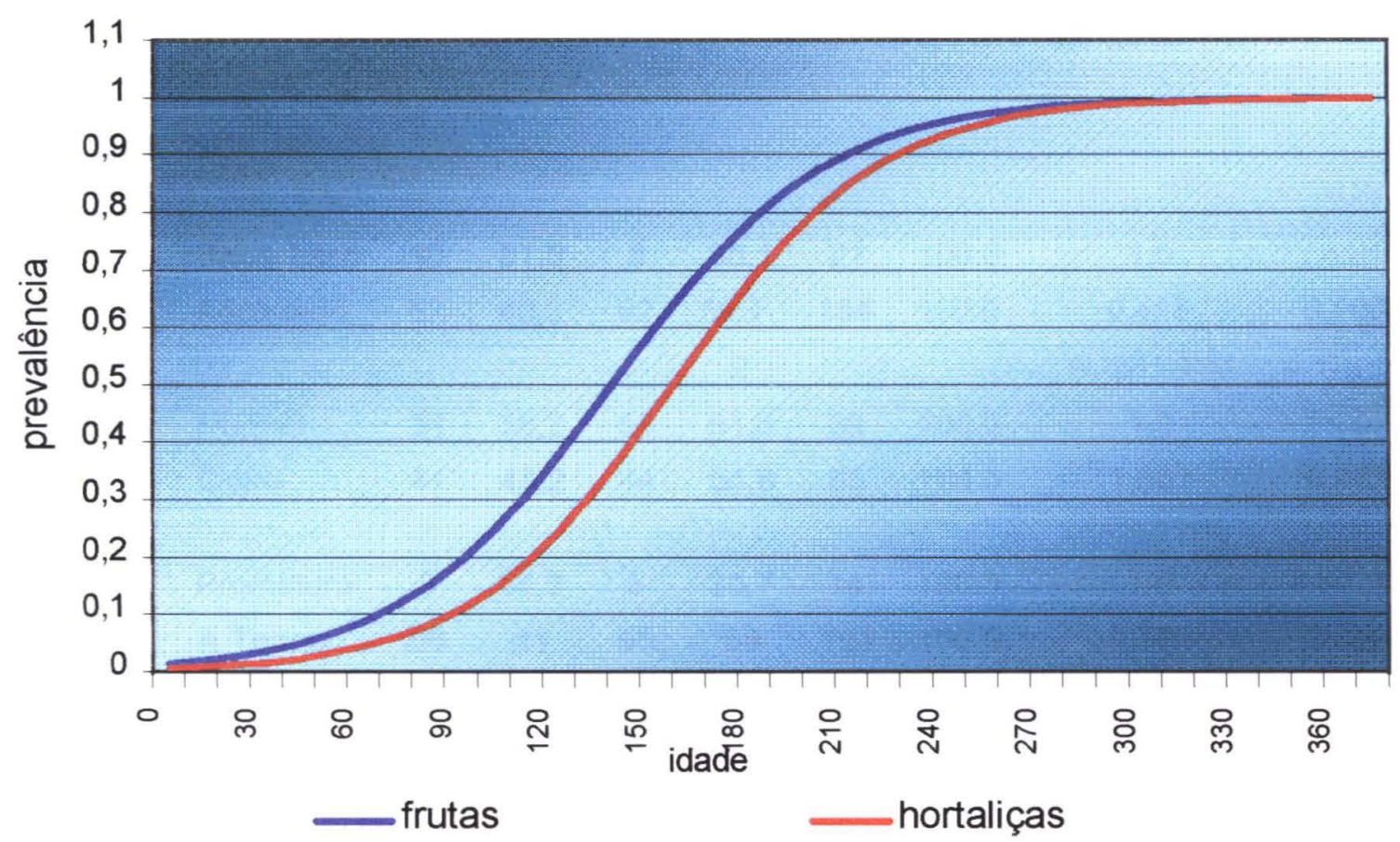

O modelo para frutas está bem ajustado $(p=0,404)$, bem como o modelo para hortaliças $(p=0,070)$.

Aos 120 dias de idade, $38 \%$ das crianças estão consumindo frutas e $24 \%$ estão consumindo hortaliças, denotando um início precoce na introdução destes alimentos. Aos 180 dias, $79 \%$ das crianças já consomem frutas e $69 \%$ consomem hortaliças. 


\subsection{Cereais}

A distribuição das crianças em relação ao consumo de cereais e as variáveis independentes estão na tabela 26

Tabela 26 - Distribuição do número e porcentagem das crianças segundo o consumo de cereais e as demais variáveis de estudo. São Paulo, 1998.

\begin{tabular}{|c|c|c|c|c|c|c|c|c|c|}
\hline \multicolumn{10}{|c|}{ Consumo de Cereais } \\
\hline \multirow[b]{2}{*}{ Variável } & \multirow[b]{2}{*}{ Categoria } & \multicolumn{2}{|c|}{ Sim } & \multicolumn{2}{|c|}{ Não } & \multicolumn{2}{|c|}{ Total } & \multirow{2}{*}{$\begin{array}{c}\text { OR } \\
\left(\text { IC }_{95 \%}^{(\text {OR) }}\right)\end{array}$} & \multirow[b]{2}{*}{ p } \\
\hline & & $\mathbf{N}$ & $\%$ & N & $\%$ & $\mathbf{N}$ & $\%$ & & \\
\hline Peso ao & Baixo peso & 13 & 61,9 & 8 & 38,1 & 21 & 100.0 & 1,0 & \\
\hline nascer & Adequado & 62 & 40,3 & 92 & $\begin{array}{c}59,7 \\
2\end{array}$ & 154 & 100.0 & $\begin{array}{c}0,415 \\
(0,162-1,059)\end{array}$ & 0,100 \\
\hline Tipo de & Normal & 34 & 38,2 & 55 & 61,8 & 89 & 100.0 & 1,0 & \\
\hline parto* & Outro & 41 & 48,2 & 44 & 51,8 & 85 & 100.0 & $\begin{array}{c}1,507 \\
(0,825-2,755)\end{array}$ & 0,273 \\
\hline $\begin{array}{l}\text { Duração } \\
\text { gestação }\end{array}$ & $\begin{array}{l}\text { Prematuro } \\
\text { A Termo }\end{array}$ & $\begin{array}{c}9 \\
66\end{array}$ & $\begin{array}{c}64,3 \\
41\end{array}$ & $\begin{array}{c}5 \\
95\end{array}$ & $\begin{array}{c}33,7 \\
59\end{array}$ & $\begin{array}{c}14 \\
161\end{array}$ & $\begin{array}{l}100.0 \\
100.0\end{array}$ & $\begin{array}{c}1,0 \\
0,386 \\
(0,124-1,204)\end{array}$ & 0,159 \\
\hline Idade da & Jovem & 16 & 44,4 & 20 & 55,6 & 36 & 100.0 & 1,0 & \\
\hline mãe & Adulta & 59 & 42,4 & 80 & 57,6 & 139 & 100.0 & $\begin{array}{c}0,922 \\
(0,441-1,929)\end{array}$ & 0,978 \\
\hline Escolaridade & Baixa & 35 & 42,2 & 48 & 57,8 & 83 & 100.0 & 1,0 & \\
\hline da mãe $e^{* *}$ & Não baixa & 39 & 43,8 & 50 & 56,2 & 89 & 100.0 & $\begin{array}{c}1,070 \\
(0,585-1,957)\end{array}$ & 0,949 \\
\hline Escolaridade & Baixa & 28 & 37,8 & 46 & 62,2 & 74 & 100.0 & 1,0 & \\
\hline do paint & Năo baixa & 39 & 44,3 & 49 & 55,7 & 88 & 100.0 & $\begin{array}{c}1,308 \\
(0,696-2,457)\end{array}$ & 0,500 \\
\hline Estado & Baixo peso & 4 & 66,7 & 2 & 33,3 & 6 & 100.0 & 1,0 & \\
\hline nutricional & Normal & 66 & 41,3 & 94 & 58,8 & 160 & 100.0 & $\begin{array}{c}0,351 \\
(0,062-1,973)\end{array}$ & 0,341 \\
\hline & Peso alto & 5 & 55,6 & 4 & 44,4 & 9 & 100.0 & $\begin{array}{c}0,625 \\
(0,073-5,350)\end{array}$ & \\
\hline
\end{tabular}

* excluido um indivíduo sem informação

** excluidos três indivíduos sem informaçăo

** excluídos treze individuos sem informaçăo 
Não houve associação estatisticamente significativa entre nenhuma das variáveis independentes e o consumo de cereais.

Optou-se por manter no modelo apenas a variável independente idade. Os parâmetros da regressão logística para o consumo de cereais estão na tabela 27

Tabela 27 - Resultados da regressão logística para consumo de cereais. São Paulo, 1998.

\begin{tabular}{lcccc}
\hline Variável dependente & $\beta$ constante & $\beta$ idade & $p$ \\
& (EP) & (EP) & \\
\hline Cereais & $-5,4695$ & 0,0338 & $<0,001$ \\
& $(0,8110)$ & $(0,0050)$ & \\
\hline
\end{tabular}

A prevalência de consumo de cereais foi estimada a partir da equação:

$$
\operatorname{Prob}(Y=1)=P=\frac{1}{1+e^{-(-5,4695+0,03381 d a d e)}}
$$

A curva de prevalência de consumo de cereais se encontra na figura 10. 
Figura 10 - Curva de prevalência de consumo de cereais nos Centros de Saúde. São Paulo, 1998.

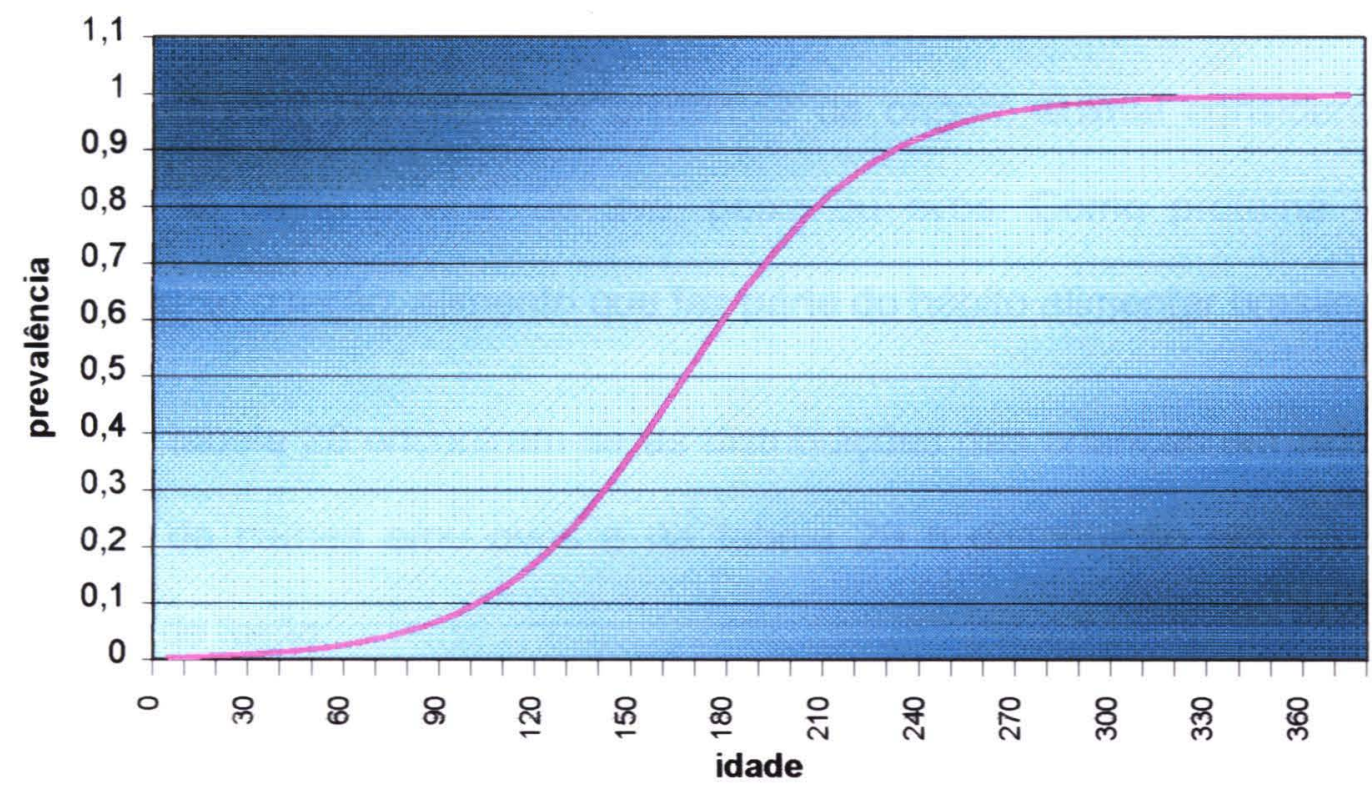

cereais

O modelo está bem ajustado $(p=0,238)$.

Pelo formato da curva, percebe-se que até o terceiro mês o consumo é baixo, sendo de $8 \%$ nesta idade. A partir daí verifica-se uma rápida ascensão, chegando a $65 \%$ no sexto mês e atingindo a maioria das crianças (95\%) no oitavo mês (figura 10). A prevalência de consumo de cereais aos 120 dias é de $20 \%$, aos 150 dias é de $40 \%$ e aos $180,65 \%$. 


\subsection{Carnes, Ovos e Feijăo}

Considerou-se o consumo de alimentos fontes de proteína, de origem animal e vegetal. No grupo de alimentos de origem animal considerourse o consumo de came bovina, de ave, peixe ou ovos. Como proteina vegetal, considerou-se o feijāo, alimento que faz parte do hábito alimentar brasileiro.

$\mathrm{Na}$ tabela 28 encontram-se as distribuiçőes das crianças em relaçăo ao consumo de cames e/ou ovos e na tabela 29 a distribuição em relação ao consumo de feijăo. 
Tabela 28 - Distribuição do número e porcentagem das crianças segundo consumo de carnes e ovos e demais variáveis de estudo. Săo Paulo, 1998.

\begin{tabular}{|c|c|c|c|c|c|c|c|c|c|}
\hline \multirow[b]{3}{*}{ Variável } & \multirow[b]{3}{*}{ Categoria } & \multicolumn{6}{|c|}{ Consumo de carnes e/ou ovos } & \multirow{3}{*}{$\begin{array}{c}\text { OR } \\
\left(\mathrm{IC}_{95 \%}{ }^{(\mathrm{OR})}\right)\end{array}$} & \multirow[b]{3}{*}{ p } \\
\hline & & \multicolumn{2}{|c|}{ Sim } & \multicolumn{2}{|c|}{ Não } & \multicolumn{2}{|c|}{ Total } & & \\
\hline & & N & $\%$ & N & $\%$ & N & $\%$ & & \\
\hline Peso ao & Baixo peso & 9 & 42,9 & 12 & 57,1 & 21 & 100.0 & 1,0 & \\
\hline nascer & Adequado & 46 & 29,9 & 108 & 70,1 & 154 & 100.0 & 0,568 & 0,341 \\
\hline & & & & & & & & $(0,224-2,440)$ & \\
\hline Tipo de & Normal & 22 & 24,7 & 67 & 75,3 & 89 & 100.0 & 1,0 & \\
\hline parto* & Outro & 33 & 38,8 & 52 & 61,2 & 85 & 100.0 & 1,933 & 0,066 \\
\hline & & & & & & & & $(1,009-3,701)$ & \\
\hline Duraçåo & Prematuro & 6 & 42,9 & 8 & 57,1 & 14 & 100.0 & 1,0 & \\
\hline gestaçăo & A Termo & 49 & 30,4 & 112 & 69,6 & 161 & 100.0 & 0,583 & 0,509 \\
\hline & & & & & & & & $(0,178-1,597)$ & \\
\hline Idade da & Jovem & 10 & 27,8 & 26 & 72,2 & 36 & 100.0 & 1,0 & \\
\hline măe & Adulta & 45 & 32,4 & 94 & 67,6 & 139 & 100.0 & 1,245 & 0,743 \\
\hline & & & & & & & & $(0,553-2,801)$ & \\
\hline Escolaridade & Baixa & 26 & 31,3 & 57 & 68,7 & 83 & 100.0 & 1,0 & \\
\hline da mãe & Não baixa & 28 & 31,5 & 61 & 68,5 & 89 & 100.0 & 1,006 & 0,884 \\
\hline & & & & & & & & $(0,528-1,917)$ & \\
\hline Escolaridade & Baixa & 24 & 32,4 & 50 & 67,6 & 74 & 100.0 & 1,0 & \\
\hline do pai" & Não baixa & 26 & 29,5 & 62 & 70,5 & 88 & 100.0 & 0,874 & 0,822 \\
\hline & & & & & & & & $(0,448-1,704)$ & \\
\hline Estado & Baixo peso & 3 & 50 & 3 & 50 & 6 & 100.0 & 1,0 & \\
\hline nutricional & Normal & 49 & 30,6 & 111 & 69,4 & 160 & 100.0 & 0,441 & 0,599 \\
\hline & & & & & & & & $(0,086-2,265)$ & \\
\hline & Peso alto & 3 & 33,3 & 6 & 66,7 & 9 & 100.0 & 0,500 & \\
\hline & & & & & & & & $(0,060-4,153)$ & \\
\hline
\end{tabular}

\footnotetext{
* excluído um individuo sem informação

* excluídos trés indivíduos sem informação

** excluidos treze indivíduos sem informaçăo
}

Não houve associação estatisticamente significativa entre nenhuma das variáveis independentes e o consumo de carnes e/ou ovos. 
Tabela 29 - Distribuição do número e porcentagem das crianças segundo consumo de feijăo e demais variáveis de estudo. Săo Paulo, 1998.

\begin{tabular}{|c|c|c|c|c|c|c|c|c|c|}
\hline \multirow[b]{3}{*}{ Variável } & \multirow[b]{3}{*}{ Categoria } & \multicolumn{6}{|c|}{ Consumo de feijão } & \multirow{3}{*}{$\begin{array}{c}\text { OR } \\
\left(\mathrm{IC}_{95 \%}{ }^{\text {(OR) }}\right)\end{array}$} & \multirow[b]{3}{*}{ p } \\
\hline & & \multicolumn{2}{|c|}{ Sim } & \multicolumn{2}{|c|}{ Não } & \multicolumn{2}{|c|}{ Total } & & \\
\hline & & $\mathbf{N}$ & $\%$ & $\mathbf{N}$ & $\%$ & $\mathbf{N}$ & $\%$ & & \\
\hline Peso ao & Baixo peso & 12 & 57,1 & 9 & 42,9 & 21 & 100.0 & 1.0 & \\
\hline \multirow[t]{2}{*}{ nascer } & Adequado & 51 & 33,1 & 103 & 66,9 & 154 & 100.0 & 0.371 & 0,056 \\
\hline & & & & & & & & $(0.147-0.939)$ & \\
\hline Tipo de & Normal & 30 & 33,7 & 59 & 66,3 & 89 & 100.0 & 1.0 & \\
\hline \multirow[t]{2}{*}{ parto* } & Outro & 33 & 38,8 & 52 & 61,2 & 85 & 100.0 & 1.248 & 0,586 \\
\hline & & & & & & & & $(0.672-2.318)$ & \\
\hline Duração & Prematuro & 7 & 50 & 7 & 50 & 14 & 100.0 & 1.0 & \\
\hline \multirow[t]{2}{*}{ gestação } & A Termo & 56 & 34,8 & 105 & 65,2 & 161 & 100.0 & 0.533 & 0,397 \\
\hline & & & & & & & & $(0.178-1.597)$ & \\
\hline Idade da & Jovem & 14 & 38,9 & 22 & 61,1 & 36 & 100.0 & 1.0 & \\
\hline \multirow[t]{2}{*}{ mãe } & Adulta & 49 & 35,3 & 90 & 64,7 & 139 & 100.0 & 0.856 & 0,833 \\
\hline & & & & & & & & $(0.402-1.820)$ & \\
\hline Escolaridade & Baixa & 29 & 34,9 & 54 & 65,1 & 83 & 100.0 & 1.0 & \\
\hline \multirow[t]{2}{*}{ da mãe } & Não baixa & 33 & 37,1 & 56 & 62,9 & 89 & 100.0 & 1.097 & 0,894 \\
\hline & & & & & & & & $(0.588-2.047)$ & \\
\hline Escolaridade & Baixa & 23 & 31,1 & 51 & 68,9 & 74 & 100.0 & 1.0 & \\
\hline \multirow[t]{2}{*}{ do pai" } & Năo baixa & 32 & 36,4 & 56 & 63,6 & 88 & 100.0 & 1.267 & 0,589 \\
\hline & & & & & & & & $(0.657-2.443)$ & \\
\hline Estado & Baixo peso & 2 & 33,3 & 4 & 66,7 & 6 & 100.0 & 1.0 & \\
\hline \multirow[t]{4}{*}{ nutricional } & Normal & 55 & 34,4 & 105 & 65,6 & 160 & 100.0 & 1.048 & 0,144 \\
\hline & & & & & & & & $(0.186-5.900)$ & \\
\hline & Peso alto & 6 & 66,7 & 3 & 33,3 & 9 & 100.0 & 4.0 & \\
\hline & & & & & & & & $(0.447-35.789)$ & \\
\hline
\end{tabular}

Não houve associação estatisticamente significativa entre as variáveis independentes e o consumo de feijão 
Optou-se por manter nos modelos apenas a variável independente idade.

Os parâmetros da regressão logística para o consumo de carnes e feijão estão na tabela 30 .

Tabela 30 - Resultados da regressão logística para consumo de carnes e feijão. São Paulo, 1998.

\begin{tabular}{cccc}
\hline Variável dependente & $\beta$ constante & $\beta$ idade & $p$ \\
& (EP) & (EP) & \\
\hline carnes & $-4,9684$ & 0,0246 & $<0,001$ \\
& $(0,713)$ & $(0,0037)$ & \\
feijão & $-4,6480$ & 0,0250 & $<0,001$ \\
& $(0,6664)$ & $(0,0037)$ & \\
\hline
\end{tabular}

A prevalência de consumo de carnes ajustado pela idade foi estimada a partir da equação:

$$
\operatorname{Prob}(Y=1)=P=\frac{1}{1+e^{-(-4,9684+0,024 \text { Gdade })}}
$$

A prevalência de consumo de feijão ajustada pela idade foi estimada a partir da equação:

$$
\operatorname{Prob}(Y=1)=P=\frac{1}{1+e^{-(-4,6480+0,0250 \text { idade })}}
$$


As curvas de prevalência de consumo de carnes e/ou ovos e feijão encontram-se na figura 11.

Figura 11 - Curvas de prevalência de consumo de cames e/ou ovos e feijão nos Centros de Saúde. São Paulo, 1998.

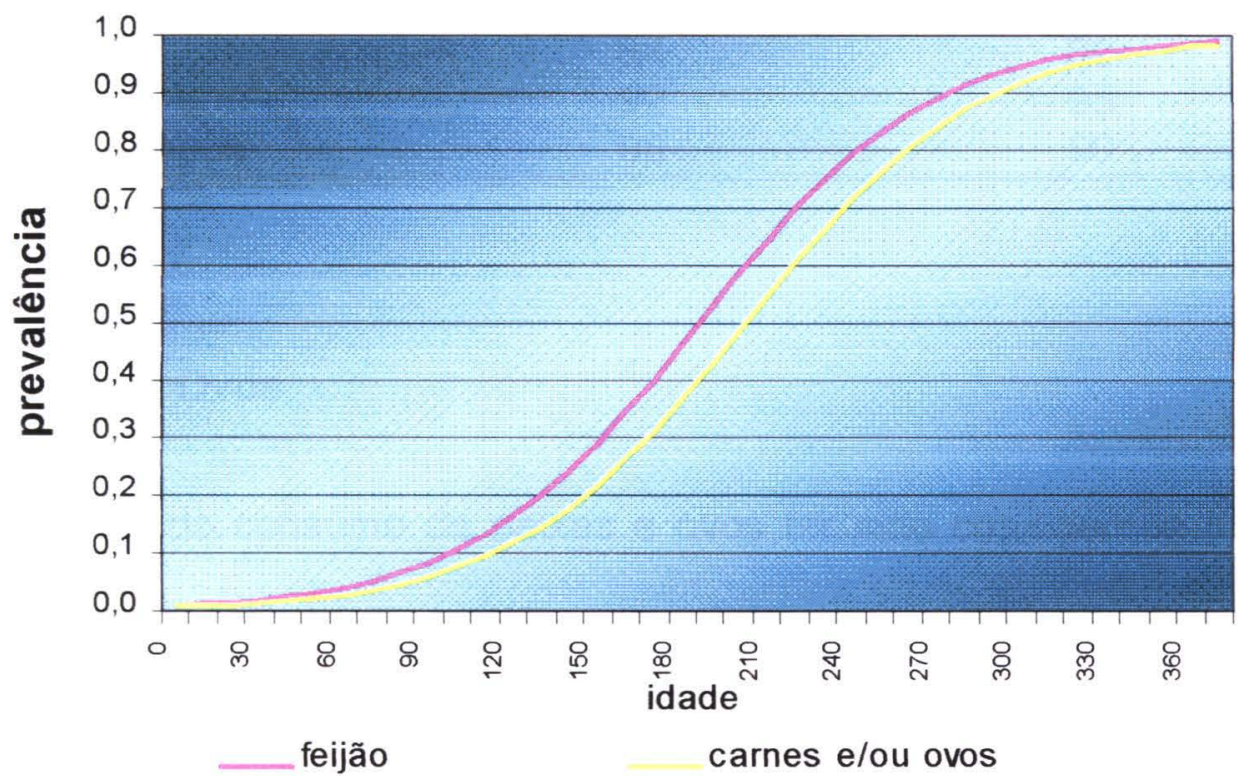

Os modelos estão bem ajustados $(p=0,420$ para o modelo com consumo de carnes elou ovos como variável dependente e $p=0,381$ para o modelo com consumo de feijão como variável dependente).

Ambas as curvas (figura 10) têm formato bastante semelhante. $O$ consumo começa a aumentar por volta do terceiro mês. Há uma ascensão mais lenta que no consumo de frutas, atingindo metade da população após o sexto mês. A tabela 31 mostra a prevalência de consumo após o $4^{\circ}$ mês até um ano. 
Tabela 31 - Prevalência de consumo de carnes e/ou ovos e feijão. São Paulo, 1998.

\begin{tabular}{ccc}
\hline $\begin{array}{c}\text { Idade } \\
\text { (dias) }\end{array}$ & $\begin{array}{c}\text { Carnes elou ovos } \\
\%\end{array}$ & $\begin{array}{c}\text { feijão } \\
\%\end{array}$ \\
\hline 120 & 12 & 16 \\
150 & 22 & 29 \\
180 & 37 & 46 \\
210 & 55 & 65 \\
240 & 72 & 79 \\
270 & 84 & 89 \\
300 & 92 & 95 \\
365 & 98 & 99 \\
\hline
\end{tabular}

\subsection{Peixes e Ovos}

Apesar do consumo de peixes e ovos ter sido considerado juntamente com o grupo de alimentos protéicos, por tratar-se de alimentos com elevada alergenicidade, verificou-se isoladamente o consumo dos mesmos. A distribuição das crianças segundo as variáveis podem ser observadas nas tabelas 32 e 33 . 
Tabela 32 - Distribuição do número e porcentagem das crianças segundo consumo de peixes e demais variáveis de estudo. São Paulo, 1998.

\begin{tabular}{|c|c|c|c|c|c|c|c|c|c|}
\hline \multirow[b]{3}{*}{ Variável } & \multirow[b]{3}{*}{ Categoria } & \multicolumn{6}{|c|}{ Consumo de peixes } & \multirow{3}{*}{$\begin{array}{c}\text { OR } \\
\left(\mathrm{IC}_{95 \%}{ }^{(\mathrm{OR})}\right)\end{array}$} & \multirow[b]{3}{*}{$p$} \\
\hline & & \multicolumn{2}{|c|}{ Sim } & \multicolumn{2}{|c|}{ Não } & \multicolumn{2}{|c|}{ Total } & & \\
\hline & & $\mathbf{N}$ & $\%$ & $\mathbf{N}$ & $\%$ & $\mathbf{N}$ & $\%$ & & \\
\hline Peso ao & Baixo peso & 3 & 14,3 & 18 & 85,7 & 21 & 100.0 & 1,0 & \\
\hline nascer & Adequado & 15 & 9,7 & 139 & 90,3 & 154 & 100.0 & $\begin{array}{c}0,647 \\
(0,171-2,456)\end{array}$ & 0,795 \\
\hline Tipo de & Normal & 11 & 12,4 & 78 & 87,6 & 89 & 100.0 & 1,0 & \\
\hline parto* & Outro & 7 & 8,2 & 78 & 9,8 & 85 & 100.0 & $\begin{array}{c}0,636 \\
(0,235-1,727)\end{array}$ & 0,520 \\
\hline Duração & Prematuro & 3 & 21,4 & 11 & 78,6 & 14 & 100.0 & 1,0 & \\
\hline gestação & A Termo & 15 & 9,3 & 146 & 90,7 & 16 & 100.0 & $\begin{array}{c}0,377 \\
(0,095-1,502)\end{array}$ & 0,331 \\
\hline Idade da & Jovem & 5 & 13,9 & 31 & 86,1 & 36 & 100.0 & 1,0 & \\
\hline mãe & Adulta & 13 & 9,4 & 126 & 90,6 & 139 & 100.0 & $\begin{array}{c}0,640 \\
(0,212-1,929)\end{array}$ & 0,624 \\
\hline Escolaridade & Baixa & 8 & 9,6 & 75 & 90,4 & 83 & 100.0 & 1,0 & \\
\hline da mãe $e^{\star \star}$ & Não baixa & 10 & 11,2 & 79 & 8,88 & 89 & 100.0 & $\begin{array}{c}1,187 \\
(0,445-3,168)\end{array}$ & 0,936 \\
\hline Escolaridade & Baixa & 8 & 10,8 & 66 & 89,2 & 74 & 100.0 & 1,0 & \\
\hline do pai ${ }^{i \star \star}$ & Não baixa & 8 & 9,1 & 80 & 90,9 & 88 & 100.0 & $\begin{array}{c}0,825 \\
(0,294-2,317)\end{array}$ & 0,919 \\
\hline Estado & Baixo peso & 2 & 33,3 & 4 & 66,7 & 6 & 100.0 & 1,0 & \\
\hline nutricional & Normal & 15 & 9,4 & 145 & 90,6 & 160 & 100.0 & $\begin{array}{c}0,207 \\
(0,035-1,225)\end{array}$ & 0,165 \\
\hline & Peso alto & 1 & 5,6 & 8 & 88,9 & 9 & 100.0 & $\begin{array}{c}0,250 \\
(0,017-3,660)\end{array}$ & \\
\hline
\end{tabular}

* excluido um indivíduo sem informação

** excluídos três indivíduos sem informação

** excluídos treze indivíduos sem informação 
Tabela 33 - Distribuição do número e porcentagem das crianças segundo consumo de ovos e demais variáveis de estudo. São Paulo, 1998.

\begin{tabular}{|c|c|c|c|c|c|c|c|c|c|}
\hline \multirow[b]{3}{*}{ Variável } & \multirow[b]{3}{*}{ Categoria } & \multicolumn{6}{|c|}{ Consumo de ovos } & \multirow{3}{*}{$\begin{array}{c}\text { OR } \\
\left(\mathrm{IC}_{95 \%}{ }^{(\mathrm{OR})}\right)\end{array}$} & \multirow[b]{3}{*}{ p } \\
\hline & & \multicolumn{2}{|c|}{ Sim } & \multicolumn{2}{|c|}{ Não } & \multicolumn{2}{|c|}{ Total } & & \\
\hline & & $\mathbf{N}$ & $\%$ & $\mathbf{N}$ & $\%$ & $\mathbf{N}$ & $\%$ & & \\
\hline Peso ao & Baixo peso & 7 & 33,3 & 14 & $\overline{66,7}$ & 21 & 100.0 & 1,0 & 0,059 \\
\hline \multirow[t]{2}{*}{ nascer } & Adequado & 22 & 14,3 & 132 & 85,7 & 154 & 100.0 & 0,333 & \\
\hline & & & & & & & & $(0,121-0,918)$ & \\
\hline Tipo de & Normal & 13 & 14,6 & 76 & 85,4 & 89 & 100.0 & 1,0 & 0,587 \\
\hline \multirow[t]{2}{*}{ parto* } & Outro & 16 & 18,8 & 69 & 81,2 & 85 & 100.0 & 1,356 & \\
\hline & & & & & & & & $(0,608-3,020)$ & \\
\hline Duração & Prematuro & 3 & 21,4 & 11 & 78,6 & 14 & 100.0 & 1,0 & 0,897 \\
\hline \multirow[t]{2}{*}{ gestação } & A Termo & 26 & 16,1 & 135 & 83,9 & 16 & 100.0 & 0,706 & \\
\hline & & & & & & & & $(0,184-2,707)$ & \\
\hline Idade da & Jovem & 5 & 13,9 & 31 & 86,1 & 36 & 100.0 & 1,0 & 0,815 \\
\hline \multirow[t]{2}{*}{ mãe } & Adulta & 24 & 17,3 & 115 & 82,7 & 139 & 100.0 & 1,294 & \\
\hline & & & & & & & & $(0,456-3,668)$ & \\
\hline Escolaridade & Baixa & 14 & 16,9 & 69 & 83,4 & 83 & 100.0 & 1,0 & 0,840 \\
\hline \multirow[t]{2}{*}{ da mãe $e^{\star \star}$} & Não baixa & 15 & 16,9 & 74 & 83,4 & 89 & 100.0 & 0,999 & \\
\hline & & & & & & & & $(0,449-2,221)$ & \\
\hline Escolaridade & Baixa & 11 & 14,9 & 63 & 85,1 & 74 & 100.0 & 1,0 & 0,871 \\
\hline \multirow[t]{2}{*}{ do pai" } & Não baixa & 15 & 17,0 & 73 & 83,0 & 88 & 100.0 & 1,177 & \\
\hline & & & & & & & & $(0,504-2,317)$ & \\
\hline Estado & Baixo peso & 3 & 50,0 & 3 & 50,0 & 6 & 100.0 & 1,0 & 0,073 \\
\hline \multirow[t]{4}{*}{ nutricional } & Normal & 25 & 15,6 & 135 & 84,4 & 160 & 100.0 & 0,185 & \\
\hline & & & & & & & & $(0,035-0,970)$ & \\
\hline & Peso alto & 1 & 11,1 & 8 & 88,9 & 9 & 100.0 & 0,125 & \\
\hline & & & & & & & & $(0,009-1,723)$ & \\
\hline
\end{tabular}

* excluído um indivíduo sem informaçăo

* excluídos três individuos sem informaçăo

*xcluídos treze indivíduos sem informação

Os parâmetros da regressão para os modelos de regressão logística para consumo de peixe e ovos estão na tabela 34 . 
Tabela 34 - Resultados da regressão logística para consumo de peixe e ovos. São Paulo, 1998.

\begin{tabular}{cccc}
\hline Variável dependente & $\begin{array}{c}\beta \text { constante } \\
\text { (EP) }\end{array}$ & $\begin{array}{c}\beta \text { idade } \\
\text { (EP) }\end{array}$ & $p$ \\
\hline Peixe & $-5,5553$ & 0,0170 & $<0,001$ \\
& $(0,9117)$ & $(0,0036)$ & \\
\multirow{2}{*}{ Ovos } & $-6,1447$ & 0,0230 & $<0,001$ \\
& $(0,9360)$ & $(0,0040)$ & \\
\hline
\end{tabular}

A prevalência de consumo de peixes, ajustado pela idade, foi estimada a partir da equação:

$$
\operatorname{Prob}(Y=1)=P=\frac{1}{1+e^{-(-5,5653+0,017 \text { dade })}}
$$

A prevalência de consumo de ovos, ajustada pela idade, foi estimada a partir da equação:

$$
\operatorname{Prob}(Y=1)=P=\frac{1}{1+e^{-(-6,1447+0,02301 d a d e)}}
$$

As curvas de prevalência de consumo de peixe e ovos se encontram na figura 12. 
Figura 12 - Curvas de prevalência de consumo de peixes e ovos nos Centros de Saúde. São Paulo, 1998.

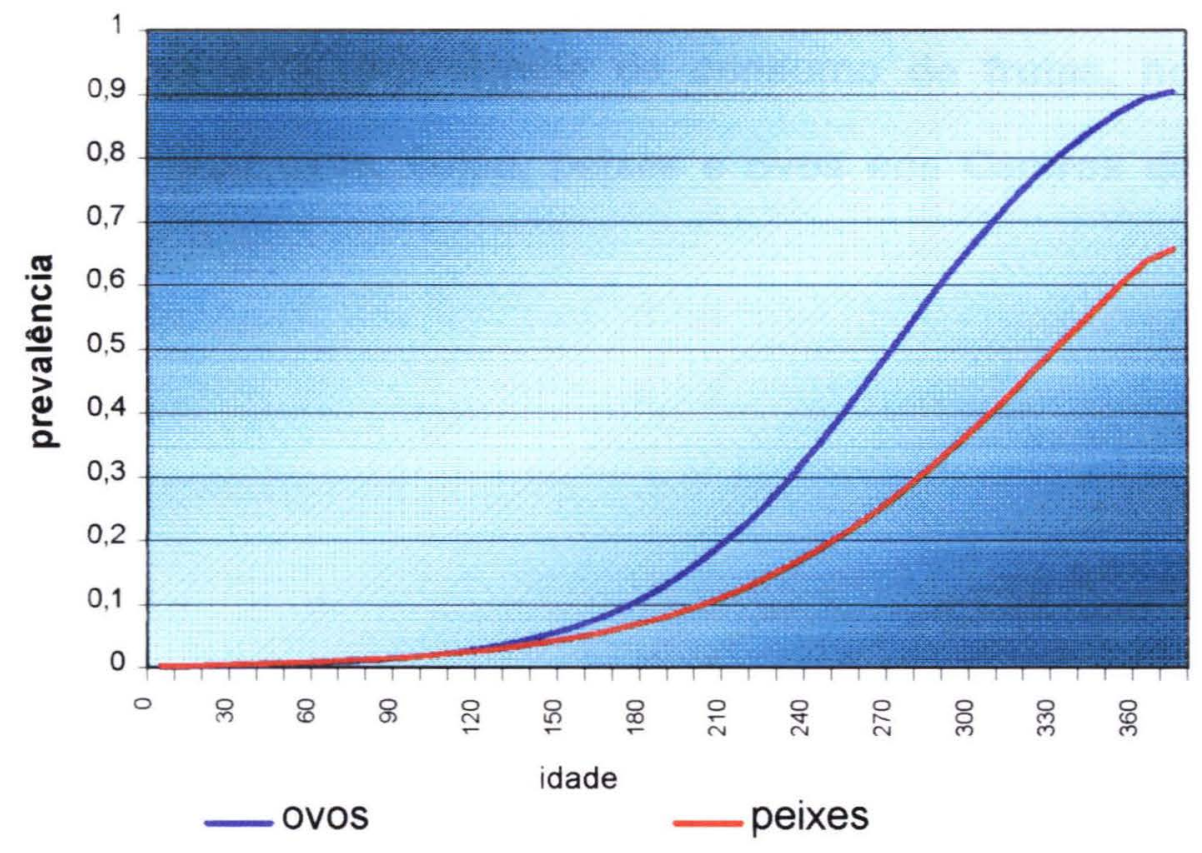

O modelo com consumo de peixes como variável dependente está bem ajustado ( $p=0,278)$. O modelo com consumo de ovo como variável dependente, no entanto, não se mostrou bem ajustado $(p=0,032)$, porém, não havia nenhuma outra variável independente (deste estudo) que melhorasse esse ajuste. Isso mostra que para o estudo dos fatores que influenciaram na introdução do ovo são necessárias outras variáveis.

Menos de $10 \%$ da população consomem ovo e peixe aos 6 meses de idade. O ovo é consumido por metade da população aos 7 meses, e ao final do primeiro ano, apenas $65 \%$ das crianças do estudo consomem peixe. 
A figura 13 apresenta as curvas de consumo dos alimentos analisados dispostas em conjunto.

Figura 13 - Curvas de prevalência de consumo de frutas, hortaliças, cereais, carnes e/ou ovos, feijão, peixes e ovos nos Centros de Saúde. São Paulo, 1998.

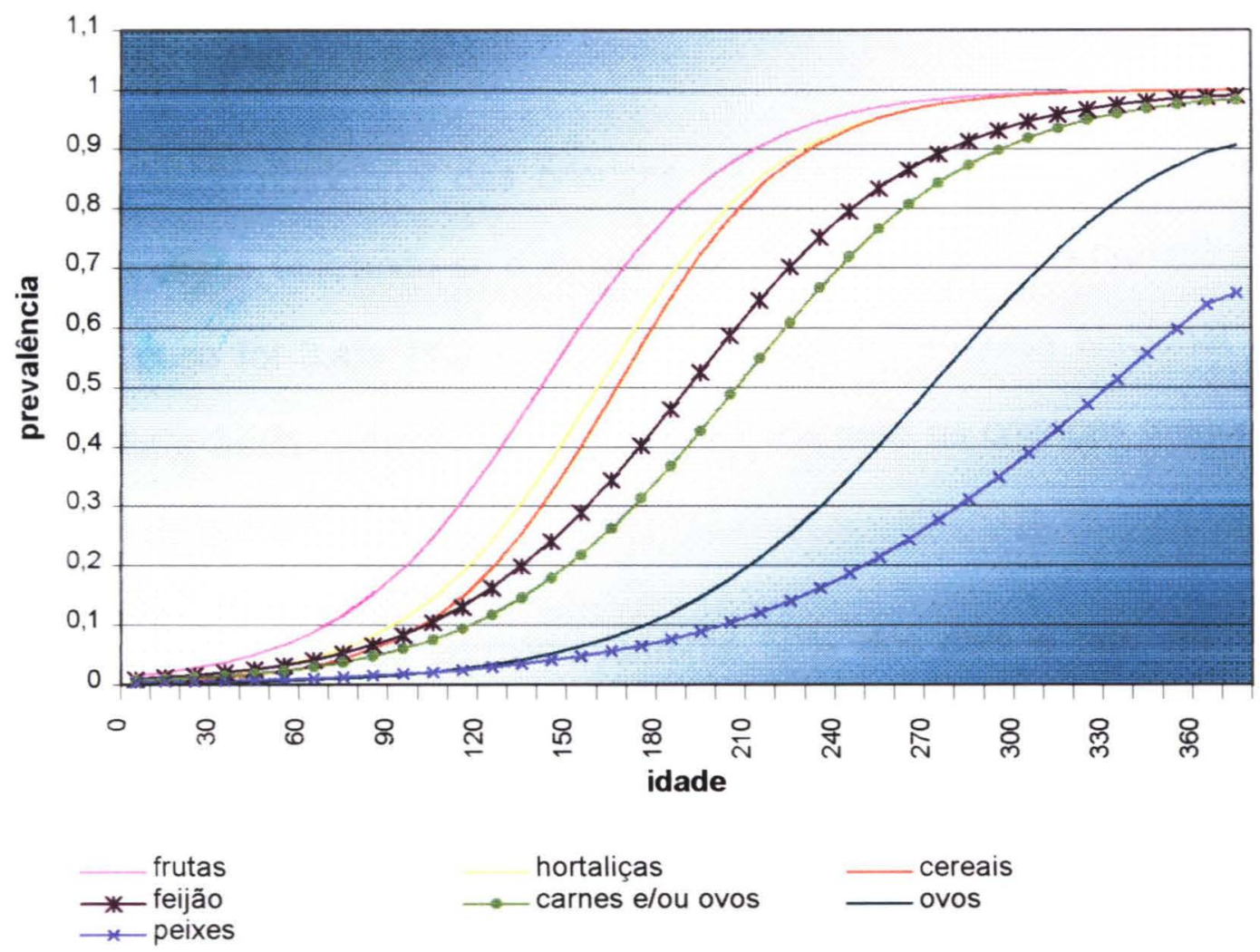




\section{DISCUSSÃO}

A população de estudo apresentou pequena predominância masculina. A maioria das crianças encontrava-se no primeiro semestre de vida (64\%). Apresentaram baixo peso ao nascer $11 \%$ das crianças da amostra, pouco acima da incidência de baixo peso de $9,2 \%$, verificada na Pesquisa Nacional em Demografia e Saúde de 1996 - PNDS -1996 (MONTEIRO 1996).

O estado nutricional das crianças foi classificado como normal em $91,4 \%$ dos casos, utilizando-se o escore $Z$ de peso para idade. A prevalência de baixo peso foi 3,4\% (<-2 escore Z). Dados da Pesquisa Nacional de Demografia e Saúde situam este índice em 2,3\% para as crianças menores de 5 anos (MONTEIRO 1996).

A escolaridade de aproximadamente $50 \%$ dos pais e das mães é baixa, até a quarta série do primeiro grau. Apenas $5 \%$ das mães e 2,5\% dos pais têm grau universitário. A população de estudo apresentou índices de escolaridade mais baixos que as médias observadas na população brasileira. Segundo dados do MINISTÉRIO DA SAÚDE, 1999, 35,2\% da população brasileira têm menos de 4 anos de estudo. Em São Paulo nessa situação estão $23,4 \%$ da população em geral e $20,2 \%$ da população da região metropolitana. 


\subsection{Consumo de alimentos}

Não há, até o momento, guias alimentares específicos para a população brasileira. A representação brasileira da OPAS/OMS apresentou o documento "Normas alimentares para crianças brasileiras menores de dois anos" (GIUGLIANI E VICTORA 1997), onde é reiterada a importância do aleitamento exclusivo, são fornecidas orientações sobre a alimentação complementar, bem como a densidade energética recomendada para a mesma. No entanto, não fornece as idades e as pautas de introdução dos alimentos.

Há poucos estudos de consumo alimentar na população infantil brasileira envolvendo amostras representativas da população que possam fornecer subsídios para a elaboração de guias alimentares. Está sendo desenvolvido com o apoio da OPAS/OMS/MS estudo multicêntrico com o objetivo de compor o Guia Alimentar.

Há dificuldade em comparar os dados do presente estudo com dados da literatura, em especial brasileira, devido à diferenças metodológicas e de delineamento. Os estudos nacionais e estaduais utilizam em geral como método de inquérito alimentar o recordatório de 24 horas. Este é um método retrospectivo, sujeito a erros de memória materna ou do responsável pela criança que responde a entrevista. A metodologia deste trabalho investiga a situação da criança no momento da entrevista, tendo como um dos pontos fortes ser menos susceptivel aos vícios citados (FERREIRA e CARDOSO 1996, RIOS e col.1992) 


\subsection{Aleitamento matemo exclusivo}

No presente estudo, evidencia-se a pouca adesão às recomendações da OPAS/OMS relativas ao periodo de amamentação exclusiva. Nas "Normas Alimentares para Crianças Brasileiras Menores de Dois Anos" o aleitamento exclusivo nos primeiros meses de vida é recomendado enfaticamente (GIUGLIANI e VICTORA 1997). A OMS recomenda que $100 \%$ das crianças sejam amamentadas exclusivamente até o quarto mês de vida (RÉA 1998).

A amamentaçăo exclusiva é pouco praticada em ambos os Centros de Saúde. No entanto, observou-se associação positiva, estatisticamente significativa, $(p=0,018)$ entre aleitamento materno exclusivo e o Centro de Saúde Periferia. Desde o início da vida, a prevalência estimada para o aleitamento materno exclusivo foi maior no CS Periferia (65\%) em relação ao CS Central (40\%), sendo que esta diferença manteve-se em todo o primeiro ano de vida.

A prevalência estimada para o aleitamento materno exclusivo aos quatro meses de idade, nas crianças com mães com escolaridade baixa, foi semelhante ao relatado por VENÂNCIO, 1996. A autora, por meio da análise de probitos, utilizando dados da Pesquisa Nacional sobre Saúde e Nutrição PNSN/89, verificou que apenas $17 \%$ das crianças brasileiras eram amamentadas exclusivamente aos 4 meses e apenas $6 \%$ aos seis meses. Segundo FERREIRA e CARDOSO, 1996, tanto a regressão logística quanto 
a regressão de probitos tendem a produzir resultados similares, o que favorece portanto a comparação dos resultados entre os estudos.

FERREIRA e colaboradores, 1995, em estudo realizado em um Centro de Saúde de Santo André, região metropolitana do estado de São Paulo, estimaram por regressão de probitos que somente $14,4 \%$ das crianças eram amamentadas exclusivamente aos 120 dias de idade, resultado semelhante ao obtido no CS Central. Aos 180 dias em Santo André a prevalência estimada foi de $4,0 \%$, menor que a estimada para ambos os Centros.

SANTOS e colaboradores, 1998, em estudo realizado em Florianópolis com amostra de 1011 crianças usuárias de postos de vacinação da cidade, conforme proposta de MONTEIRO e colaboradores, 1998, utilizando a análise de regressão de probitos, estimaram em 10,5\% a prevalência do aleitamento materno exclusivo na idade de 6 meses.

VASCONCELOS e colaboradores, 1998, em estudo realizado em João Pessoa, utilizando a proposta de Monteiro e colaboradores, 1998, com crianças usuárias de postos de vacinação da cidade, utilizando a análise de regressão de probitos, estimaram em $4,6 \%$ a prevalência do aleitamento materno exclusivo na idade de 6 meses.

Segundo dados do PNDS-1996, o indicador da prática de aleitamento materno exclusivo, calculado como a proporção de crianças menores de quatro meses de idade cujas mães informaram que o único alimento dado à criança nas últimas 24 horas era o leite materno, foi de 39\% (MONTEIRO 
1996), acima portanto do observado nesta pesquisa. A diferença na metodologia utilizada dificulta a comparação entre as prevalências.

Para aleitamento materno exclusivo, consumo de leite não materno e consumo de água ou chá não se verificou associação com escolaridade materna, escolaridade paterna e idade materna. No entanto, apesar de não significativa estatisticamente, as mães com escolaridade não baixa apresentam taxas mais elevadas que as mães com escolaridade baixa, principalmente até o terceiro mês. Também as prevalências de consumo de leite não matemo até 2 meses de idade e de água ou chá, até 4 meses, são maiores para as crianças cujas mães tem baixa escolaridade.

O Índice de Descontinuidade cumulativo para amamentação exclusiva diferiu dos obtidos por FERREIRA e CARDOSO, 1996, em estudo realizado em Centro de Saúde de Santo André, com amostra de 2411 crianças, calculado por regressão de probitos, aproximando-se dos índices obtidos por SILVA e colaboradores, 1995, em Cuba (tabela 35). 
Tabela 35 - Comparação entre os Índices de Descontinuidade cumulativos para aleitamento materno exclusivo de 0 a 30,60120 e 180 dias de idade nos Centros de Saúde. São Paulo, Santo André e Cuba 1998.

\begin{tabular}{ccccc}
\hline \multirow{2}{*}{$\begin{array}{c}\text { Periodo } \\
\text { (dias) }\end{array}$} & \multicolumn{4}{c}{$\begin{array}{l}\text { Indice de Descontinuidade } \\
\%\end{array}$} \\
\cline { 2 - 5 } & Central & Periferia & $\begin{array}{c}\text { Santo } \\
\text { André }\end{array}$ & Cuba $^{* *}$ \\
\hline $0-30$ & 21,6 & 13,7 & 51,3 & 21,4 \\
$0-60$ & 40,3 & 28,1 & 64,6 & 37,8 \\
$0-120$ & 68,0 & 55,1 & 85,6 & 74,9 \\
$0-180$ & 83,9 & 75,0 & 96,0 & 90,6 \\
\hline
\end{tabular}

Fonte *FERREIRA E CARDOSO, 1996; "*SILVA e col., 1995.

Os menores índices de descontinuidade foram observados no CS Periferia: aos 120 dias, $55 \%$ das crianças que haviam iniciado a amamentação de forma exclusiva haviam abandonado esta forma de alimentação, em comparação com $68 \%$ no CS Central, $86 \%$ em Santo André (FERREIRA e CARDOSO 1996) e 74,9\% em Cuba (SILVA e col. 1995).

Os resultados apresentados permitem concluir que a amamentação exclusiva não é prática adotada na população de estudo. 


\subsection{Aleitamento Materno}

O aleitamento materno neste estudo mostrou associação positiva, estatisticamente significativa, com escolaridade materna $(p<0,05)$. As curvas de prevalência para o consumo de leite materno nas duas categorias de escolaridade mostram-se praticamente paralelas em todo o intervalo do primeiro ano, mantendo uma diferença de aproximadamente $20 \%$ após os 120 dias, sempre com as taxas mais baixas nas crianças com mães de escolaridade baixa. Estes resultados estão de acordo com a hipótese da OMS. Segundo este órgão, o retorno à amamentação seria desencadeado por mulheres da área urbana, com maior poder aquisitivo e maior escolaridade. (WHO 1982).

VENÂNCIO, 1996, observou que as taxas de amamentação no Brasil cresceram em duas décadas (79-89) entre as mulheres com maior grau de escolaridade. A autora, verificou que aos 4 meses de idade da criança, $58 \%$ das mães com escolaridade entre 1 e 4 anos, e $57 \%$ das mães com escolaridade maior que 4 anos amamentavam; aos 6 meses, $51 \%$ na primeira categoria e $47 \%$ na segunda. Aos 12 meses $40 \%$ na primeira e $32 \%$ na segunda. Os valores obtidos no presente estudo mostram maiores taxas de amamentaçăo aos quatro meses $(65 \%$ e $83 \%)$ e aos 6 meses $(56 \%$ e $77 \%$ ) em ambas as categorias de escolaridade, quando comparado com os dados obtidos por VENÂNCIO, 1996.

BARBER e colaboradores, 1997, em estudo na cidade de Toronto, Canadá, para determinar o início e a duração do aleitamento matemo em 
uma amostra probabilística de 432 mães, observaram que a duração do aleitamento estava relacionada à educação, paridade, informação e suporte, uso de fórmulas infantis e país de nascimento.

BOURGOIN e colaboradores, 1997, em estudo no Canadá, observaram que os fatores que influenciaram positivamente a duração do aleitamento materno foram: maior escolaridade, maior renda, paridade, experiência prévia na amamentação, decisão prévia em amamentar e introdução tardia de sólidos.

Estes resultados destoam da tendência verificada por PÉREZESCAMILLA, 1993, em estudo realizado com o objetivo de comparar os padrões de aleitamento materno em nove países da América Latina e Caribe, utilizando dados de inquéritos de demografia e saúde realizados entre 1984 e 1988. As mães com escolaridade mais baixa amamentaram por mais tempo seus filhos na Guatemala, Bolívia, Peru, Equador, Colômbia, México, Trinidad Tobago, República Dominicana e Brasil.

Neste estudo, o declínio do início da curva até o final dos 12 meses não é abrupto. Ao final do primeiro ano, estimou-se que metade das mulheres de escolaridade não baixa continuavam amamentando seus filhos. Tal fato parece denotar uma valorização da prática da amamentação, que contrasta com a baixa adesão à amamentar as crianças de forma exclusiva. Parece, portanto, ser importante amamentar, mas sem deixar de fornecer precocemente outros alimentos. 


\subsection{Leite nåo materno}

Desde o início da vida, a prevalência estimada para o consumo de leite não matemo foi elevada. Maior prevaléncia de consumo foi observada no CS Central. Isto foi verificado em praticamente metade da população estudada naquela localidade e na categoria de escolaridade baixa (37\%), apesar de, neste caso, a diferença não ter sido significativa estatísticamente.

Apesar das recomendaçōes atuais contrárias à introduçăo do leite de vaca integral no primeiro ano de vida (ARREGUÍN 1994, CABALLERO e col. 1994, PALMA e col. 1998), esta pratica foi comum. Das crianças que não estavam em aleitamento materno exclusivo, apenas $21,7 \%$ estavam recebendo fórmula láctea no momento da pesquisa., sendo que o restante, $78,3 \%$, estava recebendo leite de vaca integral.

Deve-se enfatizar que no primeiro ano de vida, o leite, incluindo o leite de peito ou fórmula, deve ser o principal líquido dado à criança (LILLY 1995). Nas recomendaçōes atuais, quando é impossivel amamentar a criança com leite de peito, devem ser utilizados sucedâneos com alto valor nutritivo, que possam ser absorvidos e utilizados pelo lactente sem causar-lhe dano e que sejam preparados higienicamente. A primeira opção seria a fórmula láctea, baseada no leite de vaca integral modificado e fortificado. $O$ leite de vaca tem uma concentração excessiva de proteínas, cálcio, fósforo e sódio, e é deficiente em vitaminas C, D e E, niacina e ácidos graxos essenciais; o ferro e o zinco, além de presentes no leite de vaca em pequenas quantidades, são menos biodisponiveis que no leite humano Quando as fórmulas 
comerciais não são acessíveis, a segundo opção é a modificação o leite de vaca, diluindo-o na proporção de um terço de água para $2 / 3$ de leite de vaca integral, e adicionando $7 \%$ de açúcar e 3\% de óleo vegetal para restituir a densidade energética (CABALLERO e col. 1994).

No documento "La alimentación del niño de 6 años en América Latina" (CABALLERO e col. 1994), elaborado para fornecer bases para o desenvolvimento de guias de alimentação na América Latina, é feita a recomendação para que os sistemas de saúde e as organizações não governamentais utilizem, em seus programas de alimentação, fórmulas lácteas enriquecidas com vitaminas A, C, D e E, ferro, zinco e ácidos graxos essenciais.

VICTORA e colaboradores, 1989, em estudo de caso-controle desenvolvido no sul do Brasil, observaram que crianças que recebiam leite de vaca em adição ao leite de peito tinham 4,2 vezes mais risco de morrer de diarréia comparado com crianças que não recebiam leite não materno. 0 consumo de água ou chá também elevou o risco de morte devido à diarréia. A diarréia é o maior problema de saúde pública para crianças, tanto em países desenvolvidos quanto em desenvolvimento. Estimam-se mais de 500 milhões de casos de diarréia no mundo todo (NEWBURG e STREET,1997). No Brasil, ainda é a segunda causa de mortalidade infantil (GIUGLIANI e VICTORA, 1997). É bastante conhecido o efeito protetor do leite materno contra diarréia (POPKIN e col. 1997, BROWN e col. 1997). 
No Brasil, um dos fatores responsáveis pelo declínio da amamentação, juntamente com a urbanização e a entrada da mulher no mercado de trabalho, foi a entrada da indústria de leite em pó e a propaganda destes produtos, por meio de estratégias de marketing que visavam atingir os profissionais de saúde além do público em geral. (ZUNIGA e MONTEIRO 1995, RÉA 1990, PATARRA 1995, GOLDEMBERG 1989.). Somente a partir da década de 70 , consonante com o movimento mundial pró-amamentação, o governo brasileiro passou a ver no aleitamento materno uma forma de proteger a saúde das crianças e de declinar as altas taxas de mortalidade infantil no país. (VENÂNCIO 1996). Em 1981 foi criado - Programa Nacional de Incentivo ao Aleitamento Materno (PNIAM), que atua através de campanhas na mídia, produção e distribuição de material educativo, apoio técnico aos bancos de leite, apoio à pesquisa e estudos ligados ao tema, além de promover a articulação entre órgão governamentais e não governamentais (MONSON 1991).

\section{5. Água ou chá}

Estudos mostram que a complementação do leite materno com líquidos não nutritivos como água ou chás nos primeiros seis meses é desnecessária sob o ponto de vista biológico, inclusive em dias quentes e secos (STINA e ALMROTH 1978, GOLDBERG e ADAMS 1983, SACHDEV e col. 1991). Além disso, essa prática interfere no volume do leite materno (DREWETT e col. 1993, SACHEDEV e col. 1991) e pode interferir na 
biodisponibilidade de nutrientes existentes no leite materno (OSKI e LANDAW 1980, BELL e col. 1987).

Após o sexto mês, outros líquidos que contenham carboidratos simples ou complexos, devem ser dados somente nas horas das refeiçōes, devido ao risco à saúde dental, devendo ser evitado a utilizaçăo de mamadeiras, em especial na hora de dormir (LILLY 1995).

Neste trabalho, observou-se o consumo de água ou chá desde o início da vida. Apesar de não haver associação estatisticamente significativa entre escolaridade e consumo de água ou chá, as taxas de prevalência de consumo são mais elevadas nas crianças cujas mães têm escolaridade mais baixa.

O consumo precoce de chá observado neste estudo é consistente com o observado por TABAl e colaboradores, 1998. Os autores, em pesquisa sobre aleitamento e prática de desmame em comunidades rurais de Piracicaba, observaram que os chás foram introduzidos antes dos dois meses de idade em $75 \%$ das crianças do estudo.

Evidencia-se a popularidade que os chás gozam em nosso meio. Creditam-se propriedades calmante ou laxativas a tais produtos. Dessa forma, a criança recebe um alimento de baixa densidade nutricional, em geral por meio de mamadeiras, iniciando-se o contato pouco desejável com os bicos de borracha e com alimentos que podem, potencialmente, ser veículos de microrganismos, quando preparados sem os devidos cuidados higiênicos. 


\subsection{Alimentos complementares}

Neste estudo, o primeiro alimento sólido complementar ao leite, materno ou outros, a figurar na dieta da criança foi a fruta, seguindo-se hortaliças, cereais, leguminosas, carnes, e por último, os ovos e peixes, contrariando as recomendaçōes da OMS.(WHO 1988). Evidenciou-se uma rápida incorporação das frutas, hortaliças e cereais na dieta infantil no periodo de 4 a 6 meses

Resultados semelhantes foram observados por TABAI e colaboradores, 1998, na zona rural do estado de São Paulo: inicio do consumo de frutas entre os 2 e 4 meses ( $43,6 \%$ das crianças); entre 4 a 6 meses houve introdução de cereais e legumes, para respectivamente $38,2 \%$ e $36,4 \%$, e de carne entre 6 a 12 meses em $38,2 \%$.

Estes resultados diferem dos verificados por Souza, 1994, em pesquisa realizada em 4 Centros de Saúde do município de São Paulo: o primeiro alimento a ser introduzido na dieta infantil além do leite foi a fruta, seguindo-se as carnes, legumes, gema e feijão.

Para os alimentos fontes de proteína e ferro (carnes e feijão), as estimativas de prevalência de consumo observadas no presente estudo foram baixas, denotando uma incorporação tardia destes alimentos na dieta infantil: as carnes são consumidas por metade das crianças somente por volta do sétimo mês, chegando próximo a $100 \%$ ao final do primeiro ano. 0 feijão é consumido por $80 \%$ das crianças no oitavo mês e, à semelhança das carnes, somente ao final do primeiro ano é consumido por praticamente 
todas as crianças. Estes resultados são consistentes com os obtidos por MONTEIRO e SZARFARC, 1988, que verificaram que a carne e o feijāo aparecem de modo sistemático na dieta das crianças do município de São Paulo somente após um ano de idade.

Da mesma forma, TUDISCO e colaboradores, 1988, verificaram que o consumo de cereais e feculentos é prática comum em quatro capitais brasileiras estudadas (São Luiz, Salvador, Rio de Janeiro e São Paulo), observando no entanto baixa frequência de consumo de carnes e hortaliças.

Observou-se que o leite de vaca teve importante participação como fonte protéica no primeiro ano de vida, já que as carnes e ovos foram incorporados à dieta da maioria das crianças somente ao final deste período. Dessa forma, os alimentos fontes de ferro biodisponível até esta idade foram escassos. Segundo UNDERWOOD, 1997, quando o leite de vaca predomina na alimentação infantil, a deficiência de ferro é um risco considerável.

É notável como na população estudada predomina a precocidade de consumo de alimentos sólidos. Estes resultados são consistentes com os observados em outros estudos. PRADO e colaboradores, 1995, observaram que na região do semi-árido baiano os alimentos complementares são introduzidos já nos primeiros dias de vida, por meio do fornecimento de uma papa feita com farinha de mandioca e sebo de boi. SILVA e colaboradores, 1993, verificaram que em Cuba, $94,7 \%$ das crianças tomavam suco aos 120 dias e 96,4\% consumiam carne aos 180 dias. NOTZON, 1984, refere tendências de precocidade de consumo da alimentação complementar no 
Caribe, América Central, África e alguns países da Ásia. Diferem, no entanto, do observado em Vancouver, Canadá, por WILLIANS e colaboradores, 1996, onde a introdução dos alimentos ocorre entre o quarto e sexto mês, conforme a pauta recomendada pelo Comitê de Nutrição da Sociedade Canadense de Pediatria. As autoras creditam o fato à orientação dos profissionais de saúde.

GREINER, 1995, alerta para o fato de que as mães raramente são orientadas em como realizar a complementação, sem que, não intencionalmente, ocorra a substituição do leite materno em decorrência do fornecimento à criança de quantidades elevadas de comida e bebida, que levam à diminuição da ingestão do leite materno.

O fato de ter sido verificado neste estudo que o primeiro alimento a complementar o leite é a fruta, pode ser indicativo da complementação estar sendo realizada com alimentos de baixa densidade energética, como os sucos de fruta e papas de legumes, ocorrendo a substituição do leite, materno ou não, por alimentos de menor valor nutricional. Tal ocorrência contraria a recomendação das Normas Alimentares para crianças brasileiras menores de 2 anos (GIUGLIANI \& VICTORA, 1997), segundo a qual sucos de frutas ou vegetais e sopas são desaconselhados, por possuirem baixa densidade energética.

Para que as crianças supram suas necessidades energéticas, os alimentos complementares devem ter uma densidade energética mínima de $0,7 \mathrm{kcal} / \mathrm{g}$ (GIUGLIANI \& VICTORA, 1997). 
MONTEIRO E SZARFARC, 1988, observaram que, na faixa etária de 6 a 12 meses, $46 \%$ das dietas não atingiam as recomendações de energia. TUDISCO e colaboradores, 1988, verificaram inadequação energética em $34 \%$ das dietas nas crianças de 6 a 8 meses e $41 \%$ nas de 9 a 11 meses.

Entretanto, EGASHIRA, 1998, verificou em São Paulo, que a densidade energética média da alimentação para crianças de 6 a 11 meses foi de $0,94 \mathrm{kcal} / \mathrm{g}$. A autora conclui que as preparações lácteas influenciaram de modo importante a densidade energética das dietas analisadas, em especial devido ao uso de açúcar e espessantes adicionados ao leite em pó e fluido.

Pode-se contrapor que, apesar dos resultados satisfatórios quanto à média da densidade energética na população de São Paulo estudada por EGASHIRA, 1998, busca-se na atualidade a complementação do leite materno por alimentos variados, e não sua substituição por mamadeiras engrossadas e adoçadas. Em São Paulo, a autora observou que $58 \%$ das preparações lácteas fornecidas para os menores de dois anos utilizavam espessantes. Neste estudo, os espessantes foram utilizados por pouco menos da metade das crianças. Poder-se-ia especular que a outra metade, que não utiliza espessantes, não atinge as recomendaçōes de energia para a faixa etária estudada.

O MINISTÉRIO DA SAÚDE, 1998, por meio da portaria $n^{\circ} 34$ de 13/01/98, fixou em $0,7 \mathrm{kcal} / \mathrm{g}$ a densidade energética mínima do produto industrializado pronto para o consumo destinado à substituir a refeição 
principal para as crianças de 0 a 3 anos de idade. É interessante notar que, neste mesmo regulamento, é fixada a idade mínima de 10 meses para o uso de clara de ovo e de 9 meses para cacau, não se fazendo distinção de idade para peixes

Os alimentos que, com maior freqüência, provocam reações de intolerância são o leite de vaca, os ovos, o trigo e o pescado. Quase a metade dos casos de alergia alimentar na infância ocorrem no primeiro ano de vida. (LESSOF 1996). CABALLERO e colaboradores, 1994, sugerem que não sejam dados clara de ovo e pescado antes do oitavo mês, ou não antes dos 12 meses para crianças com antecedentes atópicos. Para a Sociedade de Pediatria de São Paulo, o ovo e outros alimentos potencialmente alergênicos só devem ser evitados após os seis meses em casos de história familiar de atopia (PALMA e col 1998). No presente estudo, nota-se que estes alimentos são os últimos a serem incorporados à dieta, assim mesmo, no final do primeiro ano, $10 \%$ das crianças não consomem ovos e $34 \%$ não consomem pescado.

Apesar das evidências da relação entre prática alimentar no primeiro ano de vida, em especial o aleitamento materno, com variáveis como idade, escolaridade e renda (GABRIEL e col. 1986, PÉREZ ESCAMILLA 1993), neste estudo, somente o aleitamento materno apresentou associação estatisticamente significativa com escolaridade materna. Para as outras formas de aleitamento, bem como para o consumo de alimentos complementares, não se observou tal associação. Também BROWN e 
colaboradores, 1989, em estudo realizado no Peru, não verificaram associação entre variáveis sócio-econômicas e alimentação praticada pelas crianças menores de um ano. 


\section{CONCLUSÕES}

Os resultados obtidos permitem as seguintes conclusões:

- As populações nos Centros de Saúde estudados foram semelhantes quanto ao sexo, distribuição etária, escolaridade paterna e materna e idade materna.

- O aleitamento materno apresentou associação positiva com escolaridade materna, sendo que, em crianças cujas mães tem escolaridade baixa, a prevalência do aleitamento materno aos quatro meses foi de $65 \% \mathrm{e}$ aos 6 meses foi de 56\%. Para as crianças de mães com escolaridade não baixa foi de $83 \%$ aos quatro meses e de $77 \%$ aos seis meses.

- O aleitamento materno exclusivo não apresentou associação com escolaridade materna. No entanto, mães com escolaridade baixa apresentaram menores taxas: $16 \%$ aos quatro meses e $8 \%$ aos seis meses, comparado com mães com escolaridade não baixa: $27 \%$ e $15 \%$ aos quatro e seis meses respectivamente.

- O aleitamento materno exclusivo apresentou associação com localidade, sendo que as maiores taxas foram observadas no Centro de Saúde localizado na periferia do municipio de São Paulo.

- O consumo de leite não materno foi de $100 \%$ aos quatro meses de idade em ambas as categorias de escolaridade estudadas. 
- Verificou-se que o primeiro alimento sólido complementar a fazer parte da dieta infantil foram as frutas, seguindo-se as hortaliças, cereais, carnes e/ou ovos e feijão.

- Evidenciou-se a introdução precoce de alimentos complementares. Aos quatro meses de idade, estimou-se que $38 \%$ das crianças do estudo consumiam frutas, $24 \%$ consumiam hortaliças e $20 \%$ consumiam cereais.

- Os alimentos fonte de proteína animal (carnes e ovos) entram mais tardiamente na alimentação infantil. No sétimo mês são consumidos por $50 \%$ das crianças, sendo que o consumo chega próximo a $100 \%$ somente ao final do primeiro ano.

- A complementação do leite materno com alimento sólidos, iniciase com alimentos de baixa densidade calórica, contrariando as recomendações para crianças brasileiras.

- Não foi observada associação entre o consumo de alimentos complementares e escolaridade dos pais, idade materna, nem tampouco com peso ao nascer, tempo de gestação, tipo de parto e estado nutricional da criança. 


\section{CONSIDERAÇÕES FINAIS}

Os dados apresentados mostram uma valorização do aleitamento materno em especial na população que tem maior escolaridade, já que estimou-se que de 4 mulheres nesta categoria três continuam amamentando seus filhos aos 6 meses de idade. Ao mesmo tempo, apenas $30 \%$ amamentam de forma exclusiva aos quatro meses de idade da criança, mostrando baixa adesão ao aleitamento exclusivo. Faz-se necessário promover esta prática, pois numerosos estudos mostram que a introdução de alimentos precocemente aumenta a morbidade e mortalidade infantil. (PLANK e MILANESE 1973, MARTELL 1981, KOVAR e col. 1984, VICTORA e col. 1987, MONTEIRO 1988, BECKER e col. 1991, SILVA e col. 1993, CABALLERO e col. 1994, CHAVES e col. 1995, LANTING e BOERSMA 1996).

As populações de estudo mostraram-se semelhantes com relação às características sócio-econômicas estudadas, e, no entanto, diferenças importantes foram observadas quanto à prática do aleitamento materno exclusivo e consumo de leite não materno nas duas localidades. É possivel que tal fato possa ser creditado a outras variáveis que não foram objeto de investigação neste estudo, tais como participação da comunidade, trabalho educativo, integração da equipe de saúde e desta com a comunidade.

O estudo das causas das diferenças observadas nos dois Centros de Saúde estudados, com maiores estimativas de aleitamento materno exclusivo e menores de consumo de leite não materno no CS Periferia, 
poderia contribuir para implementar ações que pudessem fornecer resultados semelhantes em outras unidades básicas de saúde.

Paralelamente ao incentivo à prática do aleitamento exclusivo, o consumo de leite não materno no primeiro ano de vida deve ser desencorajado. Nos casos em que a mãe não puder amamentar, e puder arcar com os custos, a opção seria a fórmula láctea. Se esta for inacessível, pode-se orientar a mãe quanto ao fornecimento do leite de vaca integral modificado domesticamente, ou seja, diluído e com acréscimo de carboidratos e lipídios. Neste estudo, observou-se que quando a criança já não está em amamentação exclusiva, o leite de vaca integral, fluido ou em pó, é o leite consumido na maioria dos casos (78\%).

A complementação do leite, materno ou outro, ao contrário do observado neste estudo, deve iniciar-se com uma mistura de cereais e alimentos fontes de proteína, adicionados de hortaliças. Deve-se manter a densidade energética da dieta igual ou superior à $0,7 \mathrm{kcal} / \mathrm{g}$. As frutas podem ser dadas na forma de sucos ou purês a partir da mesma faixa etária.

No presente trabalho, evidenciou-se o início precoce dos alimentos sólidos, com alimentos de baixa densidade energética e protéica. Estes são pontos importantes para serem levados em consideração no aconselhamento dietético para o primeiro ano de vida na população dos centros de saúde estudados.

Os resultados apresentados limitam-se à população estudada. Ressalta-se que são estimativas da prevalência de consumo, influenciadas 
pelo tamanho da população do estudo e número de indivíduos em cada intervalo de idade. A natureza da seleção dos participantes do estudo - por conveniência - impede inferências estatísticas para outras populações. No entanto, a metodologia do trabalho, por meio de questionários estruturados, com perguntas simples e procedimentos estatísticos que podem ser realizados por meio de programas de domínio público, permitem a obtenção de gráficos que apresentam os resultados de forma clara, podendo auxiliar as equipes de saúde a visualizar e diagnosticar situaçōes problemas para o planejamento educativo da unidades de saúde, beneficiando a comunidade atendida por eles. Esta é uma hipótese que poderia ser testada a seguir, juntamente com o estudo de novas variáveis que explicassem as diferenças nas prevalências de consumo de leite não materno e prática de amamentação exclusiva observadas nas duas localidades onde se realizou o estudo. 


\section{REFERÊNCIAS}

Agostini C, Riva E, Giovannini M. Dietary fiber in weaning foods of young children. Pediatrics 1995; 96:1002-5.

Akerblom HK, Savilahti E, Knip M. A nutrição nas primeiras etapas da vida e o diabetes tipo I. In: Resumos do $36^{\circ}$ Seminário Nestlé Nutrition; 1994; Filipinas. sl. Nestlé Nutrition Services; 1994. p. 36-7.

Akré J. Infant feeding: the physiological basis. Bull World Health Organ 1989; 67 Suppl: 1-108.

Akré J. Alimentação infantil: bases fisiológicas. São Paulo: Organização Mundial de Saúde; 1994. p. 51-61.

Amador M; Silva LC; Valdéz-Lazo F. Breast feeding trends in Cuba and the Americas. Bull Pan Am Health Organ 1994; 28: 220-8.

Arregin OL. Actualidades en alimentacion infantil. Gac Med Mex. 1994;130(5): 328-34.

Ballabriga A, Rey J, editors. Weaning: why, what and when? New York: Raven Press; 1987.

Barber CM, Abernathy T, Steinmetz B, Charlesbois J. Using a breastfeeding prevalence survey to identify a population for targeted programs. Can $\mathbf{J}$ Public Health 1997; 88:242-5. 
Barness LA. History of infant feeding practices. Am J Clin Nutr 1987; 46: $168-70$

Barros MBA. A utilização do conceito de classe social nos estudos dos perfis epidemiológicos: uma proposta. Rev Saúde Pública 1986; 20:269-76.

Bell JG, Keen CL, Lonnerdal B. Effect of infant cereals on zinc and cooper absortion during weaning. Am J Dis Child 1987; 141:1128-32.

Becker HJ, Bentley M, Black RE, Blum D, Kanashiro HC. Investigaciones sobre las practicas mejoradas de lactancia para prevenir diarréia o reducir su gravedade. Bol Oficina Sanit Panam 1991; 110:499-508.

Bergmann R, Bergmann KC. Nutrition and growht in infancy. In: Falkner $F$, Tanner JM. Human growth. New York: Plenun Press; 1979. v.3.

Borch-Johnsen K, Mandrup-Poulsen T, Zachau-Christiansen B, Jone G, Christy M, Katrup K, Nerup, J. Relation between breast-feeding and incidence rates of insulin-dependent diabetes mellitus: a hypothesis. Lancet 1984; 2:1083-6.

Borrensen HC. Rethinking current recommendations to introduce solid food between four and six months to exclusively breast feeding infants. J Hum Lact 1995; 11: 201-4.

Bourgoin GL, Lahaie NR, Rheaume BA, Berger MG, Dovigi CV, Picard LM, Sahai VF. Can J Public Health 1997; 88:238-41.

Broadway Pediatrics Associates. Infant feeding guidelines [on line]. Disponivel na Internet, via www.URL http://www.ni.com/ dis/feed.htm. [1997 maio]. 
Brown, KH, Black RE, Romaña GL, Kanashiro HC. Infant feeding practices and their relationship with diarrheal and other diseases in Huascar (Lima), Peru. Pediatrics 1989; 83:31-40.

Brown KH, Kanashiro HC, Dewey KG. Optimal complementary feeding practices to prevent childhood malnutrition in developing counties. Food Nutr Bull 1995a; 16: 320-39.

Brown KH, Griñan MS, Perez F, Peerson JM, Ganoza L, Stern JS. Effects of dietary energy density and feeding frequency on total daily energy intakes of recovering malnourished children. Am J Clin Nutr 1995b; 62:13-8.

Brown KH. Complementary feeding in developing countries: factors affecting energy intake. Proc Nutr Soc 1997; 56:139-48.

Bullough VL. Bottle feeding: an amplification. Bull Hist Med 1987; 55: 2579.

Caballero B, Carmuega E Giugliani E, Lara Pantin E, Lopez de Blanco M, O'Donnel $A$ et al. La alimentación del nino menor de 6 anos en America latina: bases para el desarollo de guias de alimentación. Arch Latinoam Nutr 1994; 44: 176-98.

Campos Filho N, Franco EL. Multiple logistic regression by unconditional and conditional methods. [computer program] Ludwig Institute for Cancer Research; 1989.

Caufield LE, Bentley ME, Ahmed S. Is prolongued breastfeeding associated with malnutrition? Int J Epidemiol 1996; 25: 693-703. 
Chaves SP, Lei DLM, Lerner BR, Stefanini MLR. Aleitamento, estado nutricional e morbidade no primeiro ano de vida. Rev Nutr PUCCAMP 1995; 8: 31-46.

Cohen RJ, Brown KH, Canahuati J, Rivera LL, Dewey KG. Effects of age of introduction of complementary foods on infant breast milk intake, total energy intake, and growth: a randomised intervention study in Honduras. Lancet 1994; 344: 288-93.

Dean AG, Dean JA, Coulombier D, Brendel KA, Smith DC, Burton HA et al. Epi Info, version 6.04: a word processing database and statistics program for epidemiology on microcomputers. Atlanta: Center for Disease Control and Prevention; 1996.

Dewey KG, Cohen RJ, Rivera LL, Brown KH. Effects of age of introduction of complementary foods on iron status of breast-fed infants in Honduras. Am J Clin Nutr 1998; 67:878-84.

Drash AL, Kramer MS, Swanson J, Udall J. Infant feeding practices and their possible relationship to the etiology of diabetes mellitus. Pediatrics $1994 ; 94: 752-4$. 
Drewett R, Amatayakul K, Wongsawasdii A, Mangkabruks S, Ruckpaopunt C, Baum D e col. Nursing frequency and the energy intake from breast milk and supplementary food in a rural Thai population: a longitudinal study. Eur J Clin Nutr 1993; 47:880-91.

Egashira EM. Características da dieta e determinantes proximais do consumo energético nos primeiros dois anos de vida no município de São Paulo. São Paulo; 1998. [Tese de Mestrado - Faculdade de Saúde Pública da USP].

Fall CHD, Barker DJP, Osmond C, Winter PD,, Clark PMS, Hales CN. Relation of infant feeding to adult serum cholesterol concentration and death from ischaemic heart disease. BMJ 1992; 304:801-5.

Ferrante E, Vania A, Mariani P, Pitzalis G, Sciarpelletti R, Imperato C. Indagine retrospettiva sul divezzamento a Roma e provincia. Minerva Pediatr 1994; 46: 275-83.

Ferreira MU, Cardoso MA, Santos ALS, Ferreira CS; Szarfarc SC. Rapid assessment of breastfeeding data: probit analysus of current status data. $\mathbf{J}$ Trop Pediatr 1996a; 42:50-3.

Ferreira MU; Cardoso, MA. Discontinuity indices of exclusive breastfeeding estimated by probit analysis of current status data. Int J Epidemiol 1996b; 25: $459-60$.

Fisberg M, Braga JAP. A fórmula infantil: passado, presente e futuro. São Paulo: Nestlé; 1996. (Temas de pediatria, 62) 
Gabriel A, Gabriel KR, Lawrence R. Cultural values and biomedical knowledge: choices in infant feeding. Soc Sci Med 1986; 23:501-9.

Gimeno SGA, Souza JMP. IDDM and milk consuption . A case control study in São Paulo, Brazil. Diabetes Care 1997; 20:1256-60.

Giugliani ERJ, Victora CG. Normas alimentares para crianças brasileiras menores de dois anos: bases científicas. Brasilia: OPAS; 1997.

Goldberg NM, Adams E., Supplementary water for breast-fed babies in a hot and dry climate not really a necessity. Arch Dis Child 1983; 58:73-4.

Goldemberg P. Repensando a desnutrição como questão social. $2^{\text {a }}$ ed. Campinas: Ed. UNICAMP; 1989.

Gómez MJM. Maduracion de las funciones metabólicas y digestivas del lactante. In: Rodríguez MH. Alimentaçăo infantil. Madri, Diaz de Santos, 1993. p 25-31.

Greiner T. Sustained breastfeeding, complementation and care. Food Nutr Bull 1995; 16: 313-19.

Haider R, Islam A, Kabir I, Habte D. Early complementary feeding is associated with low status nutricional of young infantis recovering from diarrhoea. J Trop Pediatr 1996; 42: 170-2.

Hefti R. Breastfeeding, then and now. Can Nurse 1993; 89:38-44.

Helsing E. Infant feeding practices in Northern Europe. Assignment Child 1981; 55/56: 73-89. 
Hendricks KM, Badruddin SH. Weaning recommendations: the scientific basis. Nutr Res 1992; 50: 125-33.

Hervada AR, Newman DR. Weaning: Historical perspectives, practical recommendations and current controversies. Curr Probl Pediatr 1992; 22:223-40.

Hokama T, Yamamoto SA. A study of iron requirement during weaning by total body iron determined by haemoglobin, serum ferritin, and body weight. J Trop Pediatr 1996; 42:120.

Holliday M. O teor de sal nos primeiros alimentos afeta a pressão sangüinea em etapas posteriores de vida? In: Resumos do $36^{\circ}$ Seminário Nestlé Nutrition; 1994; Filipinas. sl. Nestlé Nutrition Services; 1994. p. 236.

Holt RD. Weaning and dental health. Proc Nutr Soc 1997; 56: 131-8.

Hosmer DW; Lemeshow S. Applied logistic regression. New York: John Wiley and Sons; 1989.

Hurrell, R.F. Bioavailability of iron. Eur J Clin Nutr 1997; 51Suppl 1:4-8.

Huttly S; Barros, FC; Victora CG; Beria JU; Vaughan, P. Do mothers overestimate breast feeding duration? An example of recall bias from a study in southern Brazil. Am J Epidemiol 1990; 132: 572-5.

James J, Underwood A. Ethnic influences on weaning diet in the UK. Proc Nutr Soc, 1997; 56:121-30.

Jason JM, Marks JS. Mortality and infectious disease associated with infantfeeding practices in developing countries. Pediatrics 1984; 74 (4 part 2): 702-27. 
Jelliffe DO, Jelliffe, EFP. An overview. Am J Clin Nutr 1971; 24:1013-24.

Kovar MG, Serdula MK, Marks JS, Fraser DW. Review of the epidemiologic evidence for an association between infant feeding and infant health. Pediatrics 1984; 74: 615-38.

Kretchmer N. Weaning: the enzimatic adaptation. Am J Clin Nutr 1985; 41: 391-8.

Lanting $\mathrm{Cl}$, Boersma ER. Lipids in infant nutrition and their impact on later development. Curr Opin Lipidol 1996; 7:43-7.

Lawrence RA. Breastfeeding: a guide for the medical profession. $4^{\text {th }} \mathrm{ed}$. St Louis: Mosby; 1994. p. 317.

Lessof MH. Alergia e intolerancia a los alimentos. Zaragoza: Acribia, 1996.

Lilly R. Weaning and the weaning diet: putting the theory into practice. Prof Care Mother Child 1995; 5(2): 41,44-5.

Lombardi C, Bronfman M, Facchini LA, Victora CG, Barros FC, Béria JU, Teixeira AMB. Operacionalização do conceito de classe social em estudos epidemiológicos. Rev Saúde Pública 1988; 22:253-65.

Lönnerdal B. Trace element nutricion in infants. Ann Rev Nutr 1989; 9:10925.

Lucas A. Programming by early nutrition: an experimental aproach.

Nutrition 1998; 128:401S-406S 
Martell M, Bertolini LA, Nieto F, Tenzer SM, Rúggia R, Belitzky R. Crescimiento y desarollo en los dos primeiros anos de vida pós natal. Washington CDC: OPAS; 1981. (OPAS - Publicacion Científica, 406).

Martinez GA, Dodd DA. 1981 milk feeding patterns in the United States during the first 12 months of life. Pediatrics 1983; 71: 166-70.

Martinez GA, Ryan AS. Nutrient intakes during the first 12 months of lif. Am J Clin Nutr 1985; 85: 826S-830S.

Martorell R, Khan K, Schoeder DG. Reversibility of stunding: epidemiological findings in children from developing countries. Eur J Clin Nutr 1994; 48: 45S-57S.

McGill HC. Childhood nutrition and adult cardiovascular disease. Nutr Rev 1997; 55(1pt 2):S2-S11.

Milner JA. Trace elements in the nutrition of children. Pediatrics 1990; 117: 147S-55S.

Ministério da Saúde. Indicadores de saúde. Available from <URL:http://www.saude.gov.br/html >.[1999 Jul 24]

Ministério da Saúde. Portaria n ${ }^{\circ} 34$ de 13/01/98: Regulamento técnico referente à alimentaçăo de transiçăo para lactentes e crianças de primeira infância. Diário oficial da República Federativa do Brasil, Brasília, 16 jan. 1998.

Monson MRR. Programa nacional de aleitamento materno. Brasilia: INAN/MS; 1991. 
Monteiro CA, Zuniga, HPP, Benício, MH, Rea MF.. Breastfeeding patterns and socio-economic status in the city of São Paulo. J Trop. Pediatr 1988; 34: $186-92$.

Monteiro CA. Saúde e nutrição das crianças de São Paulo: diagnóstico, contrastes sociais e tendências São Paulo: HUCITEC/ EDUSP, 1988.

Monteiro CA, Szarfarc S. A alimentação. In: Monteiro C A. Saúde e nutrição das crianças de São Paulo: diagnóstico, contrastes sociais e tendéncias. São Paulo: HUCITEC/EDUSP; 1988.

Monteiro CA, Venâncio SI, Kitoko P, Réa MF, Silva NN. Diagnóstico rápido de práticas de alimentação infantil em campanhas de vacinação: descrição de uma proposta. In: Livro de resumos do $4^{\circ}$ Congresso Brasileiro; 1998; Rio de Janeiro. Rio de Janeiro: ABRASCO; 1998. P 310.

Monteiro CA. O panorama da nutrição infantil nos anos 90 , Brasilia: UNICEF; 1996. (Cadernos de Políticas Sociais, Série Documentos para Discussão, 1).

Mott GE. A alimentação nas primeiras etapas da vida e o surgimento da aterosclerose. In: Resumos do $36^{\circ}$ Seminário Nestlé Nutrition; 1994; Filipinas. sl: Nestlé Nutrition Services, 1994. p. 14-6.

Newburg DS, Street JM. Milk sugars sweeten the argument for breast feeding. Nutr Today 1997; 32:191-201.

Nóbrega FJ, Campos ALR. Distúrbios nutricionais e fraco vínculo mãe/filho. Rio de Janeiro: Revinter; 1996.

Notzon F. Trends in infant feeding in developing countries. Pediatrics, 
1984; 74Suppl 2: 648-66.

Oski FA, Landaw AS. INHlbition of iron absorption from human milk by baby food. Am J Dis Child 1980; 134:459-60.

Palma D, Sarni RS, Oliveira FLC, Valverde MA. Alimentação da criança nos primeiros anos de vida. Rev Paul Pediatr 1998; 16:112-7.

Palmer G. The politics of breastfeeding. $4^{\text {th }}$ ed. London: Pandon Press; 1993.

Patarra NL. Mudanças na dinâmica demográfica. In: Monteiro, C.A. Velhos e novos males da saúde no Brasil: a evolução do pais e de suas doenças. São Paulo: HUCITECIABRASCO/NUPENS-USP; 1995. p 61-78.

Péres Escamilla LLA. Patrones de la lactancia natural en la America Latina y el Caribe. Bol Oficina Sanit Pan 1993; 115: 185-93.

Plank SJ, Milanesi M.L. Infant feeding and infant mortality in rural Chile. Bull World Health Organization 1973; 48: 203-10.

Popkin BM, Adair L, Akin JS, Black R, Briscoe J, Flieger W. Berast-feeding and diarmeal morbidity. Pediatrics 1990; 86: 874-82.

Poskitt, EME. A alimentação nas primeiras etapas da vida e a obesidade. In: Seminário Nestlé Nutrition, In: Resumos do $36^{\circ}$ Seminário Nestlé Nutrition; 1994; Filipinas, sl: Nestlé Nutrition Services, 1994. p. 14-6.

Potur AH, Kalmaz N. An investigation into feeding errors of 0 - 4 month - old infants. J Trop Pediatr 1993; 42: 173-175. 
Prado MS, Assis AMO, Freitas MCS, Silva RCR, Varjão ML. Padrão e seleção de alimentos complementares e sucedâneos do leite materno em comunidades rurais no semiárido baiano. Rev Nutr PUCCAMP 1995; 8:47-64.

Pridham, K.F. Feeding behaviour of 6-12 month-old infants: assessment and sources of parental information. J Pediatr 1990; 117: 174S-80S.

Radbill SX. Infant feeding through the ages. Clin Pediatr 1981; 20: 613-21.

Radrigan ME, Juez GG, Corone FO. Alimentacion en el primer año de vida. Rev Chil Pediatr 1989; 60: 9S-19S.

Ramakrishnan U. UNICEF-Cornell colloquium on care and nutrition of the young chil-planning. Food Nutr Bull 1995; 16:286-92.

Raphael K. Recall bias: a proposal for assessment and control. Int J Epidemiol 1987; 16: 167-70.

Réa M. Substitutos do leite materno - passado e presente. Rev Saúde Publica 1990; 24: 242-9.

Réa MF. A amamentação e o uso de leite humano: o que recomenda a Academia Americana de Pediatria. J Pediatr 1998; 74:171-3.

Rios E, Neuhauser L; Margen S; Melnick V. Accuracy of mother's responses to questions about breast-feeding practices. Food Nutr Bull 1992; 14: 115-8. 
Roberts SB, McDonald R. The evolution of a new research field: metabolic programming by early nutrition. J Nutr 1998; $128: 400$ S.

Rodrígues MH. Alimentação infantil. Madri: Diaz de Santos; 1993.

Ryan S, Schafer E. lowa family child care handbook. lowa: lowa State University Print and Publi Bldg; 1995.

Sachdev HPS, Krishna J, Puri RK, Satyanarayana L, Kumar S. Water supplementation in exclusively breastfed infants during summer in the tropics. Lancet 1991; 337: 929-33.

Scott F. Cow milk and insulin-dependent diabetes mellitus: is there a relashionship? Am J Clin Nutr 1990; 51:489-91.

Scown P. Weaning and the weaning diet: a summary of the departmente of health report. Prof Care Mother Child 1995; 5: 39-40.

SECRETARIA DA SAÚDE DO ESTADO DA BAHIA. Indicadores do aleitamento materno. Salvador: DEPAS/DIPROS/SISVAN/UNICEF; 1995.

Sigulem DM, Tudisco ES. Aleitamento natural em diferentes classes de renda no município de São Paulo. Arch Latinoam Nutr 1980; 30: 401-416.

Silva LC; Valdéz-Lazo F; Amador M. Discontinuity indice: a tool for epidemiological studies on breastfeeding. Int J Epidemiol 1995; 24: 965-9.

Silva LS, Fuentelsaz C, Amador M. Caracteristicas de la introducción de alimentos al lactente en Cuba. Bol Oficina Sanit Panam 1993; 113:407-15. 
Souza SB. Anemia e alimentação no primeiro ano de vida. São Paulo;1994. [Tese de Doutorado - Faculdade de Saúde Pública da USP]

Stina G, Almoroth MNS. Water requirements of breast fed infants in a hot climate. Am J Clin Nutr 1978; 31: 1154-7.

Tabai KC, Carvalho JF, Salay E. Aleitamento materno e prática de desmame em duas comunidades rurais de Piracicaba - SP. Rev Nutr 1998; 11:117-24.

Torún B, Menchú MT, Elias LG. Recomendaciones dietéticas diarias del INCAP. Guatemala: INCAP; 1996.

Tudisco E, Marin P, Shrimpton R, Costa M, Donohue R. Alimentação de desmame em áreas periurbanas de quatro capitais brasileiras: resultados preliminares. J Pediatr 1988; 64:231-6.

Underwood BA.. Weaning practices in deprived environments: the weaning dilemma. Pediatrics 1984; 84: 194S-198S.

Vasconcelos AC, Venâncio SI, Kitoko P, Réa MF, Monteiro CA. . Diagnóstico rápido de práticas de alimentação infantil em campanhas de vacinação: a experiência de João Pessoa, PB em 1997. em 1997. In: Livro de resumos do $4^{\circ}$ Congresso Brasileiro; 1998; Rio de Janeiro. Rio de Janeiro: ABRASCO; 1998. p 311.

Vasconcelos FAG. Avaliação nutricional de coletividades. Florianópolis: Ed. UFSC; 1993.

Venâncio SI. Evolução da prática de aleitamento materno no Brasil nas décadas de 70 e 80. São Paulo;1996.[Tese de Mestrado - Faculdade de Saúde Pública da USP]. 
Victora CG, Fachini LA, Barros FC. Pobreza e saúde: como medir nível sócio-econômico em estudos epidemiológicos de saúde infantil? In: Anais do $1^{\circ}$ Congr. Brasileiro de Epidemiologia; 1990; São Paulo. São Paulo: UNICAMP; 1990. p. 302-14

Victora CG, Vaughan JP, Lombardi C, Fuchs SMC, Gigante LP, Smith PG et al. Evidence for protection by breastfeeding against infant deaths from infectious diseases in Brazil. Lancet 1987; 8: 319-22.

Waterlow JC, Thomson AM. Observation on the adequacy of breast feeding. Lancet 1979; 2: $238-42$.

Weinberg F. Infant fedding through the ages. Can Fam Physician 1993; 39:2016-20.

Wharton BA. Weaning in Britain practice, policy and problems. Proc Nutr Soc 1997; 56: 105-19.

Whitehead RG. Infant physiologiy, nutritional requirements and lactational adequacy. Am J Clin Nutr 1985; 41: 447-50.

Whitehead RG. For how long is exclusive breast-feeding adequate to satisfy the dietary energy needs of the average young baby? Pediatr Res 1995; 37 : $239-43$.

[MHO] World Health Organization, UNICEF. Sobre la alimentacion del niño pequeno, Ginebra: WHO; 1979.

[WHO] World Health Organization. The prevalence and duration of breastfeeding: a critical review of available information. World Health Statat Q 1982; 35: 92-116.

[WHO] World Health Organization. Weaning from breast milk to family food: a guide for health and community workers. Geneva: 1988. 
[WHO] World Health Organization. Innocenti Declaration on the protection, promotion and support of breast feeding. Ecol Food Nutr 1990; 26: 271 -3.

[WHO] World Health Organization. The WHO's infant feeding recommendation. Wkly Epidemiol Rec 1995a; 70: 119-20.

[WHO] World Health Organization. An evaluation of infant growth: the use and interpretation of anthropometry in infants. Bull World Health Organization 1995b; 73: 165-73.

Williams PL, Innis SM, Vogel AMP. Breastfeeding and weaning practices in Vancouver. Can J Publ Health 1996; 87:231-6.

Wilson AC, Forsyth JS, Greene AS, Irvine L, Hau C, Howie PW. Relation of infant diet to childhood health: seven year follow up of cohort of children in Dundee infant feeding study. BMJ 1998; 316:21-25.

Woiski JR. Nutriçăo e dietética em pediatria. Rio de Janeiro: Atheneu; 1988.

Wong WW. A alimentação nas primeiras etapas da vida e a regulação do metabolismo do colesterol. In: Resumos do $36^{\circ}$ Seminário Nestlé Nutrition; 1994; Filipinas. sl: Nestlé Nutrition Services; 1994. p. 17-20.

Zuniga HPP, Monteiro CA. Uma nova hipótese para a ascensão da mortalidade infantil da cidade de São Paulo nos anos 60. In: Monteiro, C.A. Velhos e novos males da saúde no Brasil: a evolução do pais e de suas doenças. São Paulo: HUCITEC/ABRASCO/NUPENS-USP; 1995. P 157-172. 
ANEXOS 
Anexo 1 


\section{TERMO DE CONSENTIMENTO PARA PARTICIPAÇÃO NA PESQUISA "ALEITA- MENTO MATERNO, DIETA DE DESMAME E ANEMTA NO PRTMEIRO ANO DE VIDA, EM CRIANÇAS ATENDIDAS NA REDE PÚBLICA DE SAÚDE" \\ (de acordo com a resolução 196 de 10/10/1996 do Conselho Nacional de Saúde)}

Eu,

livremente, permito que meu(minha) filho(o) participe da pesquisa "Aleitamento materno, dieta de desmame e anemia no primeiro ano de vida, em crianças atendidas na rede pública de saúde" sob responsabilidade das pesquisadoras Sonia Buongermino de Souza, Professora Doutora da Faculdade de Saúde Pública da USP e Sophia Cornbluth Szarfarc, Professora Associada da Faculdade de Saúde Pública da USP.

\section{Fui informado(a) sobre o seguinte:}

Objetivo da Pesquisa: Verificar a prevalência da anemia no primeiro ano de vida e sua relação com a prática alimentar e com o crescimento e o desenvolvimento, em crianças atendidas em serviços públicos de saúde.

Participação: Responder às perguntas necessárias e permitir que sejam feitas medidas de peso e de altura e a colheita de $20 \mu l$ de sangue, por puntura do pé, de meu(minha) filho(a), para dosagem de hemoglobina para diagnóstico da anemia. Todos os procedimentos para a colheita de sangue serão feitos com material descartável.

Riscos: Não haverá riscos para a integridade física, mental ou moral de meu(minha) filho(a).

Benefícios: As informações obtidas nesta pesquisa poderão ser úteis cientificamente e de ajuda para todos. Se a criança estiver anêmica será encaminhada, imediatamente, ao médico, para tratamento.

Privacidade: Os dados individualizados serão confidenciais. Os resultados coletivos serão divulgados nos meios cientificos.

Contato com os pesquisadores: Terei acesso a telefone para esclarecimento de dúvidas ou reclamações. 
Anexo 2 


\section{ALIMENTAÇAO NO PRIMEIRO ANO DE VIDA}

Localidade: Saro Paulo No: $|0| 2 \mid$

Nome da criança:

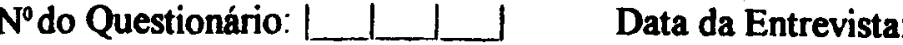

Concentração de Hemoglobina Sexo: Masc. (1) Fem. (2)

DENTIFICACÃO

\section{1-PESO AO NASCER (g)}

2- COMPRIMENTO AO NASCER $(\mathrm{cm})$

3- PESO ATUAL (g)

4- ALTURA ATUAL (cm)

5- IDADE DA MÃE (anos completos)

6- ESCOLARIDADE DA MÃE (séries cursadas)*

7. ESCOLARIDADE DO PAI (séries cursadas)*

8- DURAÇ̃̃O DA GESTAČ̃̃ (meses)

9- TIPO DE PARTO*

10-RECEBEU LEITE MATERNO Não(0) Sim(1)

11-SE RECEBEU, POR QUANTO TEMPO (meses)

$\Rightarrow$ Menos de 1 mês especificar em dias.

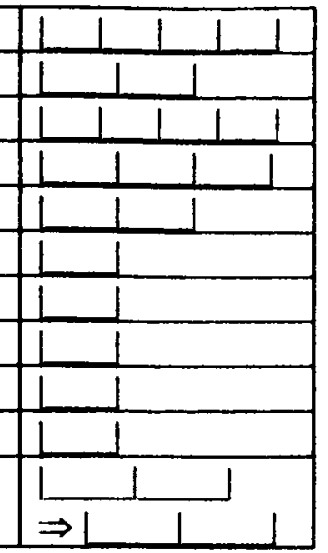

SINAIS DE DESENVOLVIMENTO NÃO $=0 \quad$ SIM $=1$

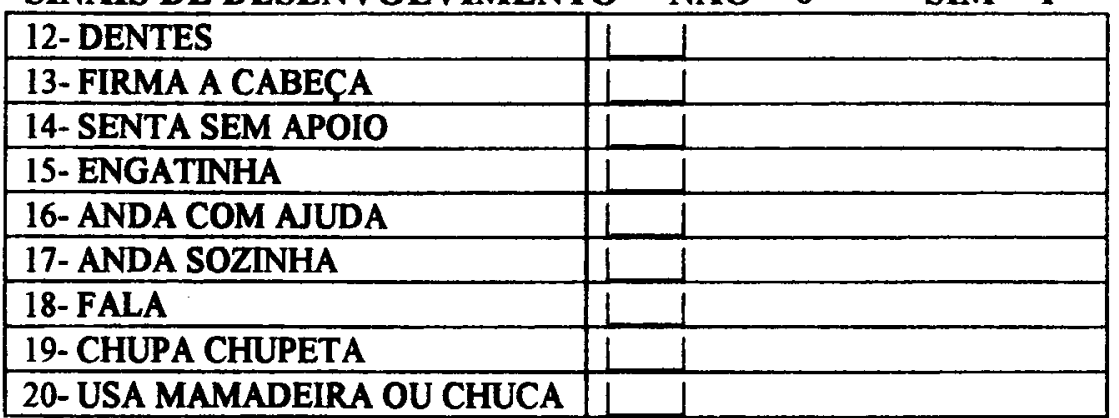

A CRIANÇA COME: $\quad$ NĀO $=0 \quad$ SIM $=1$

\begin{tabular}{|c|c|}
\hline 21- LEITE DE PEITO & ] \\
\hline 22- ÁGUA E/OU CHÁ & $\perp$ \\
\hline 23- LEITE DE SAQUINHO OU CAIXINHA & \\
\hline 24- LEITE EM PÓ & \\
\hline 25-ACÚCAR & \\
\hline 26- ENGROSSANTE (Ex: Maizena, Fúba etc...) & \\
\hline 27-FRUTAS (Sucos e/ou papinha) & \\
\hline 28-LEGUMES (Ex: Tomate, Cenoura, Beterraba etc...) & \\
\hline 29- VERDURAS (Ex: Alface, Couve, Espinafre etc...) & \\
\hline 30- BATATA (Ou Cará, Mandioca, Batata Doce etc...) & \\
\hline 31-GEMA DE OVO & $\perp$ \\
\hline 32- OVO INTEIRO & L \\
\hline 33-CALDO DA CARNE & \\
\hline 34- CARNE & \\
\hline 35- PEIXE & \\
\hline 36- FRANGO OU OUTRAS AVES & \\
\hline 37- FIGADO & \\
\hline 38-CALDO DO FEIJÃO & \\
\hline 39- FEIJÃO & 1 \\
\hline 40- ARROZ E/OU MACARRÃO & \\
\hline 41- PÃO E/OU BOLACHA & \\
\hline 42-OUTROS Especificar & $L$ \\
\hline
\end{tabular}

"Os códigos de resposta estão no MANUAL DE USO DO FORMULÁRIO 